WCH-42

Rev. 1

River Corridor Closure Contract

\title{
Annual Report for Gravity Collection Lysimeter Monitoring Plan - ERDF Cells 5 and 6
}

December 2006

Washington Closure Hanford

Prepared for the U.S. Department of Energy, Richland Operations Office Office of Assistant Manager for River Corridor 
TRADEMARK DISCLAIMER

Reference herein to any specific commercial product, process, or service by trade name, trademark, manufacturer, or otherwise, does not necessarily constitute or imply its endorsement, recommendation, or favoring by the United States Government or any agency thereof or its contractors or subcontractors.

This report has been reproduced from the best available copy. Available in paper copy and microfiche.

Available for a processing fee to U.S. Department of Energy and its contractors from:

U.S. Department of Energy

Office of Scientific and Technical Information

P.O. Box 62

Oak Ridge, TN 37831-0062

(865) $576-8401$

fax: (865) 576-5728

email: reports@adonis.osti.gov

online ordering: http://www.doe.gov/bridge

Available for sale to the public, in paper, from:

U.S. Department of Commerce

National Technical Information Service

5285 Port Royal Road

Springfield, VA 22161

(800) 553-6847

fax: (703) 605.6900

email: orders@ntis.fedworld.gov

online ordering: http://www.ntis.gov/ordering.htm

Printed in the Unifed States of America

DISCLM-5.CHP (11/99) 


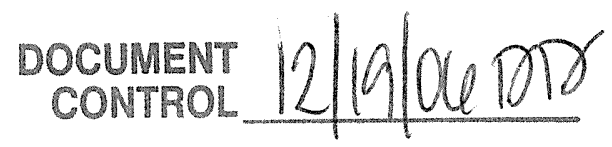

Rev. 1

OU: $\quad$ N/A

TSD: N/A

ERA: N/A

\section{STANDARD APPROVAL PAGE}

Title: $\quad$ Annual Report for Gravity Collection Lysimeter Monitoring Plan ERDF Cells 5 and 6

Author Name: W. E. Remsen

Approval: $\quad$ J. E. Rugg, Environmental Lead

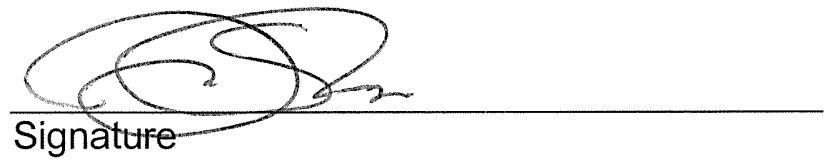

$\frac{12 / 18 / 06}{\text { Date }}$

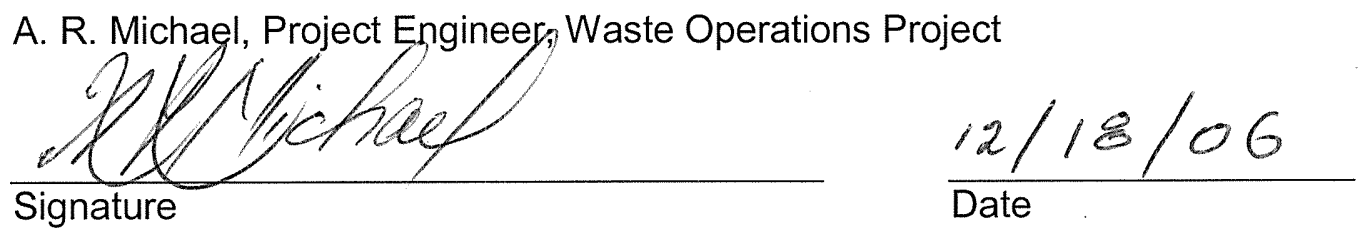

The approval signatures on this page indicate that this document has been authorized for information release to the public through appropriate channels. No other forms or signatures are required to document this information release. 

WCH-42

Rev. 1

\section{River Corrildor Closure Contract}

\section{Annual Report for Gravity Collection Lysimeter Monitoring Plan - ERDF Cells 5 and 6}

December 2006

Author:

W. E. Remsen 



\section{TABLE OF CONTENTS}

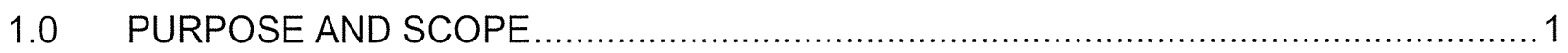

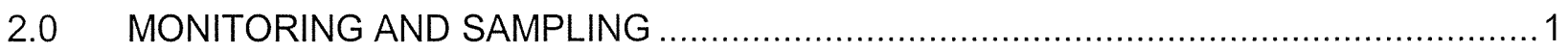

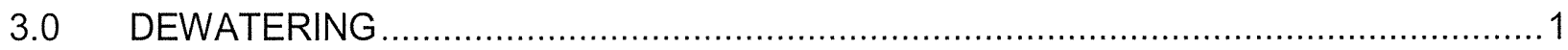

\section{APPENDIX}

A SAF-B05-039 ERDF LYSIMETER SAMPLING FINAL DATA PACKAGE

$A-i$ 


\section{REVISION HISTORY}

\begin{tabular}{|c|c|l|c|}
\hline Revision & Date & \multicolumn{1}{|c|}{ Reason for revision } & Revision initiator \\
\hline 0 & $06 / 2006$ & Initial issuance & NA \\
\hline 1 & $12 / 2006$ & $\begin{array}{l}\text { Section 3.0 was revised to reflect the second } \\
\text { round of dewatering completed in June and July } \\
2006 .\end{array}$ & W.E. Remsen \\
\hline
\end{tabular}




\subsection{PURPOSE AND SCOPE}

This report has been prepared in accordance with the Gravity Collection Lysimeter Monitoring Plan - ERDF Cells 5 and 6 (Monitoring Plan), dated March 30, 2005. As identified in Section 4 of the Monitoring Plan, the objectives of the annual report are to:

- Describe changes in the volume of liquid seen in each lysimeter (if any).

- Describe concentrations and changes or trends in the concentrations of leachate-indicator constituents in any liquids accumulated in each lysimeter.

- Summarize the finding in regard to the presence or absence of leachate in each lysimeter.

- Make recommendations, if any, limited to vadose-zone study-related variables.

The data and analyses contained in this report reflect the initial characterization of construction and consolidation water in Cells 5 and 6 lysimeters. Therefore, the scope of this report will be to establish constituent levels and document dewatering activities completed to date.

\subsection{MONITORING AND SAMPLING}

Initial sampling and analysis efforts on lysimeters in Cells 5 and 6 at ERDF took place August 23, 24, and 25, 2005. The samples were analyzed for the following four constituents:

- Chloride

- Gross Alpha

- Technicium 99

- Gross Beta.

The analysis (included as Appendix A) was conducted in order to establish a baseline representative of the construction and consolidation water present in the lysimeters. If water is discovered during future monitoring activities (after dewatering is complete) a representative sample will be taken, analyzed for the constituents identified above, and compared to the initial baseline.

\subsection{DEWATERING}

The Monitoring Plan recomimends the lysimeters be dewatered. The Monitoring Plan also recognizes the fact that the construction water will fully draw down and come to equilibrium very slowly due to the fairly low hydraulic conductivity of the backfill, especially near the bottom of the prism and because of the very low head that will be driving the last volumes of construction water. Because of these conditions, recharge is occurring at an unknown rate and full drying of the lysimeters will not occur until full equilibrium is reached. Therefore, dewatering of the 
lysimeters at Cells 5 and 6 will occur over time through a series of pumping activities, anticipated to take place in the spring and fall of each year. Once it is determined that all water that can be removed via pumping has occurred, a follow on drying activity will take place with rags or some other innovative means to fully dry the lysimeters.

The initial dewatering effort was met with a number of challenges. The cold weather made pumping activities difficult due to freezing of water transport lines and compressor equipment. In addition, the weather lead to technical difficulties with the pump, leading to unanticipated stops. Lastly, it was determined that the amount of water contained within the lysimeters was a great deal more than first estimated.

The initial dewatering effort for the Cell 6 lysimeter began December 6, 2005, and ended on December 20, 2005. A total of 2,302 gal were removed from the Cell 6 lysimeter. Dewatering of Cell 5 lysimeter began January 4, 2006, and ended January 5, 2006. A total of 1,651 gal were removed from the Cell 5 lysimeter.

A second round of dewatering was conducted during the summer of 2006. A total of $1890 \mathrm{gal}$ of water were removed from Cell 5 beginning on June 27, 2006 and ending on July 6, 2006. A total of $273 \mathrm{gal}$ were removed from Cell 6 beginning on July 6, 2006 and ending on July 14, 2006.

It is anticipated that the next dewatering round for both Cells 5 and 6 will begin in the spring of 2007. The Monitoring Plan states that routine lysimeter inspections and sampling of any wet lysimeters be conducted semi-annually for the first two years and then annually thereafter. Due to the ongoing dewatering efforts planned, the semi-annual/annual sampling efforts will not begin until all dewatering series are completed. 


\section{APPENDIX A}

\section{SAF-B05-039}

\section{ERDF LYSIMETER SAMPLING}

FINAL DATA PACKAGE 
WCH-42

Rev. 1 
Ms. Joan Kessner

Bechtel Hanford Inc.

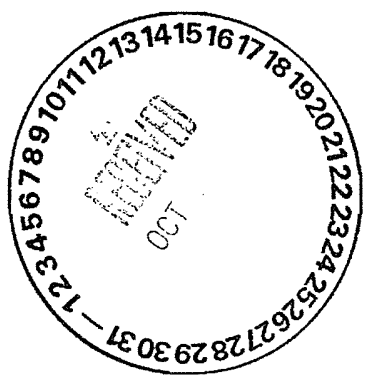

3190 George Washington Way

MSIN H9-02

Richland, WA 99352

Reference: P.O. \#630

Eberline Services R5-08-231-7300, SDG H3340

Dear Ms. Kessner:

Enclosed is a data report for one water sample designated under SAF No. B05-039 received at Eberline Services on August 29, 2005. The sample was analyzed according to the accompanying chain-of-custody documents.

Please call if you have any questions conceming this report.

Sincerely,

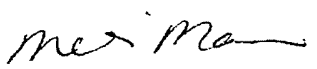

Melissa C. Mannion

Senior Program Manager

MCM

Enclosure: Data Package 


\subsection{GENERAL}

Bechtel Hanford Inc. (BHI) Sample Delivery Group H3340 was composed of one water sample designated under SAF No. B05-039 with a Project Designation of: ERDF Lysimeter Sampling.

Equal parts (by weight) of sample J03X89 (water) and J03X90 (soil) were thoroughly mixed together for four hours. The slurry was than filtered using 0.45 -micron filters and than analyzed for gross alpha/beta and Tc-99. The filtered slurry sample was called J03 $\times 89$.

The sample was received as stated on the Chain-of-Custody document. Any discrepancies are noted on the Eberline Services Sample Receipt Checklist. The results were transmitted to BHI via e-mail on October 5, 2005.

\subsection{ANALYSIS NOTES}

\subsection{Gross Alpha and Gross Beta Analyses}

No problems were encountered during the course of the analyses.

\subsection{Technetium-99 Analyses}

No problems were encountered during the course of the analyses.

\section{Case Narrative Certification Statement}

"I certify that this data package is in compliance with the SOW, both technically and for completeness, for other than the conditions detailed above. Release of the data obtained in this hard copy data package has been authorized by the Laboratory Manager or a designee, as verified by the following signature."

Mus'ma.m

Melissa C. Mannion

Senior Program Manager

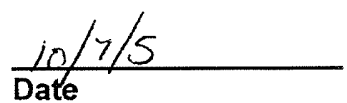


E B E R. I I N E S E R V I C E S / R I C H M O N D SAMPLE DELIVERY GROUP H3340

$\begin{aligned} & \text { SDG } 7300 \\ & \text { Contact Melissa C. Mannion }\end{aligned}$

Client Hanford

Contract No. 630

Case no SDG H3340

S U M M A R Y D A T A S E C T I O N

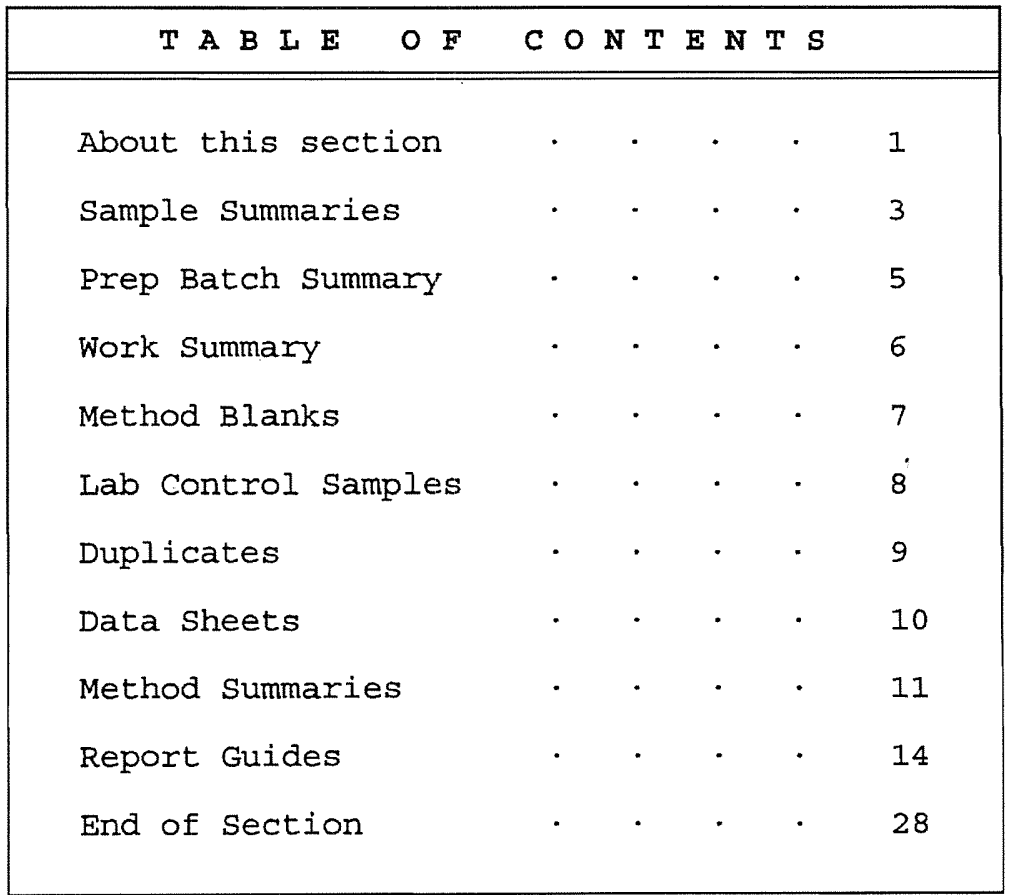

Mecesin Manom

Prepared by

Muse'Mome

Reviewed by
Lab id EBRLNE

Protocol Hanford

Version Ver 1.0

Form DVD-TOC

Version 3.06

Report date $09 / 28 / 05$ 
EBERINE SERVICES/RICHMOND

SDG 7300

Contact Melissa C. Mannion
SAMPLE DELIVERY GROUP H3340

REPORT G UIDE
Client Hanford

Contract No. 630

Case no SDG H3340

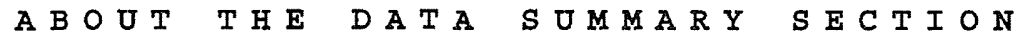

The Data Summary Section of a Data Package has all data, in several useful orders, necessary for first level, routine review of the data package for a Sample Delivery Group (SDG). This section follows the Data Package Narrative, which has an overview of the data package and a discussion of special problems. It is followed by the Raw Data section, which has full details.

The Data Summary Section has several groups of reports:

SAMPLE SUMMARIES

The Sample and $Q C$ Summary Reports show all samples, including $Q C$ samples, reported in one SDG. These reports cross-reference client and lab sample identifiers.

PREPARATION BATCH SUMMARY

The Preparation Batch Summary Report shows all preparation batches (lab groupings reflecting how work was organized) relevant to the reported SDG with information necessary to check the completeness and consistency of the SDG.

WORK SUMMARY

The work Summary Report shows all samples and work done on them relevant to the reported SDG.

METHOD BLANKS

The Method Blank Reports, one for each Method Blank relevant to the SDG, show all results and primary supporting information for the blanks.

LAB CONTROL SAMPLES

The Lab Control Sample Reports, one for each Lab Control Sample relevant to the SDG, show all results, recoveries and primary supporting information for these QC samples.

REPORT GUIDES

Page 1

SUMMARY DATA SECTION

Page 1
Lab id EBRLNE

Protocol Hanford

Version Ver 1.0

Form DVD-RG

Version 3.06

Report date $\underline{09 / 28 / 05}$ 
WCH-42

Rev. 1

E B ERIINE SERVICES/RICH M N D

SDG 7300

Contact Melissa C. Mannion
SAMPLE DELIVERY GROUP H3340

G UIDE, cont.
Client Hanford

Contract No. 630

Case no SDG H3340

\section{A BOUT THE DATA SUMMARY SECTION}

DUPLICATES

The Duplicate Reports, one for each Duplicate and Original sample pair relevant to the SDG, show all results, differences and primary supporting information for these $\mathrm{QC}$ samples.

MATRIX SPIKES

The Matrix Spike Reports, one for each Spiked and Original sample pair relevant to the SDG, show all results, recoveries and primary supporting information for these QC samples.

DATA SHEETS

The Data Sheet Reports, one for each client sample in the SDG, show all results and primary supporting information for these samples.

METHOD SUMMARIES

The Method Summary Reports, one for each test used in the SDG, show all results, $Q C$ and method performance data for one analyte on one or two pages. (A test is a short code for the method used to do certain work to the client's specification.)

REPORT GUIDES

The Report Guides, one for each of the above groups of reports, have documentation on how to read the associated reports.

REPORT GUIDES

Page 2

SUMMARY DATA SECTION

Page 2
Lab id EBRLNE Protocol Hanford Version Ver 1.0 Form DVD-RG version 3.06 Report date $\underline{09 / 28 / 05}$ 
WCH-42

Rev. 1

EBERLINE SERVICES/RICHMOND

SAMPLE DELIVERY GROUP H3340

SDG 7300

LAB SAMPLE SUMMARY

Client hanford

Contract No. 630

Case no SDG H3340

\begin{tabular}{|c|c|c|c|c|c|c|c|}
\hline $\begin{array}{l}\text { LAB } \\
\text { SAMPLE ID }\end{array}$ & CUIENT SAMPLE ID & LOCATION & MATRIX & LEVVEL & SAF NO & $\begin{array}{l}\text { CHATN OF } \\
\text { COSTODY }\end{array}$ & COLLECTED \\
\hline R508231-01 & J03×89 & ERDF Add-Mix/Raw water & WATER & & B05-039 & B05-039-2 & $05 / 25 / 05 \quad 10: 45$ \\
\hline R508231-02 & Lab Control Sample & & WATER & & B05-039 & & \\
\hline R508231-03 & Method Blank & & WATER & & B05-039 & & \\
\hline R508231-04 & Duplicate (R508231-01) & ERDF Add-Mix/Raw water & WATER & & B05-039 & & $05 / 25 / 05 \quad 10: 45$ \\
\hline
\end{tabular}

LAB SUMAMARY

Page 1

SDMARY DATA SECTION

Page 3
Lab id EBRLNE Protocol Hanford

Version Ver 1.0

Form DVD-LS

Version 3.06

Report date $09 / 28 / 05$ 
WCH-42

Rev. 1

\section{EBERLINE SERVICES/RICHMOND}

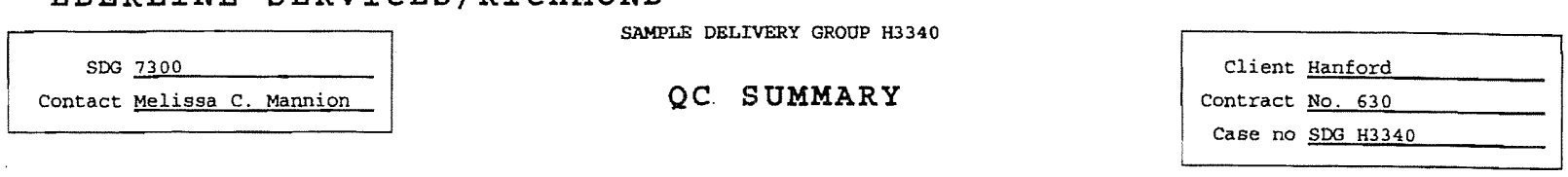

\begin{tabular}{|c|c|c|c|c|c|c|c|c|c|c|}
\hline QC ВАTCH & $\begin{array}{l}\text { CHATN OF } \\
\text { CUSTODY }\end{array}$ & CLISNT SAMPLE ID & MATRIX & $\begin{array}{c}* \\
\text { SOLIDS }\end{array}$ & $\begin{array}{l}\text { SAMPLE } \\
\text { AMOUNT }\end{array}$ & $\begin{array}{l}\text { BASIS } \\
\text { AMOUNT }\end{array}$ & $\begin{array}{l}\text { DAYS S } \\
\text { RECEIVED }\end{array}$ & $\begin{array}{l}\text { SINCE } \\
\text { COLLt }\end{array}$ & $\begin{array}{c}\text { LAB } \\
\text { SAMPLE ID }\end{array}$ & $\begin{array}{l}\text { DEPARTMENT } \\
\text { SAMPLE ID }\end{array}$ \\
\hline \multirow[t]{4}{*}{7300} & B05-039-2 & J03X89 & WATER & & $0.98 \mathrm{~L}$ & & $08 / 29 / 05$ & 96 & $R 508231-01$ & $7300-001$ \\
\hline & & Method Blank & WATER & & & & & & $R 508231-03$ & $7300-003$ \\
\hline & & Lab Control Sample & WATER & & & & & & R508232-02 & $7300-002$ \\
\hline & & Duplicate (R508231-01) & WATER & & $0.98 \mathrm{I}$ & & $08 / 29 / 05$ & 96 & R508231-04 & $7300-004$ \\
\hline
\end{tabular}

QC SUMMARY

Page 1

SUMARY DATA SECTION

Page 4
Lab id EBRLN

Protocol Hanford

version ver 1.0

Form DVD-OS

version 3.06

Report date 09/28/05 
WCH-42

Rev. 1

EBERLINE SERVICES/RICHMOND

SAMPLE DELIVERY GROUP H3340

SDG 7300

Contact Melissa C. Mannion

PREP BATCH SUMMARY

Client hanford

Contract №. 630

Case no SDG H3340

\begin{tabular}{|c|c|c|c|c|c|c|c|c|c|c|c|}
\hline \multirow[b]{2}{*}{ TEST } & \multirow[b]{2}{*}{ MATRIX } & \multirow[b]{2}{*}{ METHOD } & \multirow{2}{*}{$\begin{array}{l}\text { PREPARATION } \\
\text { BATCH }\end{array}$} & \multirow{2}{*}{$\begin{array}{r}\text { ERROR } \\
2 \sigma \quad z\end{array}$} & & & \multicolumn{2}{|c|}{ ANALYZED } & \multirow{2}{*}{$\begin{array}{l}\text { QUALI- } \\
\text { FIERS }\end{array}$} \\
\hline & & & & & CLIBNT & MORE & $\begin{array}{l}\text { PLA } \\
\text { RE }\end{array}$ & $\begin{array}{l}\text { NCHETS } \\
\text { BLANK }\end{array}$ & $\begin{array}{l}\text { ANALYZ } \\
\text { LCS }\end{array}$ & DUR/ORIG MS/ORIG & \\
\hline Beta & Counting & & & & & & & & & & \\
\hline$T C$ & WATER & Technetium 99 in water & $7136-100$ & 10.0 & 1 & & & 1 & 1 & $1 / 1$ & \\
\hline Gas $P$ & Proportion & 1 counting & & & & & & & & & \\
\hline $93 \mathrm{~A}$ & WATER & Gross Alpha in water & $7136-100$ & 20.0 & 1 & & & 1 & $I$ & $1 / 1$ & \\
\hline $93 \mathrm{~B}$ & WATER & Gross Beta in water & $7136-100$ & 15.0 & 1 & & & 1 & 1 & $1 / 1$ & \\
\hline
\end{tabular}

Duplicates and Matrix Spikes are those with original (Client) sample in this Sample Delivery Group.

Blank and LCS planchets are those in the same preparation batch as some Client, Duplicate or Spike sample.

PREP BATCH SOMMARY

Page 1

SUMMARY DATA SECTION

Page 5
Lab id EBRLNE

Protocol Hanford

Version Vex 1.0

Form DVD-PBS

Version 3.06

Report date $09 / 28 / 05$ 
WCH-42

Rev. 1

EBERLINE SERVICES / RICHMOND

SAMPLE DELIVERY GRODP H3340

LAB WORK SUMMARY
Client Hanford

Contract No. 630

Caвe no SDG H3340

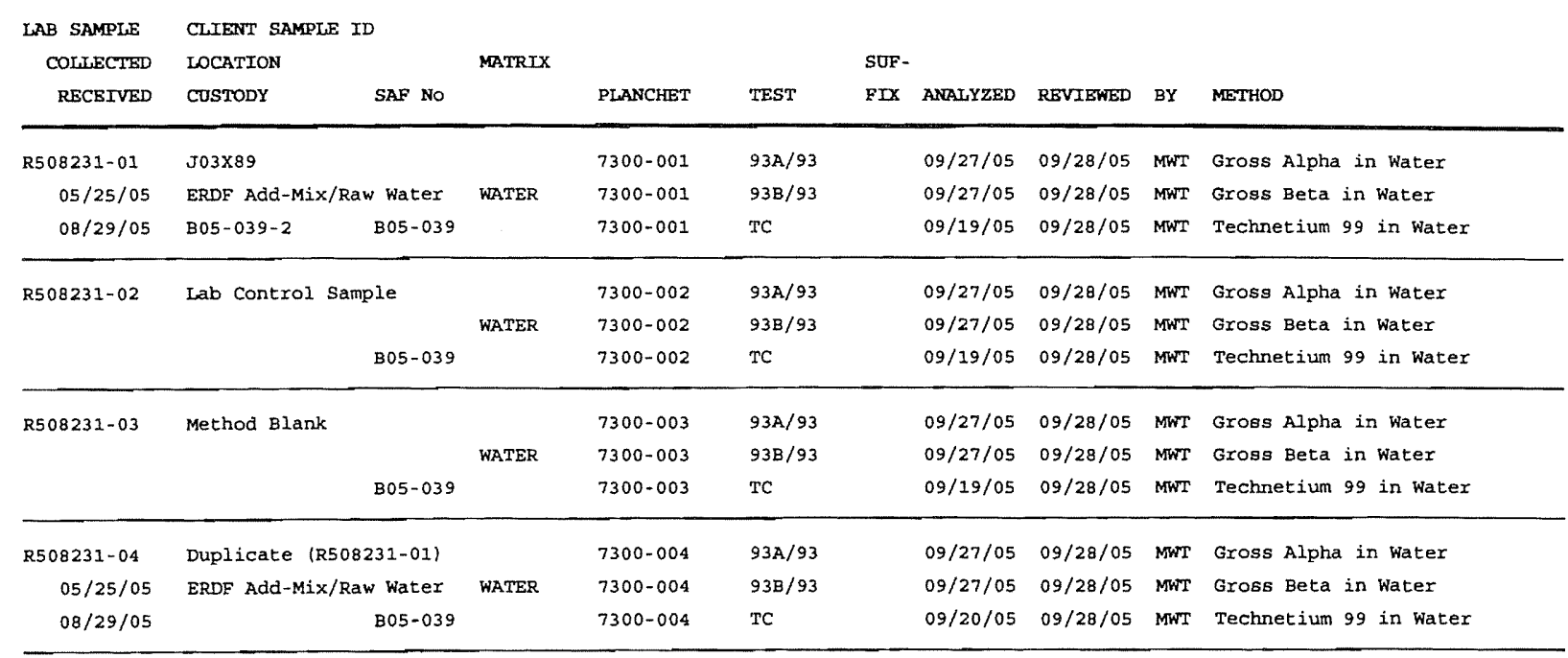

\begin{tabular}{|c|c|c|c|c|c|c|c|c|c|c|c|}
\hline TEST & SAF NO & COUNTS & OF & $\underset{\text { REFERENCE }}{\text { TESTS BY }}$ & $\underset{\text { CLIENT }}{\operatorname{SAMPLE} T}$ & $\begin{array}{l}\text { TY P E } \\
\text { MORE }\end{array}$ & $R E$ & BLANR & LCS & DUP SPIKE & TOTAL \\
\hline $93 A / 93$ & B05-039 & Gross Alpha in water & & 900.0 _ALPHABETA_GPC & 1 & & & 1 & 1 & 1 & 4 \\
\hline $93 \mathrm{~B} / 93$ & B05-039 & Grogs Beta in Water & & 900.0 _ALPHABETA_GPC & 1 & & & 1 & 1 & 1 & 4 \\
\hline $\mathrm{TC}$ & B05-039 & Technetium 99 in water & & TC99_TR_SEP_LSC & 1 & & & 1 & 1 & 1 & 4 \\
\hline TOTALS & & & & & 3 & & & 3 & 3 & 3 & 12 \\
\hline
\end{tabular}

WORX SUMMARY

Page 1

SUMMARY DATA SECTION

Page 6
Lab id EBRLNE

Pxotocol hanford

Version ver 1.0

Form DVD-LWS

Version 3.06

Report date $09 / 28 / 05$ 
WCH-42

Rev. 1

EBERIINESERVICES/RICHMOND SAMPLE DELIVERY GROUP H3340

$7300-003$

METHOD BIAN R

Method Blank

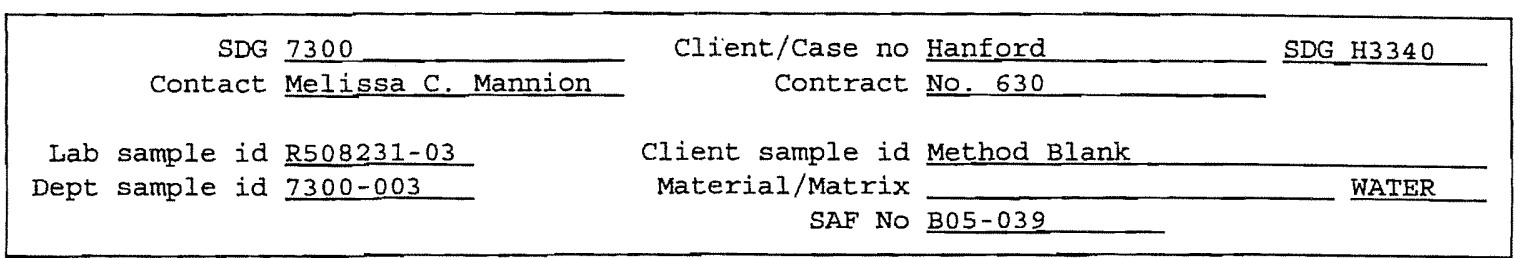

\begin{tabular}{|llcccccc|}
\hline ANALYTE & CAS NO & $\begin{array}{c}\text { RESULT } \\
\text { pCi/L }\end{array}$ & $\begin{array}{c}2 \sigma \text { ERR } \\
\text { (COUNT) }\end{array}$ & $\begin{array}{c}\text { MDA } \\
\text { pCi/L }\end{array}$ & $\begin{array}{c}\text { RDI } \\
\text { pCi/L }\end{array}$ & $\begin{array}{c}\text { QUALI- } \\
\text { FIERS }\end{array}$ & TEST \\
\hline Gross Alpha & $12587-46-1$ & -0.163 & 0.59 & 1.4 & 3.0 & U & $93 A$ \\
Gross Beta & $12587-47-2$ & 0.638 & 1.1 & 1.9 & 4.0 & U & $93 B$ \\
Technetium 99 & $14133-76-7$ & -1.64 & 1.4 & 5.4 & 15 & U & TC \\
\hline
\end{tabular}

ERDF Iysimeter Sampling

QC-BLANK 54349

METHOD BLANRS

Page 1

SUMMARY DATA SECTION

Page 7
Lab id EBRLNE

Protocol Hanford

Version Ver 1.0

Form DVD-DS

Version 3.06

Report date 09/28/05 
WCH-42

Rev. 1

EBERLINE SERVICES/RICHMOND

SAMPLE DELIVERY GROUP H3340

$7300-002$

LAB CONTROI SAMPLE

Lab Control Sample

\begin{tabular}{|cc|}
\hline SDG $\frac{7300}{\text { Contact Melissa C. Mannion }}$ & $\begin{array}{c}\text { Client/Case no Hanford } \\
\text { Contract No. 630 }\end{array}$ \\
Lab sample id R508231-02 & Client sample id Lab Control Sample \\
Dept sample id $\frac{7300-002}{\text { Material/Matrix }}$ & SAF No B05-039 \\
\hline
\end{tabular}

\begin{tabular}{|c|c|c|c|c|c|c|c|c|c|c|c|}
\hline ANALYTE & $\begin{array}{l}\text { RESULT } \\
\mathrm{pCi} / \mathrm{L}\end{array}$ & $\begin{array}{l}2 \sigma \text { ERR } \\
(C O N N T)\end{array}$ & $\begin{array}{c}\mathrm{MDA} \\
\mathrm{pCi} / \mathrm{L}\end{array}$ & $\begin{array}{c}\mathrm{RDL} \\
\mathrm{pCi} / \mathrm{L}\end{array}$ & $\begin{array}{l}\text { QUALI- } \\
\text { FIERS }\end{array}$ & TEST & $\begin{array}{l}\text { ADDED } \\
\mathrm{pCi} / \mathrm{L}\end{array}$ & $\begin{array}{r}2 \sigma \text { ERR } \\
\mathrm{pCi} / \mathrm{L}\end{array}$ & $\begin{array}{r}\mathrm{REC} \\
t\end{array}$ & $\begin{array}{l}3 \sigma \text { LMTS } \\
\text { (TOTAL) }\end{array}$ & $\begin{array}{l}\text { PROTOCOL } \\
\text { LIMITS }\end{array}$ \\
\hline Gross Alpha & 27.1 & 3.6 & 1.3 & 3.0 & & $93 A$ & 34.0 & 1.4 & 80 & $71-129$ & $70-130$ \\
\hline Gross Beta & 35.1 & 2.6 & 2.0 & 4.0 & & $93 \mathrm{~B}$ & 33.1 & 1.3 & 106 & $73-127$ & $80-120$ \\
\hline Technetium 99 & 1070 & 72 & 5.9 & 15 & & $\mathrm{TC}$ & 1090 & 44 & 98 & $81-119$ & $80-120$ \\
\hline
\end{tabular}

ERDF Lysimeter Sampling

QC-LCS 54348

LAB CONTROL SAMPLES

page 1

SUMMARY DATA SECTION

Page 8 
WCH-42

Rev. 1

EBERLINE SERVICES/RICHMOND

SAMPLE DELIVERY GROUP H3340

7300-004

DUPLICATE

J03Хв 9

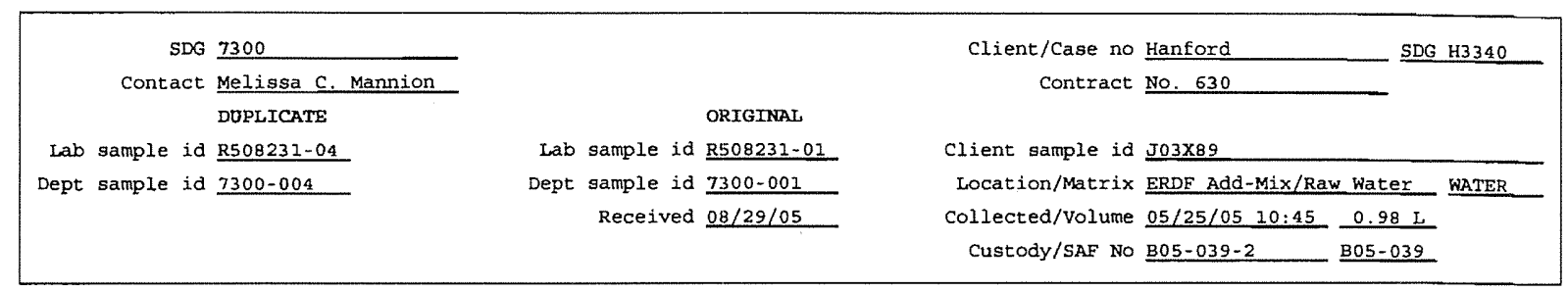

\begin{tabular}{|c|c|c|c|c|c|c|c|c|c|c|c|c|}
\hline ANALYTE & $\begin{array}{c}\text { DOPLICATE } \\
\text { pCi/L }\end{array}$ & $\begin{array}{l}2 \sigma \text { ERR } \\
\text { (COUNT) }\end{array}$ & $\begin{array}{c}\mathrm{MDA} \\
\mathrm{pCi} / \mathrm{L}\end{array}$ & $\begin{array}{c}\mathrm{RDL} \\
\mathrm{pCi} / \mathrm{L}\end{array}$ & $\begin{array}{l}\text { QUALI- } \\
\text { FIERS }\end{array}$ & TEST & $\begin{array}{l}\text { ORIGINAL } \\
\qquad \mathrm{pCi} / \mathrm{L}\end{array}$ & $\begin{array}{l}2 \sigma \mathrm{ERR} \\
(\mathrm{COUNT})\end{array}$ & $\begin{array}{c}\mathrm{MDA} \\
\mathrm{pCi} / \mathrm{L}\end{array}$ & $\begin{array}{l}\text { QUALI- } \\
\text { FIERS }\end{array}$ & $\begin{array}{r}\text { RPD } \\
?\end{array}$ & $\begin{array}{cc}3 \sigma & \text { PROT } \\
\text { TOT } & \text { LIMTT }\end{array}$ \\
\hline Gross Alpha & 0.086 & 1.3 & 2.8 & 3.0 & $\mathrm{U}$ & $93 \mathrm{~A}$ & 2.12 & 1.6 & 1.8 & & 184 & 286 \\
\hline Gross Beta & 5.12 & 1.4 & 2.0 & 4.0 & & $93 \mathrm{~B}$ & 4.87 & 1.5 & 2.0 & & 5 & 69 \\
\hline Technetium 99 & 1.45 & 2.2 & 4.7 & 15 & 0 & TC & -0.607 & 1.4 & 3.9 & 0 & - & \\
\hline
\end{tabular}

ERDE Lysimeter Sampling

QC-DUP\# 154350

DUPLICATES

page 1

SUMMARY DATA SECTION

page 9
Iab io EBRT.NE Protocol Hanford

version ver 1.0

Form DVD-DUP

version 3.06

Report date $09 / 28 / 05$ 
WCH-42

Rev. 1

E B ERIINESERVICES/RICHMOND SAMPLE DELIVERY GROUP H3340

$7300-001$

DA TA SHEET

J03×89

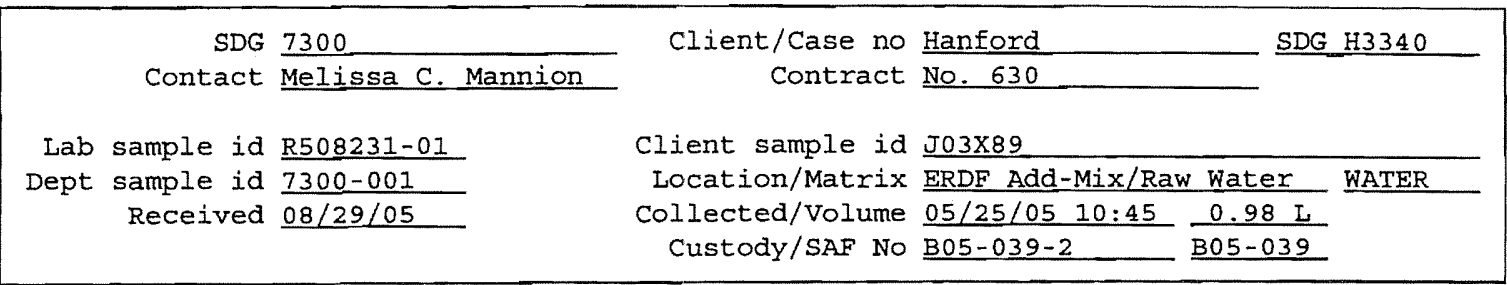

\begin{tabular}{|c|c|c|c|c|c|c|c|}
\hline ANALYTE & CAS NO & $\begin{array}{r}\text { RESULT } \\
\mathrm{pCi} / \mathrm{L}\end{array}$ & $\begin{array}{l}2 \sigma \text { ERR } \\
\text { (COUNT) }\end{array}$ & $\begin{array}{c}\mathrm{MDA} \\
\mathrm{pCi} / \mathrm{L}\end{array}$ & $\begin{array}{c}\mathrm{RDL} \\
\mathrm{pCi} / \mathrm{L}\end{array}$ & $\begin{array}{l}\text { QUAII - } \\
\text { FIERS }\end{array}$ & TEST \\
\hline Gross Alpha & $12587-46-1$ & 2.12 & 1.6 & 1.8 & 3.0 & & $93 A$ \\
\hline Gross Beta & $12587-47-2$ & 4.87 & 1.5 & 2.0 & 4.0 & & $93 B$ \\
\hline Technetium 99 & $14133-76-7$ & -0.607 & 1.4 & 3.9 & 15 & $\mathrm{U}$ & $\mathrm{TC}$ \\
\hline
\end{tabular}

ERDF Lysimeter Sampling

DATA SHEETS

Page 1

SUMMARY DATA SECTION

Page 10
Lab id EBRLNE

Protocol Hanford

version Ver 1.0

Form DVD-DS

Version 3.06

Report date $\underline{09 / 28 / 05}$ 
WCH-42

Rev. 1

EBERLINE SERVICES/RICHMOND

SAMPLE DELTVBRY GROUP H3340

Test TC Matrix WATER

SDG $\underline{7300}$

Contact Melissa_C. Mannion
LAB METHOD SUMMARY

TECHNETIOM 99 IN WATER

BETA COUNTING
Client Hanford

Contract NO. 630

Contract SDG H3340

\section{RESULTS}

LAB RAW SUF-

Technetium

SAMPLE ID TEST FIX PLANCHET CLIENT SAMPLE ID 99

preparation batch $7136-100$

R508231-01

R508231-02 7300-002

R508231-03 7300-003

R508231-04

$7300-004$

J03X89 $\mathrm{v}$

LCS $(Q C$ ID $=54348) \quad$ ok

BLK (QC ID $=54349$ )

Duplicate (R508231-01)

$\mathrm{u}$

Nominal values and limits from method RDLs (pCi/L) 15

ERDF Lysimeter Sampling

METHOD PERFORMANCE

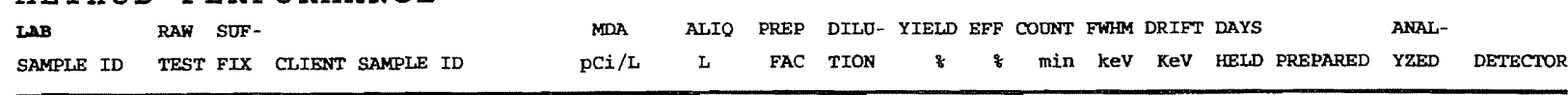

Preparation batch 7136-100 20 prep error 10.0 \& Reference Lab Notebook 7136 pg. 100

$\begin{array}{llllll}\text { R508231-01 } & \text { J03X89 } & 3.9 & 0.300 & 95 & 100\end{array}$

$\begin{array}{llllr}\text { R508231-02 LCS (QC ID 5 54348) } & 5.9 & 0.100 & 91 & 50\end{array}$

$\begin{array}{llllll}\text { R508231-03 BLK } \text { (QC ID } 54349) & 5.4 & 0.100 & 95 & 50\end{array}$

$\begin{array}{llllll}\text { R508231-04 Duplicate (R508231-01) } & 4.7 & 0.100 & 94 & 66\end{array}$

$(\mathrm{QC} \mathrm{ID}=54350)$

\begin{tabular}{lllll}
\hline Nominal values and limits from method & I5 & 0.100 & $20-105$ & 50 \\
\hline
\end{tabular}

$\begin{array}{lll}\text { PROCEDURES } & \text { REFERENCE } & \text { TC99_TR_SEP_LSC } \\ \text { CP-431 } & \text { Technetium-99 purification of Soil ox Resin by } \\ & \text { Extraction Chromatography, rev } 2 \\ \text { CF-008 } & \text { Heavy Element Electroplating, rev } 9\end{array}$

AVERAGES \pm 2 SD
FOR 4 SAMPLES $\quad$ YIELD $\frac{5.0}{94} \pm \frac{1.7}{4}$

METHOD SUMARIES

page 1

SUMMARY DATA SECTION

Page 11

Lab id EBRLNE

Protocol Hanford

Version Vex 1.0

Form DVD-LMS

version 3.06

Report date 09/28/05 
EBERIINE SERVICES/RICHMOND

SAMPLE DELIVERY GROOP H3340

\section{IAB METHOD SUMMARY \\ GROSS ALPHA IN WATBR \\ GAS PROPORTIONAL COUNTING}

Client Hanford

Contract No. 630

Contract SDG H3340

\section{RESULTS}

LAB RAW SUF-

SAMPLE ID TEST FIX PLANCHET CLIENT SAMPLE ID Grosg Alpha

Preparation batch $7136-100$

$\begin{array}{lllllll}\text { R50823I-01 } & 93 & 7300-001 & 303 \times 89 & 2.12 & \\ \text { R50823I-02 } & 93 & 7300-002 & \text { LCS (QC ID=54348) } & 0 \mathrm{k} & \\ \text { R508231-03 } & 93 & 7300-003 & \text { BLK (QC ID=54349) } & 0 & \\ \text { R50823I-04 } & 93 & 7300-004 & \text { Duplicate (R50823I-01) } & \text { ok } & \text { O }\end{array}$

Nominal values and limits from method RDLs (pCi/L) 3.0

ERDF Lysimeter Sampling

METHOD PERFORMANCE

LAB RAW SUF- MDA ALIQ PREP DILO- RESID EFE COUNT FWHM DRIFT DAYS ANAL-

SAMPLE ID TEST FIX CLIENT SAMPLE ID pCi/L $L$ FAC TION mg $t$ min keV KeV HELD PRBPARED YZED DETECTOR

Preparation batch $7136-100 \quad 20$ prep error $20.0 \div$ Reference Lab Notebook 7136 pg. 100

$\begin{array}{lllllll}R 508231-01 & 93 & \text { J03X89 } & 1.8 & 0.290 & 150 & 100\end{array}$

$\begin{array}{rllll}\text { R508231-02 } 93 & \text { LCS (OC ID }=54348) & 1.3 & 0.300 & 60\end{array}$

$\begin{array}{llllll}R 508231-03 & 93 & \text { BLK }(Q C \text { ID }=54349) & 1.4 & 0.300 & 58\end{array}$

$\begin{array}{llllll}\text { R508231-04 } 93 & \text { Duplicate }(R 508231-01) & 2.8 & 0.290 & 150 & 100\end{array}$

(QC ID $=54350)$

Nominal values and limits from method $\quad 3.0 \quad 0.300 \quad 5-250 \quad 100 \quad 180$

PROCEDURES REFERENCE 900.0_ALPHABETA_GPC

SPP-120 Gross Alpha and Gross Beta in water, rev 0 
$\mathrm{WCH}-42$

Rev. 1

EBERIINE SERVICES/RICHMOND

SAMPLE DELIVERY GRONP H3340

Test $93 \mathrm{~B}$ Matrix WATER

SDG 7300

Contact Melissa C. Mannion

\section{LAB METHOD SUMMARY \\ GROSS BETA IN WATER}

GAS PROPORTIONAI, COUNTING
Client Hanford

Contract No. 630

Contract SDG H3340

\section{RESULTS}

LAB RAW SUF-

SAMPLE ID TEST FIX PLANCHET CLIENT SAMPLE ID Gross Beta

Preparation batch $7136-100$

$\begin{array}{llllc}\text { R508231-01 } & 93 & 7300-001 & \text { J03X89 } & 4.87 \\ \text { R508231-02 } & 93 & 7300-002 & \text { LCS (OC ID=54348) } & \text { ok } \\ \text { R508231-03 } & 93 & 7300-003 & \text { BLK (OC ID } 54349 \text { ) } & \text { U } \\ \text { R508231-04 } & 93 & 7300-004 & \text { Duplicate (R508231-01) } & \text { Ok }\end{array}$

R508231-04 93 7300-004 Duplicate (R508231-01) ok

Nominal values and limits from method RDLs (pCi/L) 4.0

ERDF Lysimetex Sampling

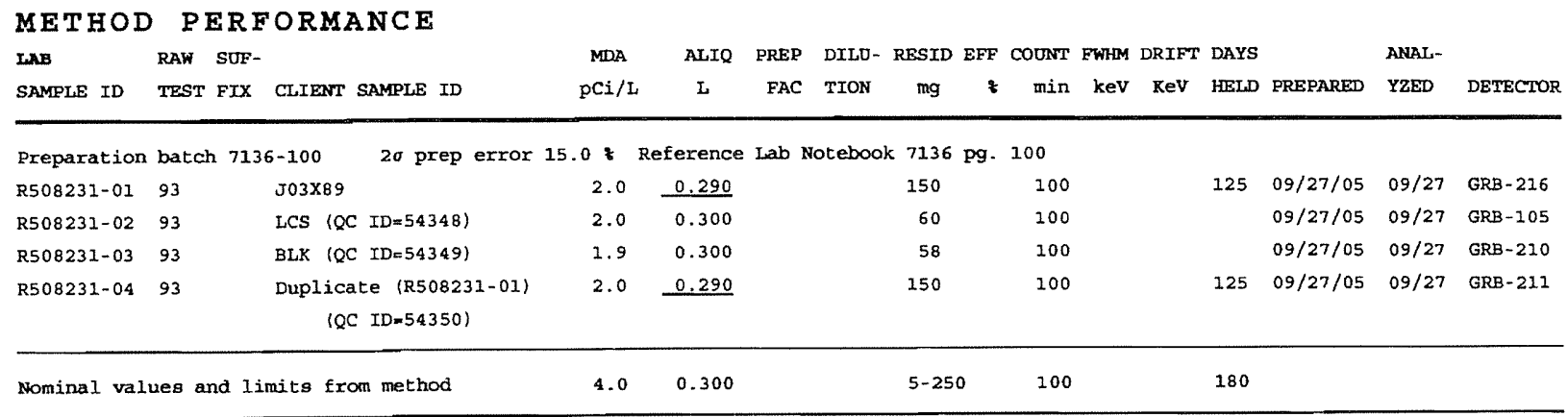

PROCEDURES REFERENCE 900.0_ALPHABETA_GPC

SPP-120 Gross Alpha and Gross Beta in water, rev 0
AVERAGES \pm 2 SD
FOR 4 SAMPLAS $\quad$ RESIDUE $\frac{2.0}{104} \pm \frac{0.10}{105}$

RESIDUE $104 \pm 105$
METHOD SUMMARIES

Page 3

SUMARY DATA SECTION

Page 13
Lab id EBRINE Protocol Hanford Version Ver 1.0 Form DVD-LMS Version 3.06 Report date $09 / 28 / 05$ 
WCH-42

Rev. 1

E B E R I N E SERVICES/RICHMOND SAMPLE DELIVERY GROUP H3340

SDG 7300 Contact Melissa C. Mannion
REPORT GUIDE
Client Hanford

Contract No. 630

Case no SDG H3340

\section{S A M I E S UM M R Y}

The Sample and QC Summary Reports show all samples, including QC samples, reported in one Sample Delivery Group (SDG).

The Sample Summary Report fully identifies client samples and gives the corresponding lab sample identification. The QC Summary Report shows at the sample level how the lab organized the samples into batches and generated $\mathrm{QC}$ samples. The Preparation Batch and Method Summary Reports show this at the analysis level.

The following notes apply to these reports:

* IAB SAMPLE ID is the lab's primary identification for a sample.

* DEPARTMENT SAMPLE ID is an alternate lab id, for example one assigned by a radiochemistry department in a lab.

* CLIENT SAMPLE ID is the client's primary identification for a sample. It includes any sample preparation done by the client that is necessary to identify the sample.

* QC BATCH is a lab assigned code that groups samples to be processed and QCed together. These samples should have similar matrices.

QC BATCH is not necessarily the same as SDG, which reflects samples received and reported together.

* Ail Lab Control Samples, Method Blanks, Duplicates and Matrix Spikes are shown that QC any of the samples. Due to possible reanalyses, not all results for all these QC samples may be relevant to the SDG. The Lab Control Sample, Method Blank, Duplicate, Matrix spike and Method Summary Reports detail these relationships.

REPORT GUIDES Page 1

SUMMARY DATA SECTION

Page 14
Lab id EBRINE Protocol Hanford Version Ver 1.0 Form DVD-RG Version 3.06 Report date $09 / 28 / 05$ 
WCH-42

Rev. 1

E B ERIINE SERVICES/RICHMOND SAMPLE DELIVERY GROUP H3340

SDG 7300 Contact Melissa C. Mannion

Client Hanford

Contract No. 630 Case no SDG H3340

PREPARATION BATCH SUMMARY

The Preparation Batch Summary Report shows all preparation batches in one Sample Delivery Group (SDG) with information necessary to check the completeness and consistency of the SDG.

The following notes apply to this report:

* The preparation batches are shown in the same order as the Method summary Reports are printed.

* Only analyses of planchets relevant to the SDG are included.

* Each preparation batch should have at least one Method Blank and LCS in it to validate client sample results.

* The QUALIFIERS shown are all qualifiers other than U, J, B, I and $\mathrm{H}$ that occur on any analysis in the preparation batch. The Method Summary Report has these qualifiers on a per sample basis.

These qualifiers should be reviewed as follows:

$x$ Some data has been manually entered or modified. Transcription errors are possible.

$P$ One or more results are 'preliminary'. The data is not ready for final reporting.

2 There were two or more results for one analyte on one planchet imported at one time. The results in DVD may not be the same as on the raw data sheets.

other lab defined qualifiers may occur. In general, these should be addressed in the SDG narrative.

REPORT GUIDES

Page 2

SUMMARY DATA SBCTION

Page 15
Lab id EBRLNE

Protocol Hanford

Version Ver 1.0

Form DVD-RG

Version 3.06

Report date 09/28/05 
WCH-42

Rev. 1

E B ERIINE SERVICES/RICHMOND SAMPLE DELIVERY GROUP H3340

SDG 7300 Contact Melissa C. Mannion

\section{R E POR T G UI D E}

Client Hanford

Contract No. 630

Case no SDG H3340

\section{WORK S UMMAR Y}

The Work Summary Report shows all samples, including QC samples, and all relevant analyses in one Sample Delivery Group (SDG). This report is often useful as supporting documentation for an invoice.

The following notes apply to this report:

* TEST is a code for the method used to measure associated analytes. Results and related information for each analyte are on the Data sheet Report. In special cases, a test code used in the summary data section is not the same as in associated raw data. In this case, both codes are shown on the Work Summary.

* SUFFIX is the lab's code to distinguish multiple analyses (recounts, reworks, reanalyses) of a fraction of the sample. The suffix indicates which result is being reported. An empty suffix normally identifies the first attempt to analyze the sample.

* The LAB SAMPLE ID, TEST and SUFFIX uniquely identify all supporting data for a result. The Method Summary Report for each TEST has method performance data, such as yield, for each lab sample id and suffix and procedures used in the method.

* PLANCHET is an alternate lab identifier for work done for one test. It, combined with the TEST and SUFFIX, may be the best link to raw data.

* For QC samples, only analyses that directly $Q C$ some regular sample are shown. The Lab Control Sample, Method Blank, Duplicate, Matrix spike and Method Summary Reports detail these relationships.

* The SAS (Special Analytical Services) Number is a client or lab assigned code that reflects special processing for samples, such as rapid turn around. Counts of tests done are lists by SAS number since it is likely to affect prices.

RBPORT GUIDES

Page 3

SUMMARY DATA SECTION

Page 16
Lab id EBRLNE

Protocol Hanford

Version Ver 1.0

Form DVD-RG

Version 3.06

Report date $\underline{09 / 28 / 05}$ 
WCH-42

Rev. 1

E B E R I NE SERVICES/RICH MON D

SDG 7300

Contact Melissa_C. Mannion SAMPLE DELIVERY GROUP H3340

R E POR T G OIDE
Client Hanford

Contract No. 630

Case no SDG H3340

\section{DA T A S H E T}

The Data Sheet Report shows all results and primary supporting information for one client sample or Method Blank. This report corresponds to both the CLP Inorganics and organics Data sheet.

The following notes apply to this report:

* TEST is a code for the method used to measure an analyte. If the TEST is empty, no data is available; the analyte was not analyzed for.

* The LAB SAMPLE ID and TEST uniquely identify work within the Summary Data Section of a Data Package. The Work Summary and Method Summary Reports further identify raw data that underlies this work.

The Method Summary Report for each TEST has method performance data, such as yield, for each Lab sample ID and a list of procedures used in the method.

* ERRORs can be labeled total or COUNT. TOTAL implies a preparation (non-counting method) error has been added, as square root of sum of squares, to the counting error denoted by COUNT. The preparation errors, which may vary by preparation batch, are shown on the Method Summary Report.

* A RESULT can be 'N.R.' (Not Reported). This means the lab did this work but chooses not to report it now, possibly because it was reported at another time.

* When reporting a Method Blank, a RESULT can be 'N.A.' (Not Applicable). This means there is no reported client sample work in the same preparation batch as the Blank's result. This is likely to occur when the Method Blank is associated with reanalyses of selected work for a few samples in the SDG.

The following qualifiers are defined by the DVD system:

U The RESULT is less than the MDA (Minimum Detectable Activity).

REPORT GUIDES Page 4

SUMMARY DATA SECTION Page 17
Lab id EBRINE Protocol Hanford Version Ver 1.0 Form DVD-RG

Version 3.06 Report date $09 / 28 / 05$ 
WCH-42

Rev. 1

E B ERIINE SERVICES/RICHMON D

SDG 7300

Contact Melissa C. Mannion SAMPLE DELIVERY GROUP H3340

GOIDE, cont.

Client Hanford

Contract No. 630

Case no SDG H3340

\section{DA T A S H E E T}

If the MDA is blank, the ERROR is used as the limit.

J The RESULT is less than the RDL (Required Detection Limit) and no $U$ qualifier is assigned.

B A Method Blank associated with this sample had a result without a U flag and, after correcting for possibly different aliquots, that result is greater than or equal to the MDA for this sample.

Normally, B is not assigned if $U$ is. When method blank subtraction is shown on this report, B flags are assigned based on the unsubtracted values while U's are assigned based on the subtracted ones. Both flags can be assigned in this case.

For each sample result, all Method Blank results in the same preparation batch are compared. The Method Summary Report documents this and other QC relationships.

I Some Lab Control Sample that QC's this sample had a low recovery. The lab can disable assignment of this qualifier.

H Similar to ' $L$ ' except the recovery was high.

P The RESULT is 'preliminary'.

$X$ Some data necessary to compute the RESULT, ERROR or MDA was manually entered or modified.

2 There were two or more results available for this analyte. The reported result may not be the same as in the raw data.

Other qualifiers are lab defined. Definitions should be in the SDG narrative.

The following values are underlined to indicate possible problems:

* An MDA is underlined if it is bigger than its RDI.

REPORT GUIDES

Page 5

SUMMARY DATA SECTION

Page 18
Lab id EBRLNE

Protocol Hanford

Version Ver 1.0

Form DVD-RG

version 3.06

Report date $09 / 28 / 05$ 
WCH-42

Rev. 1

EB ERIINESERVICES/RICH MOND SAMPLE DELIVERY GROUP H3340

SDG 7300 Contact Melissa C. Mannion

GUIDE, cont. Client Hanford Contract No. 630 Case no SDG_H3340

\section{DATA S HE T}

* An ERROR is underlined if the 1.645 sigma counting error is bigger than both the MDA and the RESULT, implying that the MDA may not be a good estimate of the 'real' minimum detectable activity.

* A negative RESULT is underlined if it is less than the negative of its 2 sigma counting ERROR.

* When reporting a Method Blank, a RESULT is underlined if greater than its MDA. If the MDA is blank, the 2 sigma counting error is used in the comparison.

REPORT GOIDES

Page 6

SUMMARY DATA SECTION

Page 19
Lab id EBRINE

Protocol Hanford

Version Ver 1.0

Form DVD-RG

Version 3.06

Report date $09 / 28 / 05$ 
$\mathrm{WCH}-42$

Rev. 1

E B E RIINE SERVICES/RICHMOND

SDG 7300 Contact Melissa C. Mannion
SAMPLE DELIVERY GROUP H3340

REPORT G TIDE
Client Hanford

Contract No. 630

Case no SDG 13340

\section{A B CONTROI SAMPIE}

The Lab Control Sample Report shows all results, recoveries and primary supporting information for one Lab Control Sample.

The following notes apply to this report:

* All fields in common with the Data Sheet Report have similar usage. Refer to its Report Guide for details.

* An amount ADDED is the lab's value for the actual amount spiked into this sample with its ERROR an estimate of the error of this amount.

An amount added is underlined if its ratio to the corresponding RDL is outside protocol specified limits.

* REC (Recovery) is RESULT divided by ADDED expressed as a percent.

* The first, computed limits for the recovery reflect:

1. The error of RESULT, including that introduced by rounding the result prior to printing.

If the limits are labeled (TOTAL), they include preparation error in the result. If labeled (COUNT), they do not.

2. The error of ADDED.

3. A lab specified, per analyte bias. The bias changes the center of the computed limits.

* The second limits are protocol defined upper and lower QC limits for the recovery.

* The recovery is underlined if it is outside either of these ranges.

REPORT GUIDES

Page 7

SUMMARY DATA SECTION

Page 20
Lab id EBRLNE

Protocol Hanford Version Ver 1.0 Form DVD-RG

Version 3.06 Report date $\underline{09 / 28 / 05}$ 
WCH-42

Rev. 1

EBERIINESERVICES/RICHMOND SAMPLE DELIVERY GROUP H3340

SDG 7300

Contact Melissa C. Mannion
REPOR T G UIDE

Client Hanford

Contract No. 630

Case no SDG $H 3340$

D U P I I C A T E

The Duplicate Report shows all results, differences and primary

supporting information for one Duplicate and associated oxiginal sample.

The following notes apply to this report:

* All fields in common with the Data Sheet Report have similax usage. This applies both to the Duplicate and original sample data. Refer to the Data Sheet Report Guide for details.

If the Duplicate has data for a TEST and the lab did not do this test to the Original, the Original's RESULTs are underlined.

* The RPD (Relative Percent Difference) is the absolute value of the difference of the RESULTS divided by their average expressed as a percent.

If both RESULTs are less than their MDAs, no RPD is computed and a ' - ' is printed.

For an analyte, if the lab did work for both samples but has data for only one, the MDA from the sample with data is used as the other's result in the RPD.

* The first, computed limit is the sum, as square root of sum of squares, of the errors of the results divided by the average result as a percent, hence the relative error of the difference rather than the error of the relative difference. The errors include those introduced by rounding the RESULTs prior to printing.

If this limit is labeled TOT, it includes the preparation error in the RESULTs. If labeled CNT, it does not.

This value reported for this limit is at most 999.

* The second limit for the RPD is the larger of:

1. A fixed percentage specified in the protocol.

\section{REPORT GUIDES}

Page 8

SUMMARY DATA SECTION

Page 21
Lab id EBRINE Protocol Hanford Version Ver 1.0 Form DVD-RG

Version 3.06

Report date $09 / 28 / 05$ 
WCH-42

Rev. 1

E B E R I N E SERVICES/RICH MON D

SDG 7300 Contact Melissa C. Mannion SAMPLE DELIVERY GROUP H3340

G UIDE, cont.
Client Hanford

Contract No. 630

Case no SDG H3340

\section{U P I I A T E}

2. A protocol factor (typically 2) times the average MDA as a percent of the average result. This limit applies when the results are close to the MDAs.

* The RPD is underlined if it is greater than either limit.

* If specified by the lab, the second limit column is replaced by the Difference Error Ratio (DER), which is the absolute value of the difference of the results divided by the quadratic sum of their one sigma errors, the same errors as used in the first limit.

Except for differences due to rounding, the DER is the same as the RPD divided by the first RPD limit with the limit scaled to 1 sigma.

* The DER is underlined if it is greater than the sigma factor, typically 2 or 3 , shown in the header for the first RPD limit.

REPORT GUIDES

Page 9

SUMMARY DATA SECTION

Page 22
Lab id EBRINE

Protocol Hanford

Version Ver 1.0

Form DVD-RG

Version 3.06

Report date $09 / 28 / 05$ 
WCH-42

Rev. 1

E B ERIINE SERVICES/RICH MON D

SDG 7300

Contact Melissa C. Mannion
SAMPLE DELIVERY GROUP H3340

RE POR T G UIDE

Client Hanford

Contract No. 630

Case no SDG H3340

M A T R I X S P I K E

The Matrix Spike Report shows all results, recoveries and primary supporting information for one Matrix Spike and associated original sample.

The following notes apply to this report:

* All fields in common with the Data Sheet Report have similar usage. This applies both to the Spiked and original sample data. Refer to the Data Sheet Report Guide for details.

If the Spike has data for a TEST and the lab did not do this test to the Original, the Original's RESULTs are underlined.

* An amount ADDED is the lab's value for the actual amount spiked into the Spike sample with its ERROR an estimate of the error of this amount.

An amount is underlined if its ratio to the corresponding RDL is outside protocol specified limits.

* REC (Recovery) is the Spike RESULT minus the Original RESULT divided by ADDED expressed as a percent.

* The first, computed limits for the recovery reflect:

1. The errors of the two RESULTs, including those introduced by rounding them prior to printing.

If the limits are labeled (TOTAL), they include preparation error in the result. If labeled (COUNT), they do not.

2. The error of ADDED.

3. A lab specified, per analyte bias. The bias changes the center of the computed limits.

* The second limits are protocol defined upper and lower QC limits

REPORT GUIDES

Page 10

SUMMARY DATA SECTION

Page 23
Lab id EBRINE

Protocol Hanford

Version Ver 1.0

Form DVD-RG

Version 3.06

Report date $09 / 28 / 05$ 
WCH-42

Rev. 1

E B ERIINE SERVICES/RICHMOND

$\begin{aligned} \text { SDG } & 7300 \\ \text { Contact Melissa C. Mannion } & \end{aligned}$
SAMPLE DELIVERY GROUP H3340

G OID, cont.

Client Hanford

Contract No. 630

Case no SDG 43340

\section{MATRIX SPIRE}

for the recovery.

These limits are left blank if the Original RESULT is more than a protocol defined factor (typically 4) times ADDED. This is a way of accounting for that when the spike is small compared to the amount in the original sample, the recovery is unreliable.

* The recovery is underlined (out of spec) if it is outside either of these ranges.

REPORT GUIDES

Page 11

SUMMARY DATA SECTION

Page 24

Lab id EBRLNE

Protocol Hanford

Version Ver 1.0

Form DVD-RG

Version 3.06

Report date $\underline{09 / 28 / 05}$ 
WCH-42

Rev. 1

\section{E B ERIINE SERVICES/RICH MOND}

SDG 7300 Contact Melissa C. Mannion
SAMPLE DELIVERY GROUP H3340

RE POR T G UIDE
Client Hanford

Contract No. 630

Case no SDG H3340

\section{METHOD S U M M R Y}

The Method Summary Report has two tables. One shows up to five results measured using one method. The other has performance data for the method. There is one report for each TEST, as used on the Data sheet Report.

The following notes apply to this report:

* Each table is subdivided into sections, one for each preparation batch. A preparation batch is a group of aliquots prepared at roughly the same time in one work area of the lab using the same method.

There should be Lab Control Sample and Method Blank results in each preparation batch since this close correspondence makes the QC meaningful. Depending on lab policy, Duplicates need not occur in each batch since they QC sample dependencies such as matrix effects.

* The RAW TEST column shows the test code used in the raw data to identify a particular analysis if it is different than the test code in the header of the report. This occurs in special cases due to method specific details about how the lab labels work.

The Lab Sample or Planchet ID combined with the (Raw) Test Code and Suffix uniquely identify the raw data for each analysis.

* If a result is less than both its MDA and RDL, it is replaced by just ' $U$ ' on this report. If it is greater than or equal to the RDL but less than the MDA, the result is shown with a ' $U$ ' flag.

The $\mathrm{J}$ and $\mathrm{X}$ flags are as on the data sheet.

* Non-U results for Method Blanks are underlined to indicate possible contamination of other samples in the preparation batch. The Method Blank Report has supporting data.

* Lab Control Sample and Matrix Spike results are shown as: ok, No data, LOW or HIGH, with the last two underlined. 'No data'

RBPORT GUIDES Page 12

SUMMARY DATA SBCTION

Page 25
Lab id EBRLNE

Protocol Hanford

Version Ver 1.0

Form DVD-RG

Version 3.06 Report date $09 / 28 / 05$ 
WCH-42

Rev. 1

\section{E B ERIINE SERVICES/RICHMOND} SAMPLE DELIVERY GROUP H3340

SDG 7300 Contact Melissa C. Mannion
G U I D E

cont.
Client Hanford Contract No. 630 Case no SDG H3340

\section{METHOD S UMMARY}

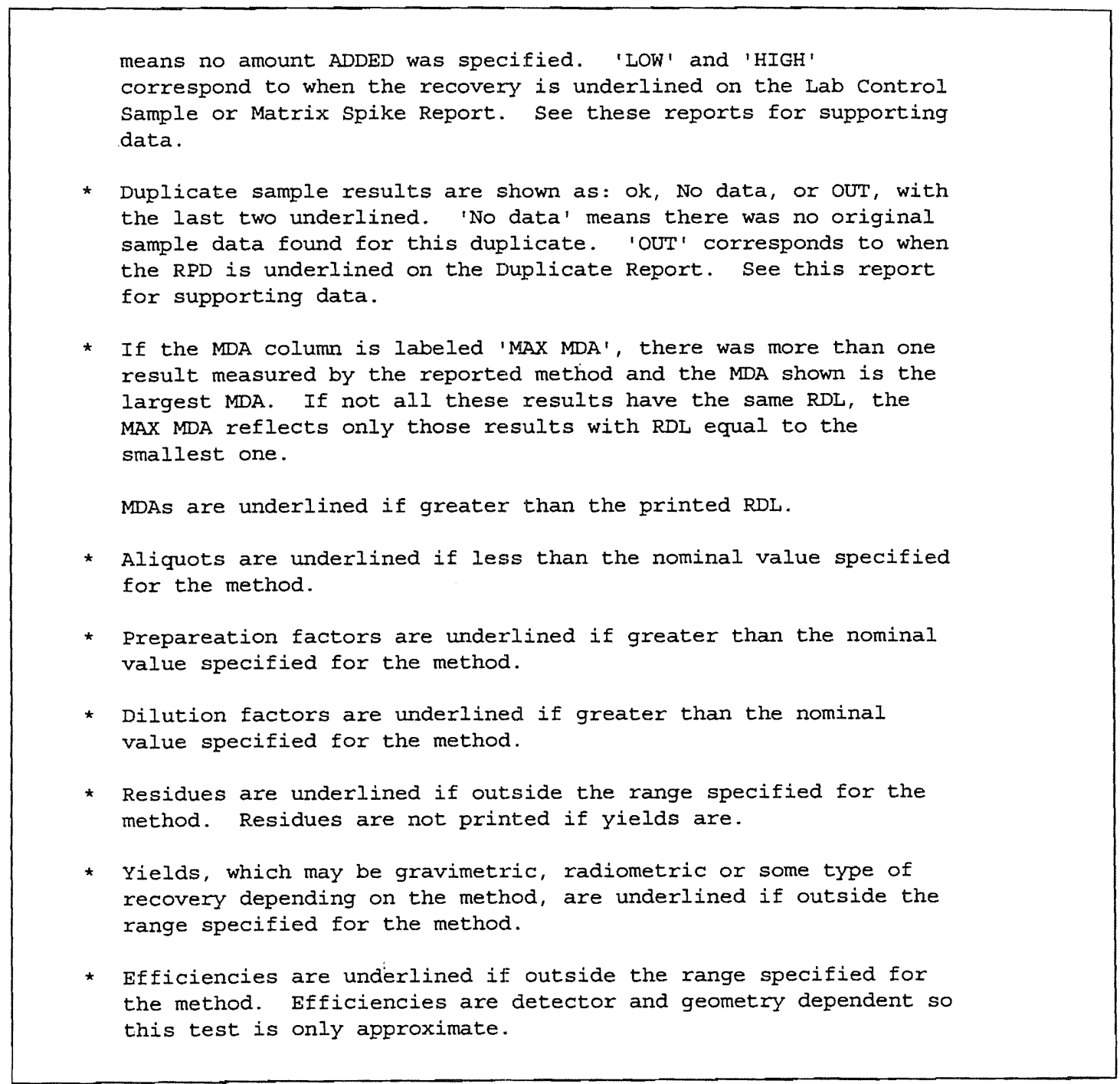

RBPORT GUIDES

Page 13

SUMMARY DATA SECTION

Page 26
Lab id EBRLNE Protocol Hanford Version Ver 1.0

Form DVD-RG

Version 3.06 Report date $09 / 28 / 05$. 
WCH-42

Rev. 1

EBERIINE SERVICES/RICH MOND SAMPLE DELIVERY GROUP H3340

SDG 7300

Contact Melissa C. Mannion

GIIDE, cont.

Client Hanford

Contract No. 630

Case no SDG H3340

METHOD S UM M R Y

* Count times are underlined if less than the nominal value specified for the method.

* Resolutions (as FWHM; Full Width at Half Max) are underlined if greater than the method specified limit.

* Tracer drifts are underlined if their absolute values are greater than the method specified limit. Tracer drifts are not printed if percent moistures are.

* Days Held are underlined if greater than the holding time specified in the protocol.

* Analysis dates are underlined if before their planchet's preparation date or, if a limit is specified, too far after it.

For some methods, ratios as percentages and error estimates for them are computed for pairs of results. A ratio column header like $11 \div 3$ ' means the ratio of the first result column and the third result column.

Ratios are not computed for Lab Control Sample, Method Blank or Matrix Spike results since their matrices are not necessarily similar to client samples'.

The error estimate for a ratio of results from one planchet reflects only counting errors since other errors should be correlated. For a ratio involving different planchets, if QC limits are computed based on total errors, the error for the ratio allows for the preparation errors for the planchets.

The ratio is underlined (out of spec) if the absolute value of its difference from the nominal value is greater than its error estimate. If no nominal value is specified, this test is not done.

For Gross Alpha or Gross Beta results, there may be a column showing the sum of other Alpha or Beta emitters. This sum includes all relevant

REPORT GUIDES

Page 14

SUMMARY DATA SECTION

Page 27
Lab id EBRLNE

Protocol Hanford

Version Ver 1.0

Form DVD-RG

Version 3.06

Report date 09/28/05 
WCH-42

Rev. 1

E B ERIINE SERVICES/RICHMOND SAMPLE DELIVERY GROUP H3340

SDG 7300 Contact Melissa C. Mannion
GUIDE, cont.
Client Hanford

Contract No. 630

Case no SDG H3340

\section{METHOD S U M A R Y}

results in the DVD database, whether reported or not. Results in the sum are weighted by a particles/decay value specified by the lab for each relevant analyte. Results less than their MDA are not included. No sums are computed for Lab Control, Method Blank or Matrix Spike samples since their various planchets may not be physically related.

If a ratio of total isotopic to Gross Alpha or Beta is shown, the error for the ratio reflects both the error in the Gross result and the sum, as square root of sum of squares, of the errors in the isotopic results.

For total elemental uranium or thorium results, there may be a column showing the total weight computed from associated isotopic results. Ignoring results less than their MDAs, this is a weighted sum of the isotopic results. The weights depend on the molecular weight and half-life of each isotope so as to convert activities (decays) to weight (atoms).

If a ratio of total computed to measured elemental uranium or thorium is shown, the error for the ratio reflects the errors in all the measurements.

REPORT GUIDES

Page 15

SUMMARY DATA SECTION

Page 28
Lab id EBRLNE

Protocol Hanford

Version Ver 1.0

Form DVD-RG

Version 3.06

Report date 09/28/05 
WCH-42

Rev. 1

"Weiss, Richard L"

$<$ richard.weiss@wch-rcc.com

$>$

09/01/2005 07:30 AM
To "'mmannion@eberlineservices.com" <mmannion@eberlineservices.com>

cc "Kessner, Joan H" <joan.kessner@wch-rcc.com>

bcc

Subject "Mud Pie" Sample

History: $\quad$ This message has been forwarded.

Melissa,

This applies to samples J03X89 and J03X90 on SAF B05-039.

I did get information from the project, but we cannot match the true "field" conditions. The field specification is for $20 \%$ moisture and that would not yield any usable liquid for testing.

So, the following is based on the typical protocols for determining things like $\mathrm{pH}$ and soluble ions in soil samples.

Perform the contact using a 1:1 liquid/solid ratio based on weight. If you can get this mixture to stir using a beaker and stir-bar, do that for 1 hour. If the beaker method doesn't work, mix the liquid and solid in a jar, shake and continue shaking to thoroughly a couple times an hour for 4 hours. Then separate the liquid from the solid (any process is acceptable) and analyze the liquid. Use sample number J03X89 for the analysis results. Please remember that you need to ship a least $100 \mathrm{ml}$ off to Lionville for chloride analysis.

If any of this doesn't make sense, let me know.

Rich Weiss

509-372-9631

Also, did you need my input on something else? 


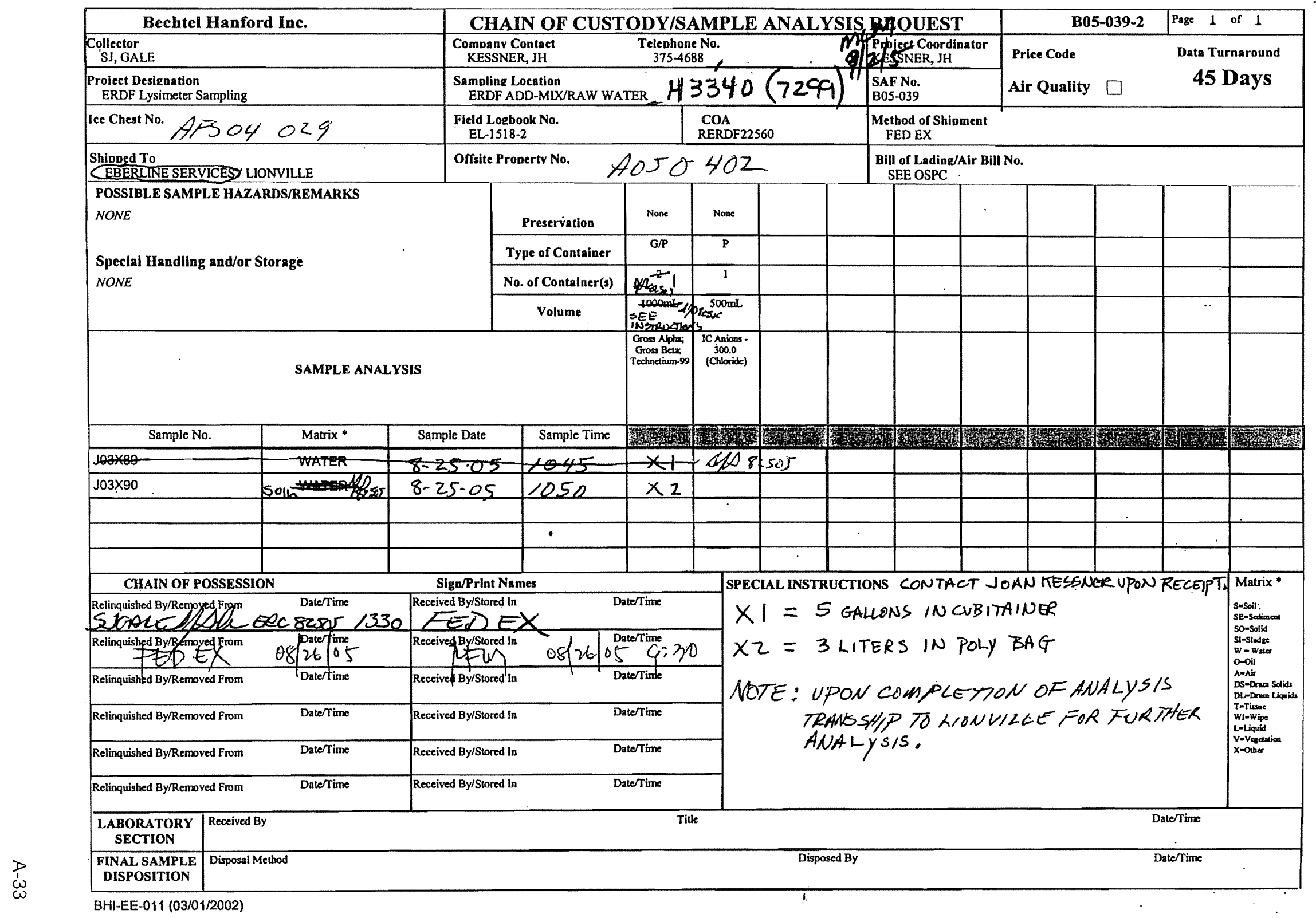


WCH-42

Rev. 1

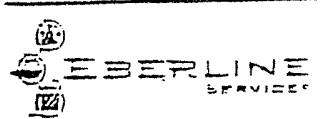

\section{FICHMDND, EA LABDRATORY}

SAMPL $=$ REIEIPT CHECKLIST

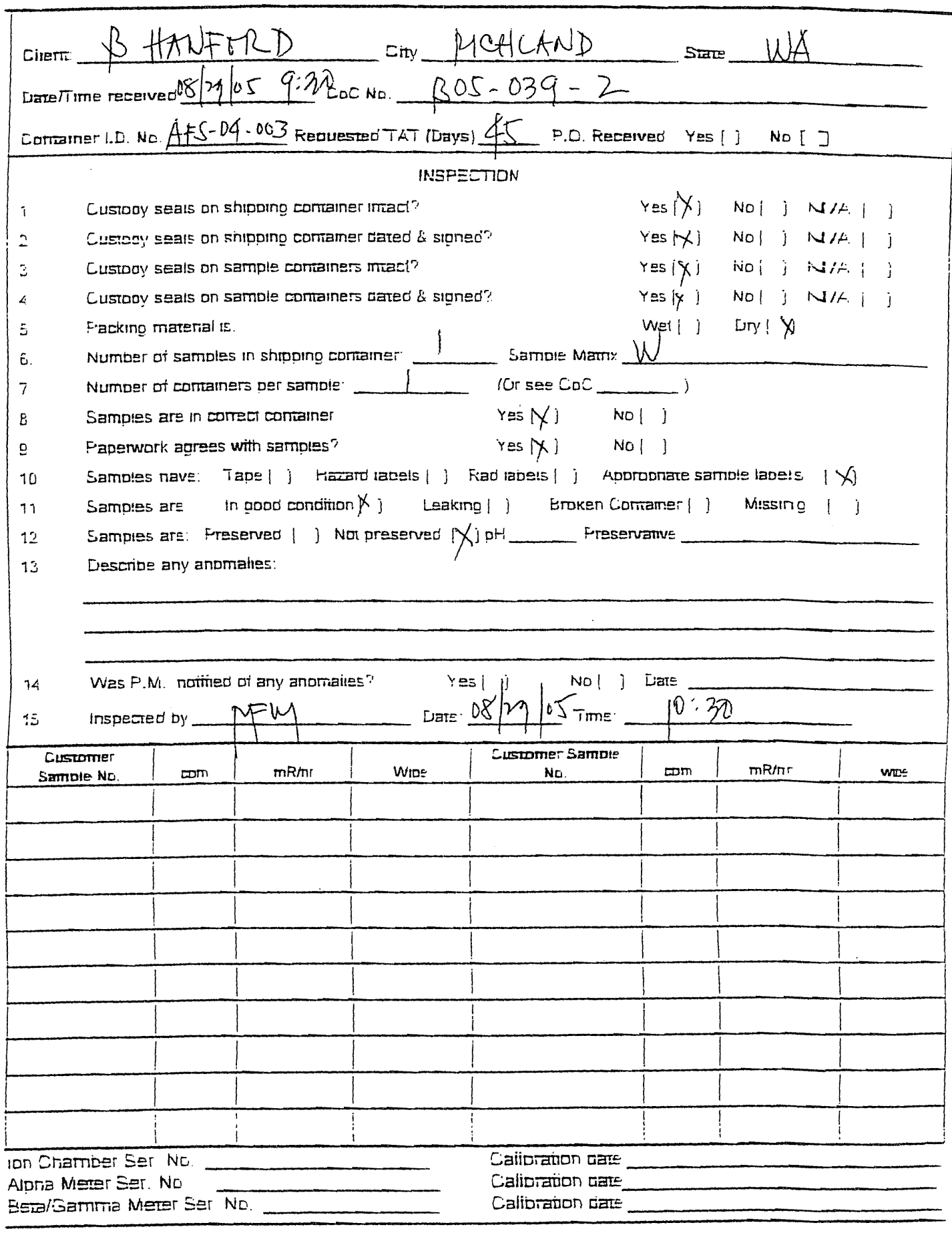

Form SCP-DI: DT-ZS- $-K$

"pver $\$ 5$ yes:s of quaity nuclear services" 
October 7, 2005

Ms. Joan Kessner

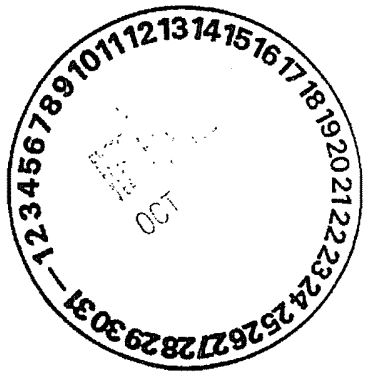

Bechtel Hanford Inc.

3190 George Washington Way

MSIN H9-02

Richland, WA 99352

Reference: P.O. \#630

Eberline Services R5-08-192-7298, SDG H3340

Dear Ms. Kessner:

Enclosed is a data report for four water samples designated under SAF No. B05-039 received at Eberline Services on August 25,2005. The samples were analyzed according to the accompanying chain-of-custody documents.

Please call if you have any questions conceming this report.

Sincerely,

Mismar

Melissa C. Mannion

Senior Program Manager

MCM/njv

Enclosure: Data Package 


\section{GENERAL}

Bechtel Hanford Inc. (BHI) Sample Delivery Group H3340 was composed of four water samples designated under SAF No. B05-039 with a Project Designation of: ERDF Lysimeter Sampling.

The samples were received as stated on the Chain-of-Custody documents. Any discrepancies are noted on the Eberline Services Sample Receipt Checklist. The results were transmitted to BHI via e-mail on September 29, 2005.

\subsection{ANALYSIS NOTES}

\subsection{Gross Alpha and Gross Beta Analyses}

No problems were encountered during the course of the analyses.

\subsection{Technetium-99 Analyses}

No problems were encountered during the course of the analyses.

\section{Case Narrative Certification Statement}

"I certify that this data package is in compliance with the SOW, both technically and for completeness, for other than the conditions detailed above. Release of the data obtained in this hard copy data package has been authorized by the Laboratory Manager or a designee, as verified by the following signature."

Mes Mazz

Melissa C. Mannion

Senior Program Manager

$\frac{10 / 7 / 5}{\text { Date }}$


WCH-42

Rev. 1

E B E R L I N E S E R V I C E S / R I C H M O N D SAMPLE DELIVERY GROUP H3340

SDG 7298

Contact Melissa C. Mannion
Client Hanford

Contract No. 630

Case no SDG H3340

S U M M R Y D A T A S E C T I O N

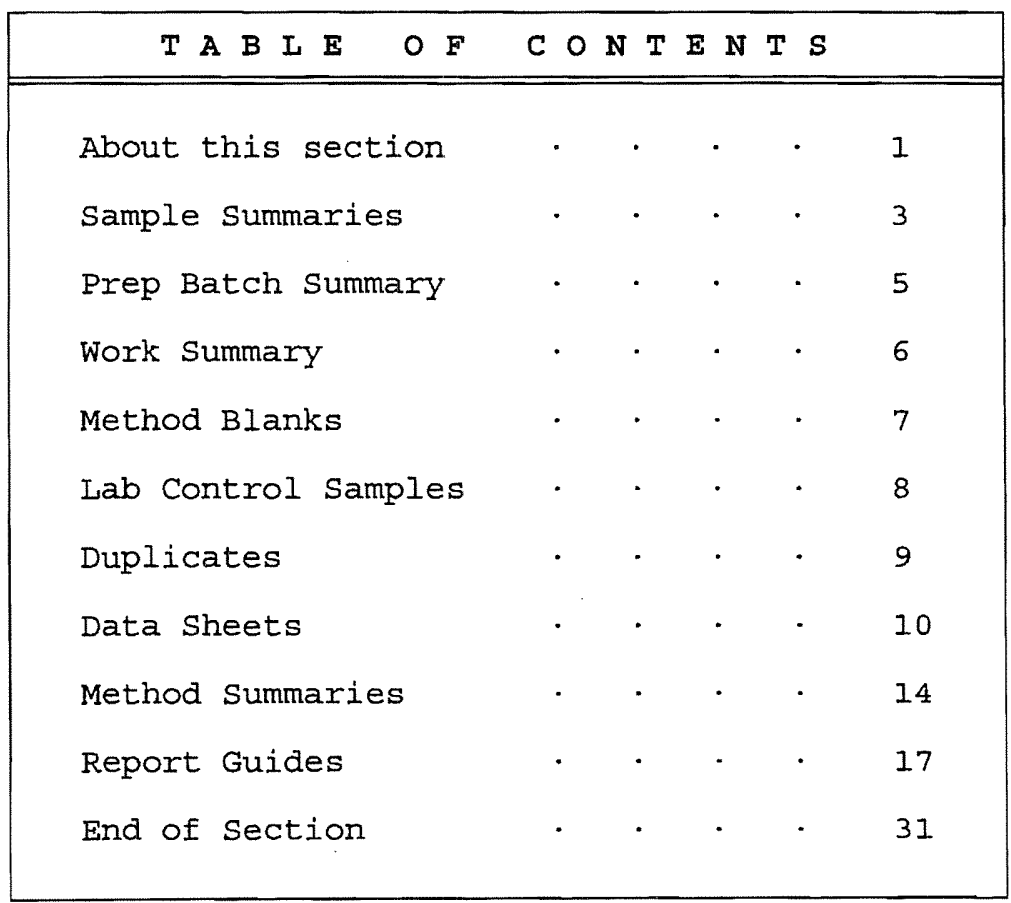

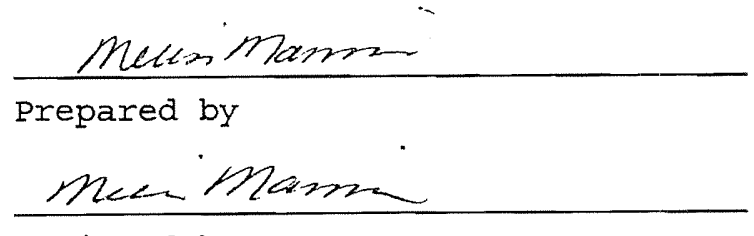

Reviewed by
Lab id EBRLNE Protocol Hanford Version Ver 1.0 Form DVD-TOC

Version 3.06 Report date $09 / 29 / 05$ 
WCH-42

Rev. 1

E B ERIINES ERVICES/RICHMOND SAMPLE DELIVERY GROUP H3340

SDG 7298

Contact Melissa C. Mannion

R E POR T G DIDE

Client Hanford

Contract No. 630

Case no SDG H3340

ABOUT THE DATA SUMMARY SECTION

The Data Summary Section of a Data Package has all data, in several useful orders, necessary for first level, routine review of the data package for a Sample Delivery Group (SDG). This section follows the Data Package Narrative, which has an overview of the data package and a discussion of special problems. It is followed by the Raw Data section, which has full details.

The Data Summary Section has several groups of reports:

SAMPLE SUMMARIES

The Sample and QC Summary Reports show all samples, including QC samples, reported in one SDG. These reports cross-reference client and lab sample identifiers.

PREPARATION BATCH SUMMARY

The Preparation Batch Summary Report shows all preparation batches (lab groupings reflecting how work was organized) relevant to the reported SDG with information necessary to check the completeness and consistency of the SDG.

WORK SUMMARY

The Work Summary Report shows all samples and work done on them relevant to the reported SDG.

METHOD BLANKS

The Method Blank Reports, one for each Method Blank relevant to the

SDG, show all results and primary supporting information for the blanks.

ILAB CONTROL SAMPLES

The Lab Control Sample Reports, one for each Lab Control Sample relevant to the SDG, show all results, recoveries and primary supporting information for these QC samples.

REPORT GUIDES

Page 1

SUMMARY DATA SECTION

Page 1

Lab id EBRLNE

Protocol hanford

Version Ver 1.0

Form DVD-RG

Version 3.06

Report date 09/29/05 
WCH-42

Rev. 1

E B ERIINE SERVICES/RICH MON D SAMPLE DELIVERY GROUP H3340

SDG 7298 Contact Melissa C. Mannion

GUIDE, cont.

Client Hanford

Contract No. 630 Case no SDG H3340

\section{ABOUT THE DATA SUMMAR SECTION}

\section{DUPLICATES}

The Duplicate Reports, one for each Duplicate and Original sample pair relevant to the SDG, show all results, differences and primary supporting information for these $Q C$ samples.

MATRIX SPIKES

The Matrix Spike Reports, one for each Spiked and original sample pair relevant to the SDG, show all results, recoveries and primary supporting information for these QC samples.

DATA SHEETS

The Data Sheet Reports, one for each client sample in the SDG, show all results and primary supporting information for these samples.

METHOD SUMMARIES

The Method Summary Reports, one for each test used in the SDG, show all results, $Q C$ and method performance data for one analyte on one or two pages. (A test is a short code for the method used to do certain work to the client's specification.

REPORT GUIDES

The Report Guides, one for each of the above groups of reports, have documentation on how to read the associated reports.

REPORT GUIDES

Page 2

SUMMARY DATA SECTION

Page 2
Lab id EBRLNE

Protocol Hanford

Version ver 1.0

Form DVD-RG

Version 3.06

Report date $\underline{09 / 29 / 05}$ 
WCH-42

Rev. 1

EBERLINE SERVICES/RICHMOND

SAMPLE DELIVERY GROUP H3340

SDG 7298 Contact Meligsa C. Mannion

IAB SAMPLE SUMMARY

Client Hanford

Contract №. 630

Case no SDG H3340

\begin{tabular}{|c|c|c|c|c|c|c|c|}
\hline $\begin{array}{l}\text { LAB } \\
\text { SAMPLE ID }\end{array}$ & CLIENT SAMPLE ID & LOCATION & MATRIX & LEVEL & SAF NO & $\begin{array}{l}\text { CHAIN OF } \\
\text { COSTODY }\end{array}$ & COLLECTED \\
\hline R508192-01 & J03 348 & ERDF Cells $5 \& 6$ & WATER & & B05-039 & B05-039-1 & $08 / 24 / 05 \quad 08: 30$ \\
\hline R508192-02 & $503 \times 49$ & ERDF Cells $5 \& 6$ & WATER & & B05-039 & B05-039-1 & $08 / 24 / 05 \quad 08: 40$ \\
\hline R508192-03 & $\mathrm{J} 03 \times 50$ & ERDF Celis $5 \& 6$ & WATER & & B05-039 & B05-039-1 & $08 / 24 / 05 \quad 10: 45$ \\
\hline R508192-04 & J03X51 & ERDF Cells $5 \& 6$ & WATER & & B05-039 & B05-039-1 & $08 / 24 / 05 \quad 10: 55$ \\
\hline R508192-05 & Lab Control Sample & & WATER & & B05-039 & & \\
\hline R508192-06 & Method Blank & & WATER & & B05-039 & & \\
\hline R508192-07 & Duplicate (R508192-01) & ERDF Celis $5 \& 6$ & WATER & & B05-039 & & $08 / 24 / 05 \quad 08: 30$ \\
\hline
\end{tabular}

LAB SUMAARY

Page 1

SUMEARY DATA SECTION

Page 3
Inab id EBRLNE

Protocol Hanford

version ver 1.0

Form DVD-LS

Version 3.06

Report date $09 / 29 / 05$ 
WCH-42

Rev. 1

\section{EBERLINE SERVICES/RICHMOND}

\begin{aligned} & SDG $\frac{7298}{\text { Contact }}$ Melissa C. Mannion \\ & \hline\end{aligned}

SAMPLE DELIVERY GROUP H3340

\section{QC SUMMARY}

\begin{tabular}{l} 
Client Yanford \\
Contract No. 630 \\
Case no SDG H3340 \\
\hline
\end{tabular}

\begin{tabular}{|c|c|c|c|c|c|c|c|c|c|c|}
\hline QC ВATCH & $\begin{array}{l}\text { CHATN OF } \\
\text { CUSTODY }\end{array}$ & CLIENT SAMPLE ID & MATRIX & SOLIDS & $\begin{array}{l}\text { SAMPLE } \\
\text { AMOUNT }\end{array}$ & $\begin{array}{l}\text { BASIS } \\
\text { AMOUNT }\end{array}$ & $\begin{array}{l}\text { DAYS S } \\
\text { RECEIVED }\end{array}$ & $\begin{array}{l}\text { SINCE } \\
\text { colite }\end{array}$ & $\begin{array}{c}\text { LAB } \\
\text { SAMPLE ID }\end{array}$ & $\begin{array}{l}\text { DEPARTMENT } \\
\text { SAMPLE ID }\end{array}$ \\
\hline \multirow[t]{7}{*}{7298} & B05 -039-1 & $\mathrm{J} 03 \times 48$ & WATER & & $2.0 \mathrm{~L}$ & & $08 / 25 / 05$ & 1 & R508192-01 & $7298-001$ \\
\hline & & J03 $\times 49$ & WATER & & $1.1 \mathrm{~L}$ & & $08 / 25 / 05$ & 1 & R508192-02 & $7298-002$ \\
\hline & & J03X50 & WATBR & & $2.0 \mathrm{~L}$ & & $08 / 25 / 05$ & 1. & R508192-03 & $7298-003$ \\
\hline & & J03X51 & WATER & & $1.3 \mathrm{~L}$ & & $08 / 25 / 05$ & 1 & R508192-04 & $7298-004$ \\
\hline & & Method Blank & WATER & & & & & & R508192-06 & $7298-006$ \\
\hline & & Lab Control Sample & WATER & & & & & & R508192-05 & $7298-005$ \\
\hline & & Duplicate (R508192-01) & WATER & & $2.0 \mathrm{~L}$ & & $08 / 25 / 05$ & 1 & R508192-07 & $7298-007$ \\
\hline
\end{tabular}

OC SOMMARY

page 1

SUMMARY DATA SECTION

Page 4
Lab id EBRLNE

Protocol hanford

version ver 1.0

Form DVD-OS

version 3.06

Report date $09 / 29 / 05$ 
WCH-42

Rev. 1

EBERLINE SERVICES/RICHMOND

SAMPLE DELIVERY GRODP H3340

SDG 7298

Contact Melissa C. Mannion

PREP BATCH SUMMARY

Client Hanford

Contract №. 630

Case no SDG H3340

\begin{tabular}{|c|c|c|c|c|c|c|c|c|c|c|c|}
\hline \multirow[b]{2}{*}{ TEST } & \multirow[b]{2}{*}{ MATRIX } & \multirow[b]{2}{*}{ METHOD } & \multirow{2}{*}{$\begin{array}{l}\text { PREPARATION } \\
\text { BATCH }\end{array}$} & ERROR & \multicolumn{2}{|r|}{ 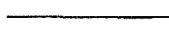 } & \multicolumn{2}{|c|}{ PLANCHETS } & \multicolumn{2}{|r|}{+} & \multirow{2}{*}{$\begin{array}{l}\text { QUALI- } \\
\text { FIERS }\end{array}$} \\
\hline & & & & $2 \sigma \&$ & CLIENT & MORE & $R E$ & BLANK & ICS & DUP/ORIG MS/ORIG & \\
\hline Beta & Counting & & & & & & & & & & \\
\hline$T C$ & WATER & Technetium 99 in water & $7136-098$ & 10.0 & 4 & & & 1 & 1 & $1 / 1$ & \\
\hline Gas $p$ & Proportion & I Counting & & & & & & & & & \\
\hline $93 \mathrm{~A}$ & WATER & Gross Alpha in water & $7136-098$ & 20.0 & 4 & & & 1 & 1 & $1 / 1$ & \\
\hline $93 B$ & HATER & Gross Beta in water & $7136-098$ & 15.0 & 4 & & & 1 & 1 & $1 / 1$ & \\
\hline
\end{tabular}

Duplicates and Matrix Spikes are those with original (Client) sample in this Sample Delivery Group.

Blank and LCS planchets are those in the same preparation batch as some client, Duplicate or Spike sample.

PREP BATCH SUMARY

Page 1

STMMARY DATA SECTION

page 5
Lab id EBRLNE

Protocol Hanford

version Vex 1.0

Form DVD-PBS

version 3.06

Report date $09 / 29 / 05$ 
WCH-42

Rev. 1

EBERIINE SERVICES/RICHMOND

SAMPLE DELIVERY GROUP H3340

IAB WORK SUMMARY
Client Hanford Contract №. 630 Case no SDG $\mathrm{H} 3340$

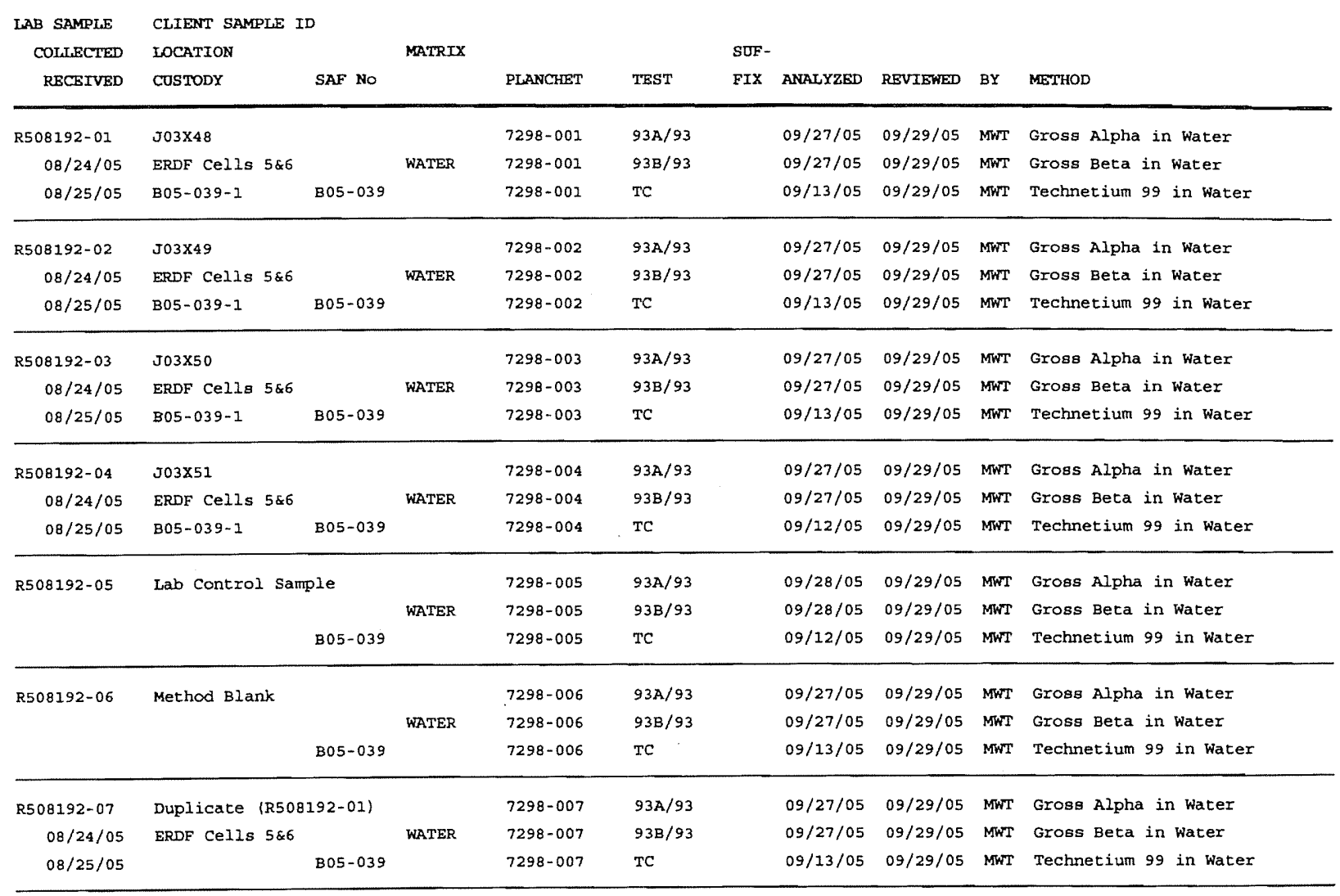

\begin{tabular}{|c|c|c|c|c|c|c|c|c|c|c|c|c|}
\hline TEST & SAF NO & COUNTS & OF & $\begin{array}{l}\text { TESTS } \\
\text { RBFERENCE }\end{array}$ & $\mathbf{B Y}$ & $\underset{\text { CLIENT }}{\operatorname{SAMPIE}} \mathbf{T}$ & $\begin{array}{c}\text { CYPE } \\
\text { MORE }\end{array}$ & RE & BLANK & LCS & DUP SPIKE & TOTAL \\
\hline $93 \mathrm{~A} / 93$ & B05-039 & Gross Alpha in water & & 900.0 ALLPHAE & 3ETA_GPC & 4 & & & 1 & 1 & 1 & 7 \\
\hline $93 \mathrm{~B} / 93$ & B05-039 & Gross Beta in water & & 900.0_ALPHAI & BETA_GPC & 4 & & & 1 & 1 & 1 & 7 \\
\hline $\mathrm{TC}$ & B05-039 & Technetium 99 in water & & TC99_TR_SEP. & $\mathrm{L}_{S \mathrm{SC}}$ & 4 & & & 2 & 1 & 1 & 7 \\
\hline TOTALS & & & & & & 12 & & & 3 & 3 & 3 & 21 \\
\hline
\end{tabular}

\section{WORR SOMAARY}

Page 1

SUMMARY DATA SECTION

Page 6
Lab id EBRLNE

Protocol Hanford

Version yer 1.0

Form DVD-LWS

Version 3.06

Report date $09 / 29 / 05$ 
$\mathrm{WCH}-42$

Rev. 1

E B ERIINESERVICES/R I CHMOND SAMPLE DELIVERY GROUP H3340

$7298-006$

M E THOD B L A N K

Method Blank

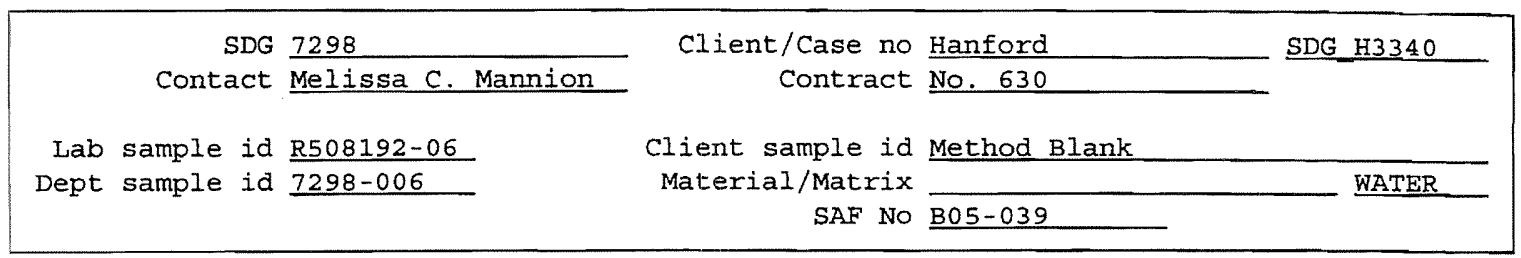

\begin{tabular}{|c|c|c|c|c|c|c|c|}
\hline ANAIYTE & CAS NO & $\begin{array}{r}\text { RESULT } \\
\mathrm{pCi} / \mathrm{L}\end{array}$ & $\begin{array}{l}2 \sigma \text { ERR } \\
(\text { COUNT) }\end{array}$ & $\begin{array}{c}\mathrm{MDA} \\
\mathrm{pCi} / \mathrm{L}\end{array}$ & $\begin{array}{c}\mathrm{RDL} \\
\mathrm{pCi} / \mathrm{I}\end{array}$ & $\begin{array}{l}\text { QUALI- } \\
\text { FIERS }\end{array}$ & TEST \\
\hline Gross Alpha & $12587-46-1$ & 0.502 & 0.80 & 1.4 & 3.0 & $\mathrm{U}$ & $93 \mathrm{~A}$ \\
\hline Gross Beta & $12587-47-2$ & 0.045 & 1.1 & 1.9 & 4.0 & $\mathrm{U}$ & $93 \mathrm{~B}$ \\
\hline Technetium 99 & $14133-76-7$ & 0.090 & 1.6 & 5.5 & 15 & $\mathrm{U}$ & $\mathrm{TC}$ \\
\hline
\end{tabular}

ERDF Lysmeter Sampling

QC-BLANK 54234

METHOD BLANKS

Page 1

SUMMARY DATA SECTION

Page 7
Lab id EBRLNE

Protocol Hanford

Version Ver 1.0 Form DVD-DS

Version 3.06

Report date $\underline{09 / 29 / 05}$ 
WCH-42

Rev. 1

EBERIINE SERVICES/RICHMOND

SAMPLE DELTVERY GROUP H3340

7298-005

IAB CONTROI SAMPLE

Lab Control Sample

\begin{tabular}{|c|c|c|}
\hline SDG $\underline{7298}$ & Client/Case no Hanford & SDG H3340 \\
\hline Contact Melissa C. Mannion & Contract No. 630 & \\
\hline Lab sample id R508192-05 & Client sample id Lab Control Sample & \\
\hline Dept sample id 7298-005 & Material/Matrix & - WATER \\
\hline & SAF No B05-039 & - \\
\hline
\end{tabular}

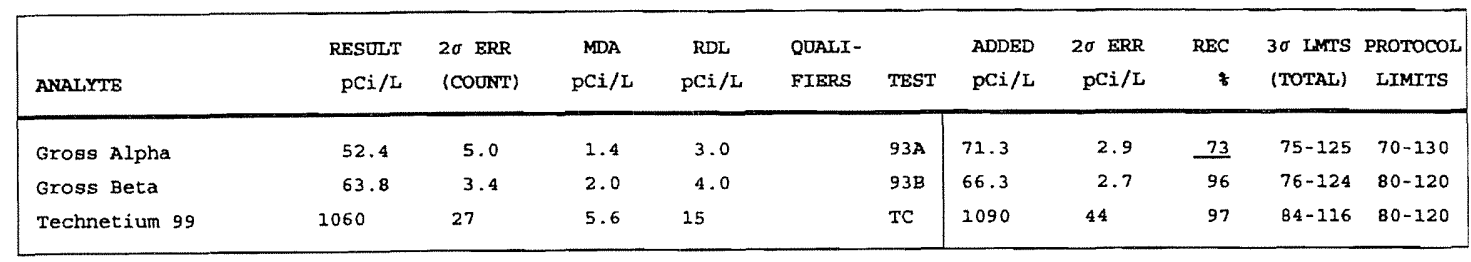

ERDF Lysmeter Sampling

QC-LCS 54233

LAB CONTROL SAMPLES

$$
\text { page } 1
$$

SURMARY DATA SECTION

page 8
Lab id EBRINE

Protocol Hanford vexsion Ver 1.0

Form DVD-LCS

version 3.05

Report date 09/29/05 
WCH-42

Rev. 1

\section{EBERLINE SERVICES/RICHMOND}

SAMPLE DBLTVERY GROUP H3340

7298-007

DUPLICATE

J0 $3 \times 48$

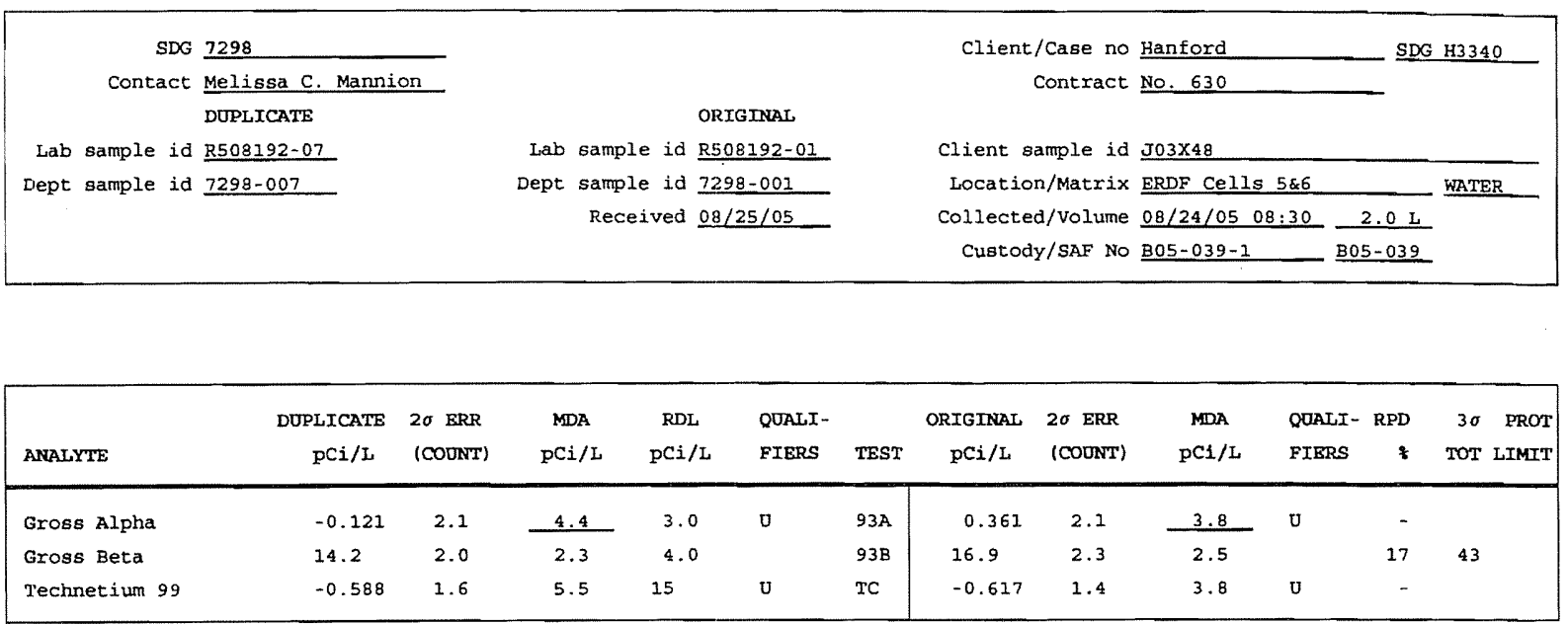

FRDF Lysmeter Sampling

QC-DOP\#1 54235

DUPLICATES

Page 1

SUMMARY DATA SECTION

page 9
Lab id EBRLNE

Protocol Hanford

version ver 1.0

Form DVD-DUP

version 3.06

Report date $09 / 29 / 05$ 
WCH-42

Rev. 1

E B.ERIINE SERVICES/RICHMOND SAMPLE DELIVERY GROUP H3340

$7298-001$

DA TA S H E T

J03X48

Client/Case no Hanford

Contract No. 630
SDG H 3340

Contact Melissa C. Mannion

Lab sample id R508192-01

Dept sample id 7298-001

Received $\underline{08 / 25 / 05}$
Client sample id J03X48

Location/Matrix ERDF Cells $5 \& 6$

Collected/Volume 08/24/05 08:30 Custody/SAF No B05-039-1
WATER

B05-039

\begin{tabular}{|c|c|c|c|c|c|c|c|}
\hline ANALYTE & CAS NO & $\begin{array}{r}\text { RESULT } \\
\mathrm{pCi} / \mathrm{L}\end{array}$ & $\begin{array}{l}2 \sigma \quad \text { ERR } \\
\text { (COUNT) }\end{array}$ & $\begin{array}{c}\mathrm{MDA} \\
\mathrm{pCi} / \mathrm{L}\end{array}$ & $\begin{array}{c}\mathrm{RDL} \\
\mathrm{pCi} / \mathrm{L}\end{array}$ & $\begin{array}{l}\text { QUALI- } \\
\text { FIERS }\end{array}$ & TEST \\
\hline Gross Alpha & $12587-46-1$ & 0.361 & 2.1 & 3.8 & 3.0 & $\mathrm{U}$ & $93 \mathrm{~A}$ \\
\hline Gross Beta & $12587-47-2$ & 16.9 & 2.3 & 2.5 & 4.0 & & $93 \mathrm{~B}$ \\
\hline Technetium 99 & $14133-76-7$ & -0.617 & 1.4 & 3.8 & 15 & U & $T C$ \\
\hline
\end{tabular}

ERDF Lysmeter Sampling

DATA SHEETS

Page 1

SUMMARY DATA SECTION

Page 10
Lab id EBRINE

Protocol Hanford

Version Ver 1.0

Form DVD-DS

Version 3.06

Report date 09/29/05 
WCH-42

Rev. 1

E B ERIINE SERVICES/RICHMOND SAMPLE DELIVERY GROUP H3340

7298-002

D A T A S H E E T

J03 449

Client/Case no Hanford SDG $H 3340$

SDG 7298

Contact Melissa C. Mannion

Lab sample id R508192-02

Dept sample id 7298-002

Received $08 / 25 / 05$
Contract No. 630

Client sample id J03X49

Location/Matrix ERDF Cells $5 \& 6$

Collected/Volume 08/24/05 08:40

Custody/SAF No B05-039-1

TII

\begin{tabular}{|c|c|c|c|c|c|c|c|}
\hline ANALYTE & CAS NO & $\begin{array}{r}\text { RESULT } \\
\mathrm{PCi} / \mathrm{L}\end{array}$ & $\begin{array}{l}2 \sigma \text { ERR } \\
(C O O N T)\end{array}$ & $\begin{array}{c}\mathrm{MDA} \\
\mathrm{PCi} / \mathrm{L}\end{array}$ & $\begin{array}{c}\mathrm{RDL} \\
\mathrm{pCi} / \mathrm{L}\end{array}$ & $\begin{array}{l}\text { QUALI- } \\
\text { FIERS }\end{array}$ & TEST \\
\hline Gross Alpha & $12587-46-1$ & -0.908 & 1.5 & 3.5 & 3.0 & $\mathrm{U}$ & $93 \mathrm{~A}$ \\
\hline Gross Beta & $12587-47-2$ & 16.1 & 2.4 & 2.7 & 4.0 & & $93 \mathrm{~B}$ \\
\hline Technetium 99 & $14133-76-7$ & -3.33 & 2.1 & 6.5 & 15 & $U$ & TC \\
\hline
\end{tabular}

ERDF Lysmeter Sampling

DATA SHEETS

Page 2

SUMMARY DATA SECTION

Page 11
Lab id EBRINE

Protocol Hanford

Version Ver 1.0

Form DVD-DS

Version 3.06

Report date $\underline{09 / 29 / 05}$ 
WCH-42

Rev. 1

E B E R I N E SERVICES/RICH MOND SAMPLE DELIVERY GROUP H3340

$7298-003$

DATA $S$ HE T

J0 $3 \times 50$

Client/Case no Hanford

SDG H3340

Contact Melissa C. Mannion

Contract No. 630

Client sample id $\mathrm{J} 03 \times 50$

Location/Matrix ERDF Cells 5\&6

Collected/Volume $08 / 24 / 05 \quad 10: 45-2.0 \mathrm{~L}$

Custody/SAF No B05-039-1 B05-039

Lab sample id $\mathrm{R} 508192-03$

Dept sample id 7298-003

Received $08 / 25 / 05$

WATER

\begin{tabular}{|lccccccc|}
\hline ANALYTE & CAS NO & $\begin{array}{r}\text { RESULT } \\
\text { PCi } / L\end{array}$ & $\begin{array}{c}2 \sigma \text { ERR } \\
\text { (COUNT) }\end{array}$ & $\begin{array}{c}\text { MDA } \\
\text { PCi/L }\end{array}$ & $\begin{array}{c}\text { RDL } \\
\text { PCi/L }\end{array}$ & $\begin{array}{c}\text { QUALI- } \\
\text { FIERS }\end{array}$ & TEST \\
\hline Gross Alpha & $12587-46-1$ & 0.262 & 2.2 & $\frac{4.1}{3.0}$ & U & $93 A$ \\
Gross Beta & $12587-47-2$ & 15.4 & 2.4 & 2.8 & 4.0 & & $93 B$ \\
Technetium 99 & $14133-76-7$ & 0.230 & 1.6 & 3.8 & 15 & U & TC \\
\hline
\end{tabular}

ERDF Lysmeter Sampling

DATA SHEETS

Page 3

SUMMARY DATA SECTION

Page 12
Lab id EBRLNE

Protocol Hanford

Version Ver 1.0

Form DVD-DS

Version 3.06

Report date $09 / 29 / 05$ 
E B ERIINE SER VICES/RICHMOND SAMPLE DELIVERY GROUP H3340

DATA SHE T

J0 $3 \times 51$

Contact Melissa C. Mannion
SDG 7298
Client/Case no Hanford

Contract No. 630

Client sample id J03X5I

Location/Matrix ERDF Cells $5 \& 6$

Collected/Volume $08 / 24 / 05 \quad 10: 55$
SDG_H3340

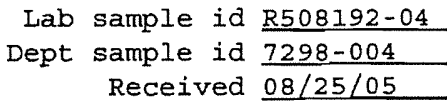

Lab sample id R508192-04

Dept sample id 7298-004 Received $\underline{08 / 25 / 05}$

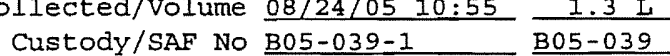

\begin{tabular}{|llcccccc|}
\hline ANALYTE & CAS NO & $\begin{array}{c}\text { RESULT } \\
\text { PCi/L }\end{array}$ & $\begin{array}{c}20 \text { ERR } \\
\text { (COUNT) }\end{array}$ & $\begin{array}{c}\text { MDA } \\
\text { pCi/L }\end{array}$ & $\begin{array}{c}\text { RDI } \\
\text { pCi/L }\end{array}$ & $\begin{array}{l}\text { QUALI- } \\
\text { FIERS }\end{array}$ & TEST \\
\hline Gross Alpha & $12587-46-1$ & -0.345 & 1.7 & 3.6 & 3.0 & U & $93 A$ \\
Gross Beta & $12587-47-2$ & 15.2 & 2.4 & 2.7 & 4.0 & & $93 B$ \\
Technetium 99 & $14133-76-7$ & -0.629 & 1.6 & 5.6 & 15 & U & TC \\
\hline
\end{tabular}

ERDF Lysmeter Sampling

DATA SHEETS

Page 4

SUMMARY DATA SECTION

Page 13
Lab id EBRLNE

Protocol Hanford

Version Ver 1.0

Form DVD-DS

Version 3.06

Report date $\underline{09 / 29 / 05}$ 
WCH-42

Rev. 1

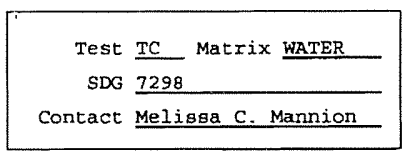

EBERLINE SERVICES/RICHMOND

SAMPLE DELIVERY GROUP H3340

\section{IAB METHOD SUMMARY \\ TECHNETIUM 99 IN WATER \\ BETA COUNTING}

Client Hanford

Contract №. 630

Contract SDG H3340

\section{RESUITS}

\section{LAB RAW SUF-}

SAMPLE TD TEST FIX PLAWCIET

Preparation batch 7136-098

R508192-01

R508192-02

R508192-03

R508192-04

R508192-05

R508192-06

R508192-07

$\begin{array}{llcc}7298-001 & J 03 \times 48 & U & \\ 7298-002 & 303 \times 49 & U & \\ 7298-003 & J 03 \times 50 & U & \\ 7298-004 & J 03 \times 51 & \text { U } & \\ 7298-005 & \text { LCS (QC ID=54233) } & \text { ok } & \\ 7298-006 & \text { BLK (QC ID } 54234) & U & \\ 7298-007 & \text { Duplicate (R508192-01) } & - & \text { U }\end{array}$

Nominal values and limits from method

RDLG $(p C i / L) \quad 15$

Technetium

CLIENT SAMPLE ID

99

ERDF Lymeter Sampling

\section{METHOD PERFORMANCE}

IANB RAW SUF-

SAMPLE ID TEST FIX CLIENT SAMPLE ID

MDA ALIQ PREP DILD- YIELD EFF COUNT FWHM DRIFT DAYS

ANAL-

$\mathrm{PCi} / \mathrm{L}$ L FAC TION \& $\quad$ min keV KeV HRLD PREPARED YZED DETECTOR

Preparation batch 7136-098 20 prep error $10.0 \&$ Reference Lab Notebook 7136 pg. 098

$\begin{array}{llllll}\text { R508192-01 J03X48 } & \text { J03 } & 3.8 & 0.100 & 93 & 100\end{array}$

$\begin{array}{llll}R 508192-02 & 503 \times 49 & 6.5 & 0.100\end{array}$

$\begin{array}{llll}R 508192-03 & J 03 \times 50 & 3.8 & 0.100\end{array}$

$\begin{array}{llll}R 508192-04 & J 03 \times 51 & 5.6 & 0.100\end{array}$

$\begin{array}{llll}\text { R508192-05 LCS }(Q C \text { ID } 54233) & 5.6 & 0.100\end{array}$

$\begin{array}{llll}\text { R508192-06 BLK } 1 Q C \text { ID } 54234) & 5.5 & 0.100\end{array}$

R508192-07 Duplicate $(R 508192-01) \quad 5.5 \quad 0.100$

(OC ID $=54235$ )

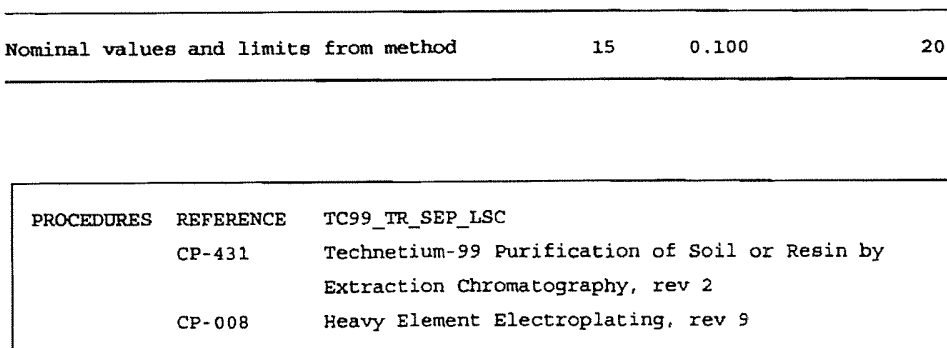

AVERAGES \pm 2 SD
FOR 7 SAMPLES $\quad$ YIELD $\frac{5.2}{87} \pm \frac{2.0}{24}$ YTELD. $87 \pm-24$
METHOD SUMMARIES

page I

SUMMARY DATA SECTION

Page 14
Lab id EBRLNE

Protocol Hanford

Version Ver 1.0

Form DVD-LMS

version 3.06

Report date $09 / 29 / 05$ 
WCH-42

Rev. 1

\section{EBERIINE SERVICES/RICHMOND}

SAMPLE DELIVERY GROUP H3340

SDG 2298

Contact Melissa C. Mannion

\section{IAB METHOD SUMMARY \\ GROSS ALPHA IN WATER}

GAS PROPORTIONAL COUNTING
Client Hanford

Contract No. 630

Contract SDG $\mathrm{H} 3340$

\section{RESUITS}

INB RAW SUF-

SAMPIE ID TEST FIX PLANCHET CLIENT SAMPLE ID

Preparation batch 7136-098

$\begin{array}{lllll}R 508192-01 & 93 & 7298-001 & 303 \times 48 & \mathrm{D}\end{array}$

$\begin{array}{lllll}R 508192-02 & 93 & 7298-002 & 303 \times 49 & 0\end{array}$

$\begin{array}{lllll}R 508192-03 & 93 & 7298-003 & \text { J03 } & \end{array} 50 \quad 0$

$\begin{array}{lllll}R 508192-04 & 93 & 7298-004 & 303 \times 51 & 0\end{array}$

R508192-05 $93 \quad 7298-005$ LCS (QC ID=54233) L LOW

R508192-07 $93 \quad 7298-007$ Duplicate (R508192-01) - U

Nominal values and limits from method RDLs (pCi/L) 3.0

ERDF Lysmeter Sampling

\section{METHOD PERFORMANCE}

LNB RAW SUF- MDA ALIQ PREP DILU- RESID EFF COUNT FWHM DRIFT DAYS

SAMPLE ID TEST FIX CLIENT SAMPLE ID pCi/L L FAC TION mg min keV KeV HELD PREPARED YZED DETECTOR

Preparation batch $7136-09820$ prep error $20.0 \div$ Reference Lab Notebook 7136 pg. 098

$\begin{array}{llllllllllll}R 508192-01 & 93 & J 03 \times 48 & 3.8 & 0.275 & 240 & 100 & 34 & 09 / 27 / 05 & 09 / 27 \quad \text { GRB-105 }\end{array}$

$\begin{array}{lllllllllll}R 508192-02 & 93 & J 03 \times 49 & 3.5 & 0.225 & 177 & 100 & 09 / 27 / 05 & 09 / 27 & \text { GRB-109 }\end{array}$

$\begin{array}{lllllllllllll}R 508192-03 & 93 & \text { J03X50 } & 4.1 & 0.260 & 230 & 100 & 09 / 27 / 05 & 09 / 27 & \text { GRB-110 }\end{array}$

$\begin{array}{lllllllllllll}R 508292-04 & 93 & J 03 \times 51 & 3.6 & 0.225 & 201 & 100 & 09 / 27 / 05 & 09 / 27 \quad \text { GRB-111 }\end{array}$

$\begin{array}{lllllllllllll}\text { R508192-05 } 93 & \text { LCS } & \text { (QC ID } 54233) & 1.4 & 0.300 & 59 & 100 & 09 / 27 / 05 & 09 / 28 & \text { GRB }-105\end{array}$

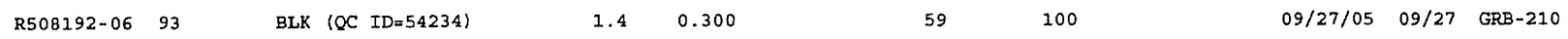

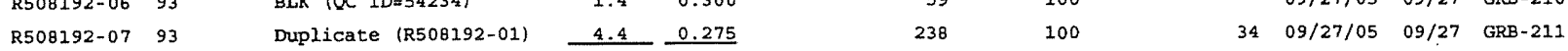

(OC ID 54235$)$

Nominal values and limits from method $\quad 3.0 \quad 0.300 \quad 5-250 \quad 100 \quad 180$

PROCEDURES REFERENCE 900.0_ALPHABETA_GPC

SPP-120 Gross Alpha and Gross Beta in watex, rev 0

AVERAGES $\pm 2 \mathrm{SD} \quad \mathrm{MDA} \quad 3.2 \pm \frac{2.5}{2}$

FOR 7 SAMPLES RESIDUE $172 \pm 161$

METHOD SUMARARIES

Page 2

SUMMARY DATA SECTION

Page 15

Lab id EBRLNE

Protocol hianford

Version ver 2.0

Form DVD-LMS

version 3.06

Report date $\underline{09 / 29 / 05}$ 
WCH-42

Rev. 1

EBERLINE SERVICES/RICHMOND

SAMPLE DET,IVERY GROUP H3340

\section{LAB METHOD SUMMARY \\ GROSS BETA IN WATER \\ GAS PROPORTIONAL COUNTINA}

Client Hanford

Contract No. 630

Contract SDG H3340

\section{RESULTS}

IANB RAW SUF-

SAMPLE ID TEST FIX PLANCHET CLIENT SAMPLE ID Groso Beta

\begin{tabular}{|c|c|c|c|c|c|}
\hline \multicolumn{5}{|c|}{ Preparation batch 7136-098 } & \\
\hline R508192 01 & 93 & $7298-001$ & J03X48 & 16.9 & \\
\hline R508192-02 & 93 & $7298-002$ & J03X49 & 16.1 & \\
\hline R508192-03 & 93 & $7298-003$ & J03X50 & 15.4 & \\
\hline R508192-04 & 93 & $7298-004$ & J03X51 & 15.2 & \\
\hline R508192-05 & 93 & $7298-005$ & LCS (QC ID $=54233)$ & ok & . \\
\hline R508192-06 & 93 & $7298-006$ & BLK (OC ID $=54234)$ & u & \\
\hline R508192-07 & 93 & $7298-007$ & Duplicate (R508192-01) & ok & \\
\hline
\end{tabular}

METHOD PERFORMANCE

\begin{tabular}{|c|c|c|c|c|c|c|c|c|c|c|c|c|c|c|c|}
\hline $\begin{array}{l}\text { IAB } \\
\text { SAMPLE ID }\end{array}$ & $\begin{array}{l}\text { RAW SUF- } \\
\text { TEST FIX }\end{array}$ & CLIEATT SAMPLE ID & $\begin{array}{c}\mathrm{MDA} \\
\mathrm{pCi} / \mathrm{L}\end{array}$ & $\begin{array}{l}\text { ALIQ } \\
x\end{array}$ & $\begin{array}{r}\text { PREP } \\
\text { FAC }\end{array}$ & $\begin{array}{l}\text { DILD- } \\
\text { TION }\end{array}$ & $\begin{array}{l}\text { RESID } \\
\text { mg }\end{array}$ & $\begin{array}{r}\mathrm{EFF} \\
\text { \& }\end{array}$ & $\begin{array}{r}\text { COUNT } \\
\min \end{array}$ & $\begin{array}{r}\text { FWHM } \\
\text { keV }\end{array}$ & $\begin{array}{l}\text { DRIFT } \\
\text { KeV }\end{array}$ & $\begin{array}{l}\text { DAYS } \\
\text { HELD }\end{array}$ & PREPARED & $\begin{array}{l}\text { ANAL- } \\
\text { YZED }\end{array}$ & DETECTOR \\
\hline Preparation & batch 7136 & $2 \sigma$ prep error & $15.0 * 1$ & Reference & Lab & Notebook & 7136 & pg. & 098 & & & & & & \\
\hline R508192-01 & 93 & J03 348 & 2.5 & 0.275 & & & 240 & & 100 & & & 34 & $09 / 27 / 05$ & $09 / 27$ & GRB -105 \\
\hline R508192-02 & 93 & J03X49 & 2.7 & 0.225 & & & 177 & & 100 & & & 34 & $09 / 27 / 05$ & $09 / 27$ & GRB-109 \\
\hline R508192-03 & 93 & J03 $\times 50$ & 2.8 & 0.260 & & & 230 & & 100 & & & 34 & $09 / 27 / 05$ & $09 / 27$ & $G R B-110$ \\
\hline R508192-04 & 93 & J03X51 & 2.7 & 0.225 & & & 201 & & 100 & & & 34 & $09 / 27 / 05$ & $09 / 27$ & GRB-1II \\
\hline R508192-05 & 93 & LCS (OC ID $=54233)$ & 2.0 & 0.300 & & & 59 & & 100 & & & & $09 / 27 / 05$ & $09 / 28$ & GRB-105 \\
\hline R508192-06 & 93 & BLK $\{Q C$ ID $=54234\}$ & 1.9 & 0.300 & & & 59 & & 100 & & & & $09 / 27 / 05$ & $09 / 27$ & GRB -210 \\
\hline R508192-07 & 93 & $\begin{array}{l}\text { Duplicate (R508192-01) } \\
\qquad(Q C I D=54235)\end{array}$ & 2.3 & 0.275 & & & 238 & & 100 & & & 34 & $09 / 27 / 05$ & $09 / 27$ & GRB-211 \\
\hline Nominal val & ues and $1 \mathrm{in}$ & mits from method & 4.0 & 0.300 & & & $5-250$ & & 100 & & & 180 & & & \\
\hline
\end{tabular}

PROCEDURES REFERENCE 900.0_ALPHABETA_GPC

SPP-120 Gross Alpha and Gross Beta in water, rev 0

AVERAGES \pm 2 SD
FOR 7 SAMPLES $\quad$ RESIDUE $\frac{2.4}{172} \pm \frac{0.72}{161}$

METHOD SUMMARIES

Page 3

SUMMARY DATA SECTION

$$
\text { Page } 16
$$

Lab id EBRLNE

Protocol Manford

Version Ver 1.0

Form DVD-IMS

version 3.06

Report date $09 / 29 / 05$ 
WCH-42

Rev. 1

E BERIINE SERVICES/RICHMOND

SDG 7298

Contact Melissa C. Mannion
SAMPLE DELIVERY GROUP H3340

RE PORT GUIDE
Client Hanford

Contract No. 630

Case no SDG H3340

SAMPIE S UMMARY

The Sample and QC Summary Reports show all samples, including QC samples, reported in one sample Delivery Group (SDG).

The Sample summary Report fully identifies client samples and gives the corresponding lab sample identification. The QC Summary Report shows at the sample level how the lab organized the samples into batches and generated $Q C$ samples. The Preparation Batch and Method Summary Reports show this at the analysis level.

The following notes apply to these reports:

* LAB SAMPLE ID is the lab's primary identification for a sample.

* department sample id is an alternate lab id, for example one assigned by a radiochemistry department in a lab.

* CLIENT SAMPLE ID is the client's primary identification for a sample. It includes any sample preparation done by the client that is necessary to identify the sample.

* QC BATCH is a lab assigned code that groups samples to be processed and QCed together. These samples should have similar matrices.

QC BATCH is not necessarily the same as SDG, which reflects samples received and réported together.

* All Lab Control Samples, Method Blanks, Duplicates and Matrix Spikes are shown that $Q C$ any of the samples. Due to possible reanalyses, not all results for all these $Q C$ samples may be relevant to the SDG. The Lab Control Sample, Method Blank, Duplicate, Matrix Spike and Method Summary Reports detail these relationships.

REPORT GOIDES

Page 1

SUMMARY DATA SECTION

Page 17
Lab id EBRLNE

Protocol Hanford

Version Ver 1.0

Form DVD-RG

Version 3.06

Report date $09 / 29 / 05$ 
WCH-42

Rev. 1

E B ERIINESERVICES/RICH MON D

SDG 7298

Contact Melissa C. Mannion
SAMPIE DELIVERY GROUP H3340

RE POR T G UIDE
Client Hanford

Contract No. 630

Case no SDG H3340

\section{PREPARATION BATCH S UMMARY}

The Preparation Batch Summary Report shows all preparation batches in one Sample Delivery Group (SDG) with information necessary to check the completeness and consistency of the SDG.

The following notes apply to this report:

* The preparation batches are shown in the same order as the Method summary Reports are printed.

* Only analyses of planchets relevant to the SDG are included.

* Each preparation batch should have at least one Method Blank and LCS in it to validate client sample results.

* The QUALIFIERS shown are all qualifiers other than U, J, B, I and $H$ that occur on any analysis in the preparation batch. The Method Summary Report has these qualifiers on a per sample basis.

These qualifiers should be reviewed as follows:

$X$ Some data has been manually entered or modified. Transcription errors are possible.

$P$ one or more results are 'preliminary'. The data is not ready for final reporting.

2 There were two or more results for one analyte on one planchet imported at one time. The results in DVD may not be the same as on the raw data sheets.

other lab defined qualifiers may occur. In general, these should be addressed in the SDG narrative.

REPORT GUIDES

Page 2

SUMMARY DATA SECTION

Page 18
Lab id EBRLNE

Protocol Hanford

Version Ver 1.0

Form DVD-RG

Version 3.06

Report date $09 / 29 / 05$ 
WCH-42

Rev. 1

E B E R I NE SERVICES/RICHMOND SAMPLE DELIVERY GROUP H3340

SDG 7298 Contact Melissa C. Mannion
REPOR T G OIDE
Client Hanford

Contract No. 630 Case no SDG H3340

WORK SUMMARY

The Work Summary Report shows all samples, including QC samples, and all relevant analyses in one Sample Delivery Group (SDG). This report is often useful as supporting documentation for an invoice.

The following notes apply to this report:

* TEST is a code for the method used to measure associated analytes. Results and related information for each analyte are on the Data Sheet Report. In special cases, a test code used in the summary data section is not the same as in associated raw data. In this case, both codes are shown on the work Summary.

* SUFFIX is the lab's code to distinguish multiple analyses (recounts, reworks, reanalyses) of a fraction of the sample. The suffix indicates which result is being reported. An empty suffix normally identifies the first attempt to analyze the sample.

* The IAB SAMPLE ID, TEST and SUFFIX uniquely identify all supporting data for a result. The Method Summary Report for each TEST has method performance data, such as yield, for each lab sample id and suffix and procedures used in the method.

* PLANCHET is an alternate lab identifier for work done for one test. It, combined with the TEST and SUFFIX, may be the best link to raw data.

* For QC samples, only analyses that directly QC some regular sample are shown. The Lab Control Sample, Method Blank, Duplicate, Matrix Spike and Method Summary Reports detail these relationships.

* The SAS (Special Analytical Services) Number is a client or lab assigned code that reflects special processing for samples, such as rapid turn around. Counts of tests done are lists by SAS number since it is likely to affect prices.

REPORT GUIDES

Page 3

SUMMARY DATA SECTION

Page 19
Lab id EBRLNE

Protocol Hanford

Version Ver 1.0

Form DVD-RG

version 3.06

Report date $09 / 29 / 05$ 
WCH-42

Rev. 1

E B ERIINE SERVICES/RICH MON D SAMPIE DELIVERY GROUP H3340

SDG 7298

Contact Melissa C. Mannion
REPORT GUIDE
Client Hanford

Contract No. 630

Case no SDG H3340

\section{A T A S H E E T}

The Data Sheet Report shows all results and primary supporting information for one client sample or Method Blank. This report corresponds to both the CLP Inorganics and Organics Data sheet.

The following notes apply to this report:

* TEST is a code for the method used to measure an analyte. If the TEST is empty, no data is available; the analyte was not analyzed for.

* The IAB SAMPLE ID and TEST uniquely identify work within the Summary Data section of a Data Package. The Work Summary and Method Summary Reports further identify raw data that underlies this work.

The Method Summary Report for each TEST has method performance data, such as yield, for each Lab Sample ID and a list of procedures used in the method.

* ERRORs can be labeled total or COUNT. TOTAL implies a preparation (non-counting method) error has been added, as square root of sum of squares, to the counting error denoted by COUNT. The preparation errors, which may vary by preparation batch, are shown on the Method Summary Report.

* A RESULT can be 'N.R.' (Not Reported). This means the lab did this work but chooses not to report it now, possibly because it was reported at another time.

* When reporting a Method Blank, a RESULT can be 'N.A.' (Not Applicable). This means there is no reported client sample work in the same preparation batch as the Blank's result. This is likely to occur when the Method Blank is associated with reanalyses of selected work for a few samples in the SDG.

The following qualifiers are defined by the DVD system:

$U$ The RESULT is less than the MDA (Minimum Detectable Activity).

REPORT GUIDES

Page 4

SUMMARY DATA SECTION

Page 20
Lab id EBRLNE

Protocol Hanford

Version Ver 1.0

Form DVD-RG

Version 3.06

Report date $09 / 29 / 05$ 
SDG 7298

Contact Melissa C. Mannion
SAMPLE DELIVRRY GROUP H3340

G UIDE, cont.
Client Hanford

Contract No. 630

Case no SDG_H3340

\section{DA TA S H E T T}

If the MDA is blank, the ERROR is used as the limit.

J The RESULT is less than the RDL (Required Detection Limit) and no $U$ qualifier is assigned.

B A Method Blank associated with this sample had a result without a U flag and, after correcting for possibly different aliquots, that result is greater than or equal to the MDA for this sample.

Normally, $B$ is not assigned if $U$ is. When method blank subtraction is shown on this report, B flags are assigned based on the unsubtracted values while U's are assigned based on the subtracted ones. Both flags can be assigned in this case.

For each sample result, all Method Blank results in the same preparation batch are compared. The Method Summary Report documents this and other $Q C$ relationships.

I Some Lab Control Sample that QC's this sample had a low recovery. The lab can disable assignment of this qualifier.

H Similar to ' $\mathrm{L}$ ' except the recovery was high.

P The RESULT is 'preliminary'.

$\mathrm{X}$ Some data necessary to compute the RESULT, ERROR or MDA was manually entered or modified.

2 There were two or more results available for this analyte. The reported result may not be the same as in the raw data.

Other qualifiers are lab defined. Definitions should be in the SDG narrative.

The following values are underlined to indicate possible problems:

* An MDA is underlined if it is bigger than its RDL.

REPORT GUIDES

Page 5

SUMMARY DATA SECTION

Page 21
Lab id EBRLNE

Protocol Hanford

Version Ver 1.0

Form DVD-RG

Version 3.06

Report date $09 / 29 / 05$ 
WCH-42

Rev. 1

E B ERIINE SERVICES/RICHMOND SAMPLE DELIVRRY GROUP H3340

SDG 7298 Contact Melissa C. Mannion

G UIDE, c O n t.

Client Hanford

Contract No. 630

Case no SDG H3340

\section{A T A S H E E T}

* An ERROR is underlined if the 1.645 sigma counting error is bigger than both the MDA and the RESULT, implying that the MDA may not be a good estimate of the 'real' minimum detectable activity.

* A negative RESULT is underlined if it is less than the negative of its 2 sigma counting ERROR.

* When reporting a Method Blank, a RESULT is underlined if greater than its MDA. If the MDA is blank, the 2 sigma counting error is used in the comparison.

REPORT GUIDES

Page 6

SUMMARY DATA SECTION

Page 22
Lab id EBRLNE

Protocol Hanford

Version Ver 1.0

Form DVD-RG

Version 3.06

Report date $09 / 29 / 05$ 
WCH-42

Rev. 1

E B ERIINE SERVICES/RICHMOND SAMPLE DELIVERY GROUP H3340

RE POR T G U I D E

Client Hanford

Contract No. 630

Case no SDG H3340

\section{A B CONTROI SAMPIE}

The Lab Control Sample Report shows all results, recoveries and primary supporting information for one Lab control Sample.

The following notes apply to this report:

* All fields in common with the Data Sheet Report have similar usage. Refer to its Report Guide for details.

* An amount ADDED is the lab's value for the actual amount spiked into this sample with its ERROR an estimate of the error of this amount.

An amount added is underlined if its ratio to the corresponding RDL is outside protocol specified limits.

* REC (Recovery) is RESULT divided by ADDED expressed as a percent.

* The first, computed limits for the recovery reflect:

1. The error of RESULT, including that introduced by rounding the result prior to printing.

If the limits are labeled (TOTAL), they include preparation error in the result. If labeled (COUNT), they do not.

2. The error of ADDED.

3. A lab specified, per analyte bias. The bias changes the center of the computed limits.

* The second limits are protocol defined upper and lower QC limits for the recovery.

* The recovery is underlined if it is outside either of these ranges.

REPORT GUIDES

Page 7

SUMMARY DATA SECTION

Page 23
Lab id EBRLNE

Protocol Hanford

Version Ver 1.0 Form DVD-RG

Version 3.06

Report date 09/29/05 
WCH-42

Rev. 1

E B ERIINESERVICES/RICHMOND

SDG 7298

Contact Melissa $C$. Mannion
SAMPLE DELIVERY GROUP H3340

R E P O R T G UI D E

Client Hanford

Contract No. 630

Case no SDG H3340

D O P I I A T E

The Duplicate Report shows all results, differences and primary

supporting information for one Duplicate and associated Original sample.

The following notes apply to this report:

* All fields in common with the Data Sheet Report have similar usage. This applies both to the Duplicate and Original sample data. Refer to the Data Sheet Report Guide for details.

If the Duplicate has data for a TEST and the lab did not do this test to the Original, the Original's RESULTs are underlined.

* The RPD (Relative Percent Difference) is the absolute value of the difference of the RESULTs divided by their average expressed as a percent.

If both RESUITs are less than their MDAs, no RPD is computed and a ' - ' is printed.

For an analyte, if the lab did work for both samples but has data for only one, the MDA from the sample with data is used as the other's result in the RPD.

* The first, computed limit is the sum, as square root of sum of squares, of the errors of the results divided by the average result as a percent, hence the relative error of the difference rather than the error of the relative difference. The errors include those introduced by rounding the RESULTs prior to printing.

If this limit is labeled TOT, it includes the preparation error in the RESULTs. If labeled CNT, it does not.

This value reported for this limit is at most 999.

* The second limit for the RPD is the larger of:

1. A fixed percentage specified in the protocol.

REPORT GUIDES

Page 8

SUMMARY DATA SECTION

Page 24
Lab id EBRLNE Protocol Hanford Version Ver 1.0 Form DVD-RG

Version 3.06 Report date $09 / 29 / 05$ 
WCH-42

Rev. 1

E B E R I N E SERVI C E S / R I C M N D SAMPLE DELIVERY GROUP H3340

SDG 7298 Contact Melissa C. Mannion
GUIDE, cont.
Client Hanford

Contract No. 630

Case no SDG H3340

D U P I I C A T E

2. A protocol factor (typically 2) times the average MDA as a percent of the average result. This limit applies when the results are close to the MDAs.

* The RPD is underlined if it is greater than either limit.

* If specified by the lab, the second limit column is replaced by the Difference Error Ratio (DER), which is the absolute value of the difference of the results divided by the quadratic sum of their one sigma errors, the same errors as used in the first limit.

Except for differences due to rounding, the DER is the same as the RPD divided by the first RPD limit with the limit scaled to 1 sigma.

* The DER is underlined if it is greater than the sigma factor, typically 2 or 3 , shown in the header for the first RPD limit.

REPORT GUIDES

Page 9

SUMMARY DATA SECTION

Page 25
Lab id EBRLNE Protocol Hanford Version Ver 1.0 Form DVD-RG

Version 3.06 Report date $09 / 29 / 05$ 
WCH-42

Rev. 1

EBERIINESERVICES/RICHMOND SAMPLE DELIVERY GROUP H3340

SDG 7298 Contact Melissa C. Mannion
REPORT GUIDE

Client Hanford

Contract No. 630

Case no SDG H3340

MATRIX SPIKE

The Matrix Spike Report shows all results, recoveries and primary supporting information for one Matrix Spike and associated original sample.

The following notes apply to this report:

* All fields in common with the Data Sheet Report have similar usage. This applies both to the spiked and original sample data. Refer to the Data sheet Report Guide for details.

If the Spike has data for a TEST and the lab did not do this test to the Original, the Original's RESULTs are underlined.

* An amount ADDED is the lab's value for the actual amount spiked into the Spike sample with its ERROR an estimate of the error of this amount.

An amount is underlined if its ratio to the corresponding RDL is outside protocol specified limits.

* REC (Recovery) is the Spike RESULT minus the Original RESULT divided by ADDED expressed as a percent.

* The first, computed limits for the recovery reflect:

1. The errors of the two RESULTs, including those introduced by rounding them prior to printing.

If the limits are labeled (TOTAL), they include preparation error in the result. If labeled (COUNT), they do not.

2. The error of ADDED.

3. A lab specified, per analyte bias. The bias changes the center of the computed limits.

* The second limits are protocol defined upper and lower QC limits

\section{REPORT GUIDES}

Page 10

SUMMARY DATA SECTION

Page 26
Lab id EBRTNE

Protocol Hanford

Version Ver 1.0

Form DVD-RG

version 3.06

Report date $\underline{09 / 29 / 05}$ 
WCH-42

Rev. 1

E B ERIINE SERVICES/RICHMOND SAMPLE DELIVERY GROUP H3340

SDG 7298 Contact Melissa C. Mannion
G U I D E.

cont.
Client Hanford Contract No. 630 Case no SDG H3340

\section{MATRIX SPIRE}

for the recovery.

These limits are left blank if the Original RESULT is more than a protocol defined factor (typically 4) times ADDED. This is a way of accounting for that when the spike is small compared to the amount in the original sample, the recovery is unreliable.

* The recovery is underlined (out of spec) if it is outside either of these ranges.

REPORT GUIDES

Page 11

SUMMARY DATA SBCTION

Page 27
Lab id EBRLNE

Protocol Hanford Version Ver 1.0 Form DVD-RG

Version 3.06 Report date $\underline{09 / 29 / 05}$ 
WCH-42

Rev. 1

E B ERIINE SERVICES/RICHMOND SAMPLE DELIVERY GROUP H3340

SDG 7298

Contact Melissa C. Mannion
REPORT G UI DE
Client Hanford

Contract No. 630

Case no SDG H3340

METHOD S UMMAR Y

The Method Summary Report has two tables. One shows up to five results measured using one method. The other has performance data for the method. There is one report for each TEST, as used on the Data sheet Report.

The following notes apply to this report:

* Each table is subdivided into sections, one for each preparation batch. A preparation batch is a group of aliquots prepared at roughly the same time in one work area of the lab using the same method.

There should be Lab Control Sample and Method Blank results in each preparation batch since this close correspondence makes the QC meaningful. Depending on lab policy, Duplicates need not occur in each batch since they $Q C$ sample dependencies such as matrix effects.

* The RAW TEST column shows the test code used in the raw data to identify a particular analysis if it is different than the test code in the header of the report. This occurs in special cases due to method specific details about how the lab labels work.

The Lab Sample or Planchet ID combined with the (Raw) Test Code and Suffix uniquely identify the raw data for each analysis.

* If a result is less than both its MDA and RDL, it is replaced by just ' $U$ ' on this report. If it is greater than or equal to the RDL but less than the MDA, the result is shown with a 'U' flag.

The $J$ and $X$ flags are as on the data sheet.

* Non-U results for Method Blanks are underlined to indicate possible contamination of other samples in the preparation batch. The Method Blank Report has supporting data.

* Lab Control Sample and Matrix Spike results are shown as: ok, No data, LOW or HIGH, with the last two underlined. 'No data'

REPORT GUIDES

Page 12

SUMMARY DATA SBCTION

Page 28
Lab id EBRLNE

Protocol Hanford

Version Ver 1.0

Form DVD-RG

Version 3.06 Report date $09 / 29 / 05$ 
WCH-42

Rev. 1

E B ERIINE SERVICES/RICHMOND SAMPLE DELIVERY GROUP H3340

SDG 7298

Contact Melissa C. Mannion
GIIDE, cont.

Client Hanford

Contract No. 630

Case no SDG H3340

\section{METHOD S U M A R Y}

means no amount ADDED was specified. 'LOW' and 'HIGH'

correspond to when the recovery is underlined on the Lab control Sample or Matrix Spike Report. See these reports for supporting data.

* Duplicate sample results are shown as: ok, No data, or ouT, with the last two underlined. 'No data' means there was no original sample data found for this duplicate. 'OUT' corresponds to when the RPD is underlined on the Duplicate Report. See this report for supporting data.

* If the MDA column is labeled 'MAX MDA', there was more than one result measured by the reported method and the MDA shown is the largest MDA. If not all these results have the same RDL, the MAX MDA reflects only those results with RDL equal to the smallest one.

MDAs are underlined if greater than the printed RDL.

* Aliquots are underlined if less than the nominal value specified for the method.

* Prepareation factors are underlined if greater than the nominal value specified for the method.

* Dilution factors are underlined if greater than the nominal value specified for the method.

* Residues are underlined if outside the range specified for the method. Residues are not printed if yields are.

* Yields, which may be gravimetric, radiometric or some type of recovery depending on the method, are underlined if outside the range specified for the method.

* Efficiencies are underlined if outside the range specified for the method. Efficiencies are detector and geometry dependent so this test is only approximate.

REPORT GUIDES

Page 13

SUMMARY DATA SECTION

Page 29
Lab id EBRLNE

Protocol Hanford

Version Ver 1.0

Form DVD-RG

Version 3.06

Report date $09 / 29 / 05$ 
WCH-42

Rev. 1

E B ERIINE SERVICES/RICH M N D SAMPLE DELIVERY GROUP H3340

SDG 7298

Contact Melissa C. Mannion
GIDE, cont.

Client Hanford

Contract No. 630

Case no SDG H3340

\section{METHOD S OMMARY}

* Count times are underlined if less than the nominal value specified for the method.

* Resolutions (as FWHM; Full Width at Half Max) are underlined if greater than the method specified limit.

* Tracer drifts are underlined if their absolute values are greater than the method specified limit. Tracer drifts are not printed if percent moistures are.

* Days Held are underlined if greater than the holding time specified in the protocol.

* Analysis dates are underlined if before their planchet's preparation date or, if a limit is specified, too far after it.

For some methods, ratios as percentages and error estimates for them are computed for pairs of results. A ratio column header like $11 \div 3$ ' means the ratio of the first result column and the third result column.

Ratios are not computed for Lab Control Sample, Method Blank or Matrix Spike results since their matrices are not necessarily similar to client samples'.

The error estimate for a ratio of results from one planchet reflects only counting errors since other errors should be correlated. For a ratio involving different planchets, if QC limits are computed based on total errors, the error for the ratio allows for the preparation errors for the planchets.

The ratio is underlined (out of spec) if the absolute value of its difference from the nominal value is greater than its error estimate. If no nominal value is specified, this test is not done.

For Gross Alpha or Gross Beta results, there may be a column showing the sum of other Alpha or Beta emitters. This sum includes all relevant

REPORT GUIDES

Page 14

SUMMARY DATA SECTION

Page 30
Lab id EBRINE

Protocol Hanford

Version Ver 1.0

Form DVD-RG

Version 3.06

Report date $09 / 29 / 05$ 
WCH-42

Rev. 1

E B ERIINESERVICES/RICH MOND SAMPLE DELIVERY GROUP H3340

SDG 7298 Contact Melissa C. Mannion

\section{G UIDE, cont.}

Client Hanford

Contract No. 630

Case no SDG H3340

\section{METHOD S UMM R Y}

results in the DVD database, whether reported or not. Results in the sum are weighted by a particles/decay value specified by the lab for each relevant analyte. Results less than their MDA are not included. No sums are computed for Lab Control, Method Blank or Matrix Spike samples since their various planchets may not be physically related.

If a ratio of total isotopic to Gross Alpha or Beta is shown, the error for the ratio reflects both the error in the Gross result and the sum, as square root of sum of squares, of the errors in the isotopic results.

For total elemental uranium or thorium results, there may be a column showing the total weight computed from associated isotopic results. Ignoring results less than their MDAs, this is a weighted sum of the isotopic results. The weights depend on the molecular weight and half-life of each isotope so as to convert activities (decays) to weight (atoms).

If a ratio of total computed to measured elemental uranium or thorium is shown, the error for the ratio reflects the errors in all the measurements.

REPORT GUIDES

Page 15

SUMMARY DATA SECTION

Page 31
Lab id EBRINE

Protocol Hanford

Version Ver 1.0

Form DVD-RG

Version 3.06 Report date $09 / 29 / 05$ 


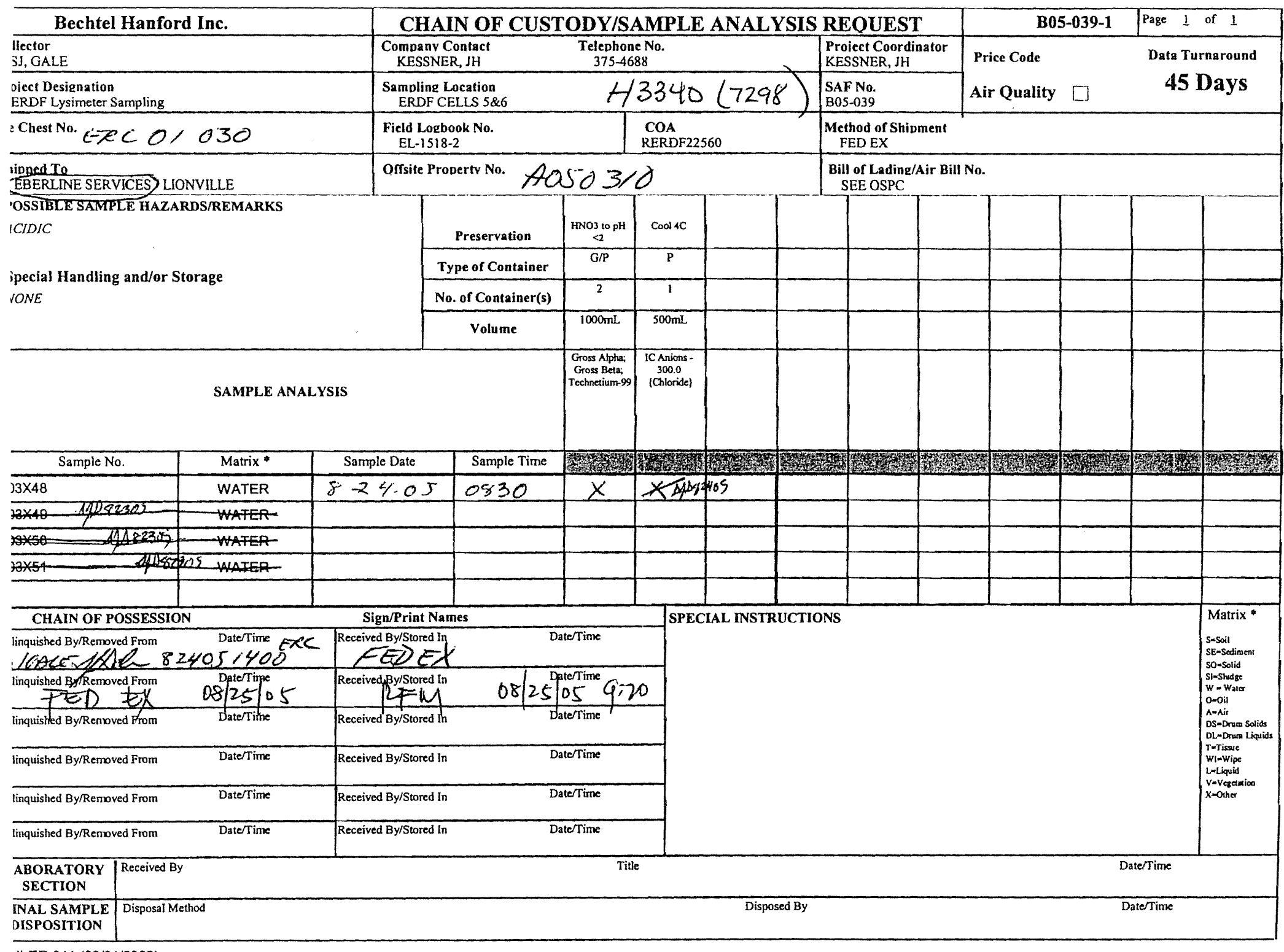




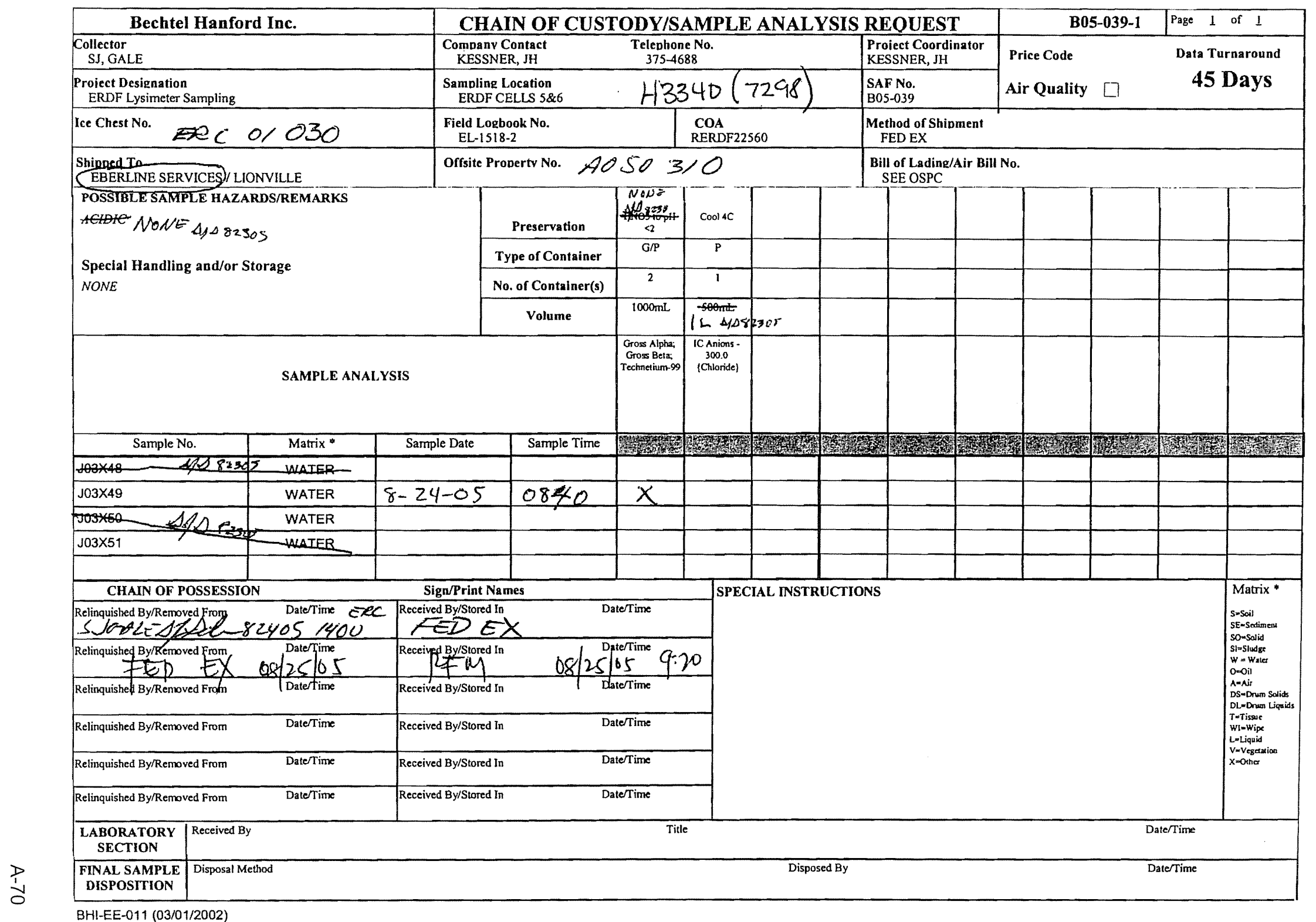




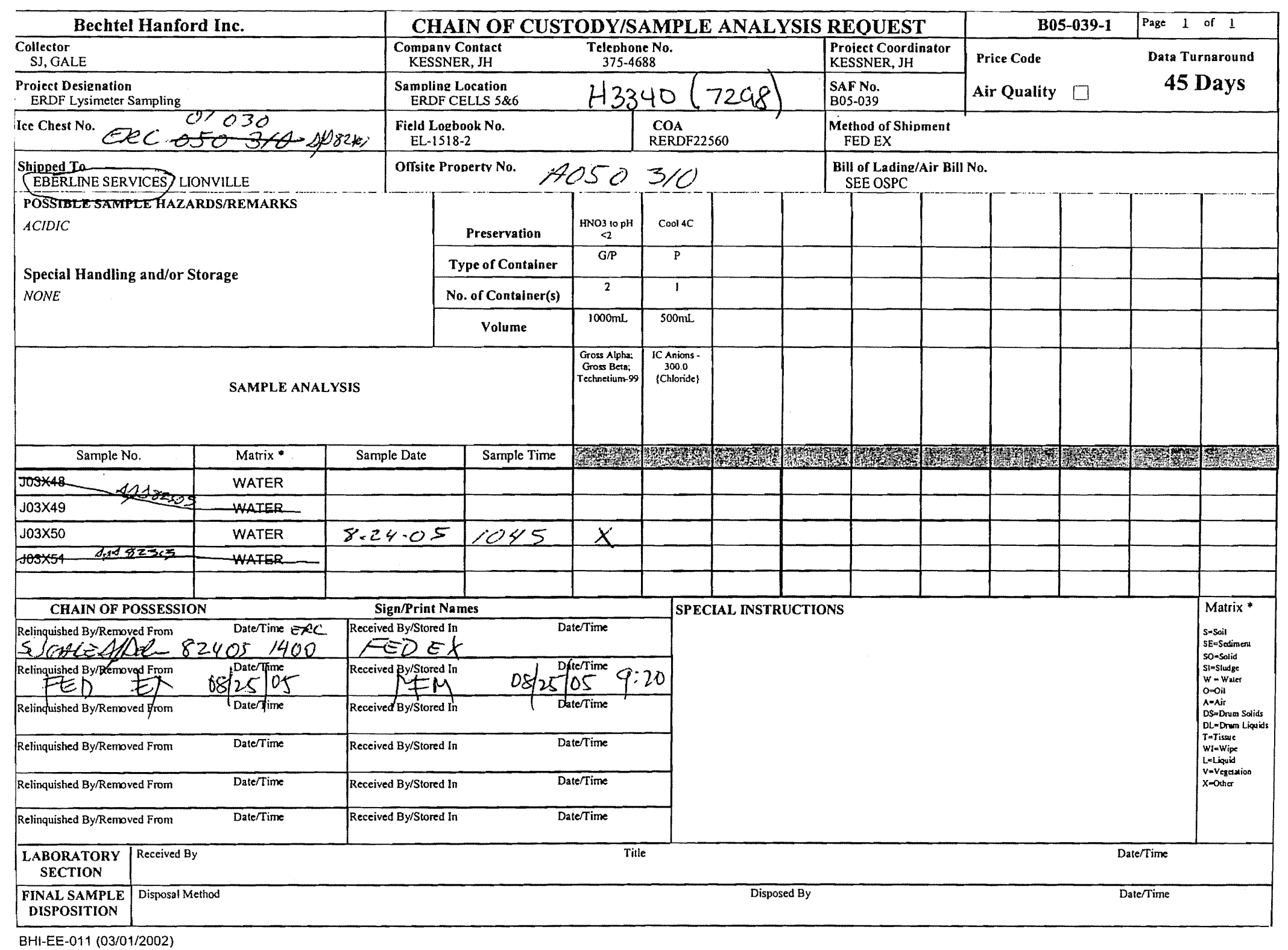




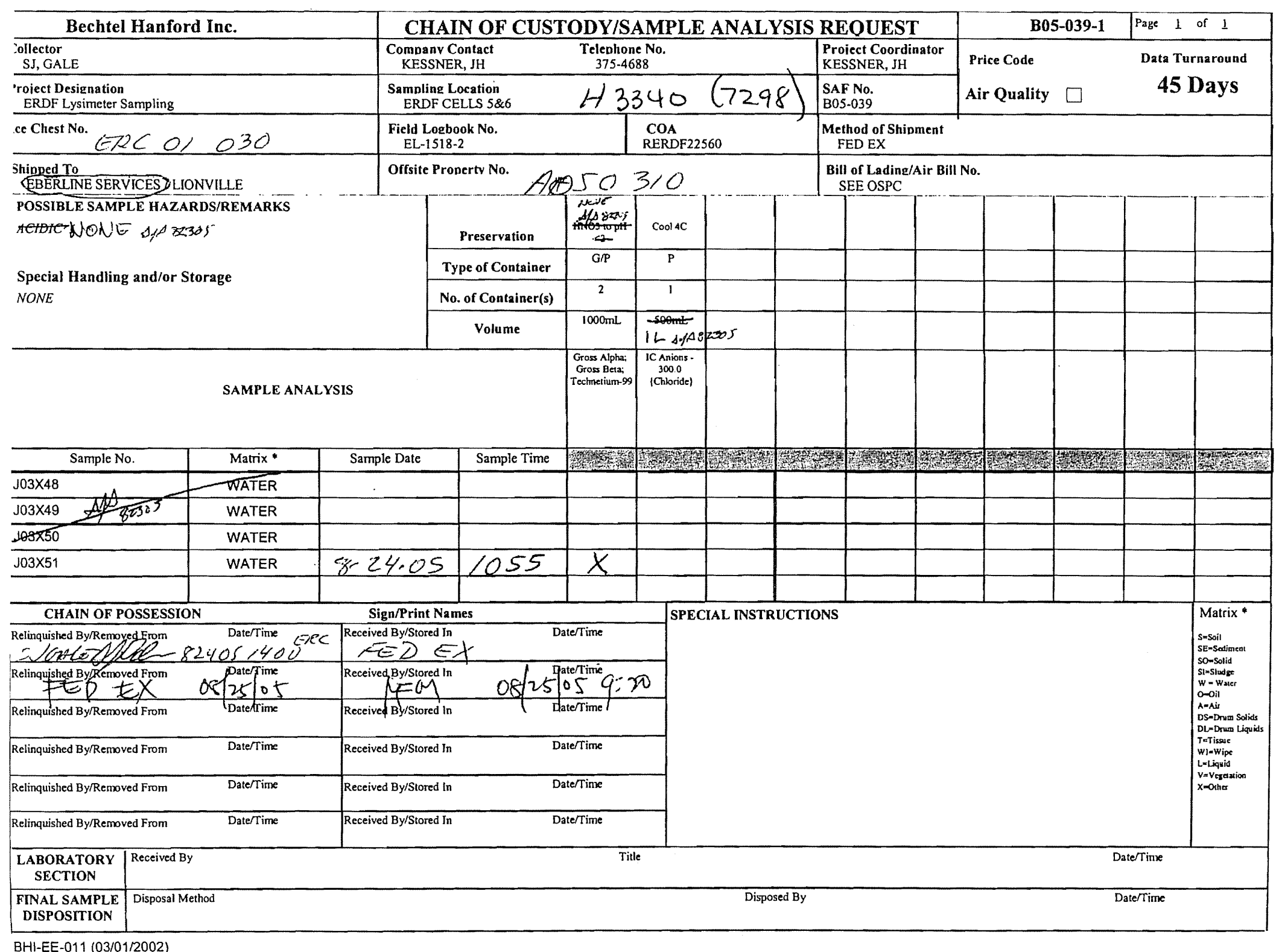




\section{(i) RICHIMEND, EA LABDRATDRY}

EEEPLINE

(12)

SAMPLE RECEIPT CHECKL:ST

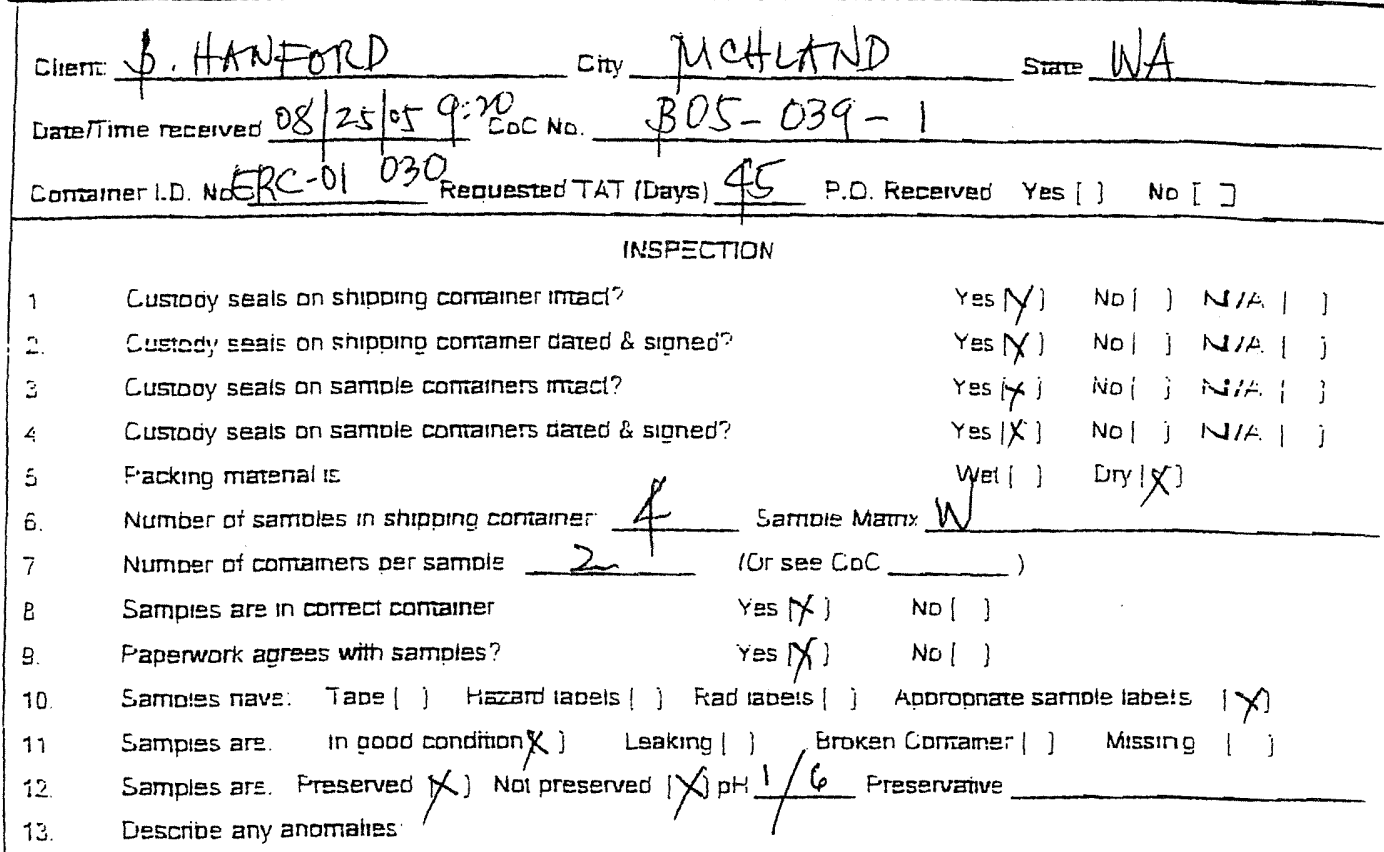

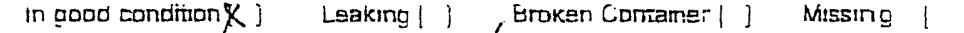
amples are. Freserved $X$ ) Nat presenved $1 X j p+1 / 6$ Fresenvaive

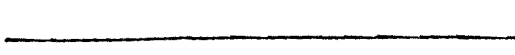
Nol I Late

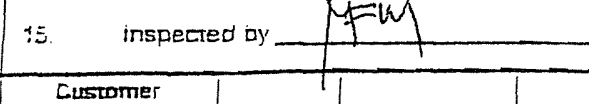
_ Date. 68/25lo5 Trme: $0: 30$

\begin{tabular}{|c|c|c|c|c|c|c|c|}
\hline $\begin{array}{l}\text { Cussomer } \\
\text { Sample No }\end{array}$ & $\mathrm{cm}$ & $\mathrm{mR} / \mathrm{nr}$ & Wros & $\begin{array}{c}\begin{array}{c}\text { Customer Sampte } \\
\text { No }\end{array} \\
\end{array}$ & $\mathrm{Eom}$ & $\mathrm{mR} / \mathrm{nr}$ & whes \\
\hline & & & & & & & \\
\hline & & & & & & & \\
\hline & & & & & & & \\
\hline & & & & & & & \\
\hline & & & & & & & \\
\hline & & & & & & & \\
\hline & & & & & & & \\
\hline & & & & & & & \\
\hline & & & & & & & \\
\hline
\end{tabular}

ion Chamber Ser No

Alpria Mleter Ser. No.

Eesa/Gammia Neter Ser. No

Form SCP.D: $2,0:-2-0$
Cailibráun ciate

Calibiaton tare

Calibiaton Gate 


\section{$\checkmark \underline{V L}$}

Joan Kessner

Bechtel-Hanford, Inc.

3190 Washington Way

MSIN H9-03

Richland, WA 99352

\section{Subject: Contract No. 630}

\section{Analytical Data Package}

Dear Ms. Kessner:

Enclosed are the hard copy analytical reports for the batch number/fraction indicated (marked $\mathrm{X}$ ) in the following table:

\begin{tabular}{|c|c|c|}
\hline LvLI Batch \# & $0508 L 223$ & \\
\hline SDG \# & $\mathrm{H} 3340$ & \\
\hline SAF \# & $B 05-004 B 05-030$ & $n B$ \\
\hline Date Received & $8-25-05$ & 1014105 \\
\hline \# Samples & 4 & \\
\hline Matrix & Water & \\
\hline Volatiles & & \\
\hline Semivolatiles & & \\
\hline Pest/PCB & & \\
\hline $\mathrm{PAH}$ & & \\
\hline DRO/KRO/GRO & & \\
\hline GC Alcohols & & \\
\hline Herbicides & & \\
\hline Metals & & \\
\hline Inorganics & $X$ & \\
\hline
\end{tabular}

The electronic data deliverable (EDD) will be emailed shortly. If you have any questions, please don't hesitate to contact me at (610) 280-3012.

Sincerely,

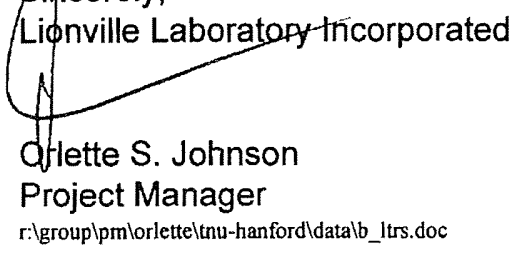

208 Welsh Pool Road - Exton, PA $19341-1313$ - (610) 280-3000 • Fax (610) 280-3041 
WCH-42

Rev. 1

Iionville Laboratory, Inc.

INORGANIC ANALYTICAL DATA PACKAGE FOR

TNUHANFORD B05-039 H3340

DATE RECEIVED: 08/25/05

LVI LOT \# :0508L223

CLIENT ID / ANALYSIS

LVI \#

MTX PREP \# COLLECTION EXTR/PREP

ANALYSIS

J03X48

CHLORIDE BY IC

CHLORIDE BY IC

CHLORIDE BY IC

001

OOI REP

W 05LICA67 08/24/05

W 05LICA67 08/24/05

$09 / 06 / 05$

001 MS

W 05LICA67 08/24/05 09/06/05

$09 / 06 / 05$

$09 / 06 / 05$

$09 / 06 / 05$

J03X49

CHLORIDE BY IC

002

W 05LICA67 08/24/05

$09 / 06 / 05$

$09 / 06 / 05$

J03X50

CHLORIDE BY IC

003

W 05LICA67 08/24/05

$09 / 06 / 05$

$09 / 06 / 05$

J03X51

CHLORIDE BY IC

004

W 05LICA67 08/24/05 09/06/05

$09 / 06 / 05$

LAB QC:

CHLORIDE BY IC

MB1

MBI BS

W 05IICA67

$N / A$

$09 / 06 / 05$

$09 / 06 / 05$

$09 / 06 / 05$

$09 / 06 / 05$

01 


\section{Analytical Report}

Client: TNU-HANFORD B05-039 H3340

LVL\#: 0508L223
W.O.\#: 11343-606-001-9999-00

Date Received: 08-25-05

\section{INORGANIC NARRATIVE}

1. This narrative covers the analysis of 4 water samples.

2. The samples were prepared and analyzed in accordance with the method checked on the attached glossary.

LvLI is NELAP accredited by the state of Pennsylvania and holds over 20 additional state accreditations. For a complete list of accrediting authorities and the corresponding analytes/methods, please contact your Project Manager.

3. Sample holding times as required by the method and/or contract were met.

4. The results presented in this report are derived from samples that met LvLI's sample acceptance policy.

5. The method blank was within the method criteria.

6. The Laboratory Control Sample (LCS) was within the laboratory control limits.

7. The matrix spike recovery was within the $75-125 \%$ control limits.

8. The replicate analysis was within the $20 \%$ Relative Percent Difference (RPD) control limit.

9. I certify that this sample data package is in compliance with SOW requirements, both technically and for completeness, other than the conditions detailed above. Release of the data contained in this hard copy package has been authorized by the Laboratory Manager or a designee, as verified by the following signature.
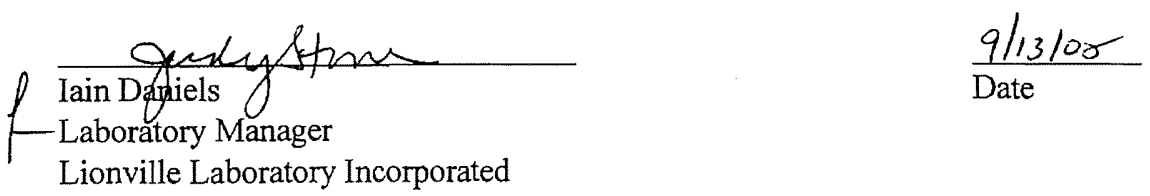

Lionville Laboratory Incorporated

n.jplio8-223

The results presented in this report relate to the analytical testing and conditions of the samples upon receipt and during storage. All pages of this report are integral parts of the analytical data. Therefore, this report slould only be reproduced in its entirety of 14 pages.

208 Welsh Pool Road • Exton, PA 19341- 1313 • (610) 280-3000 • Fax (610) 280-3041 
WCH-42

Rev. 1

\section{Lionville Laboratory Incorporated}

WET CHEMISTRY

METHODS GLOSSARY FOR WATER SAMPLE ANALYSIS

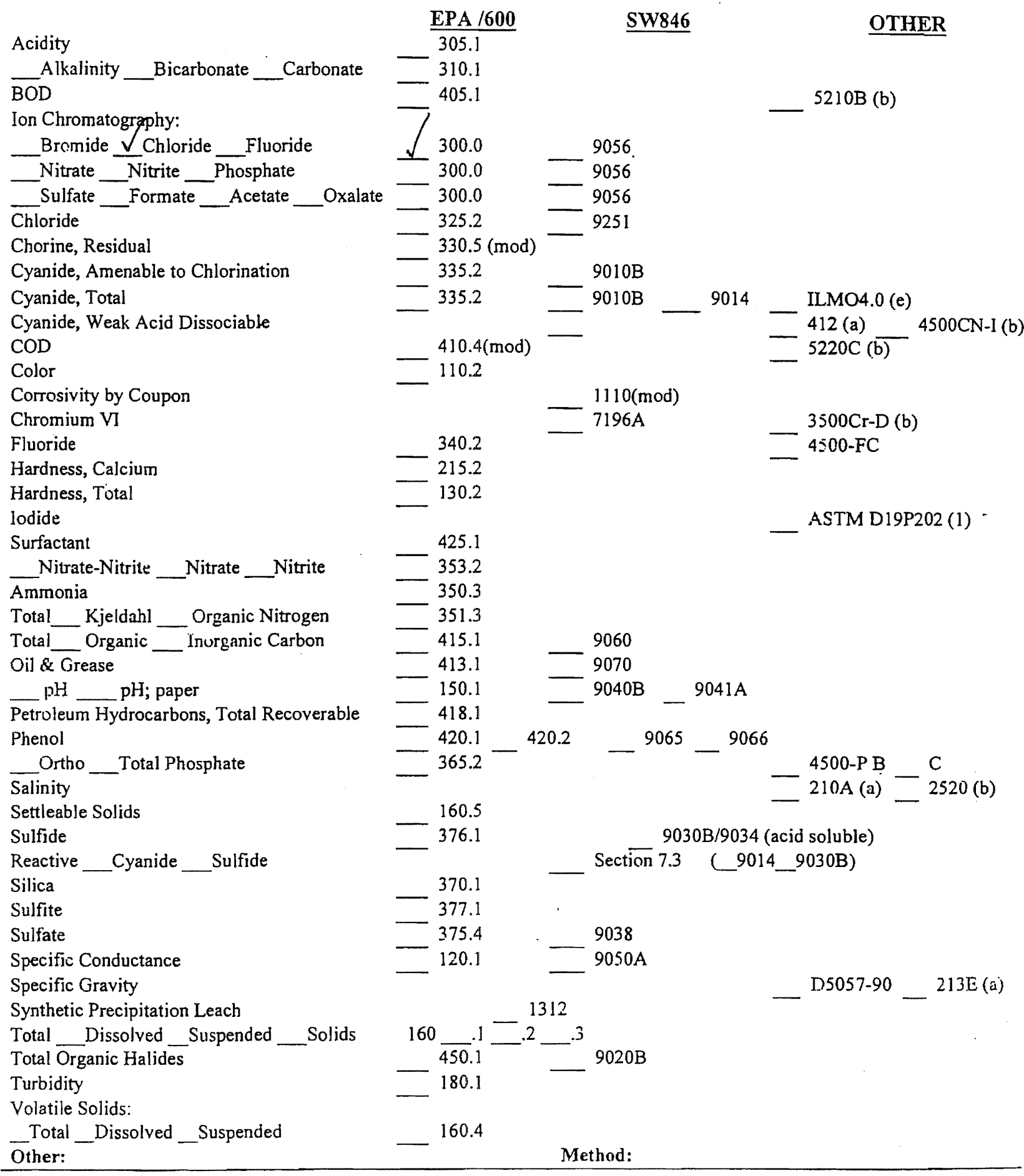




\section{Lionville Laboratory Incorporated}

\section{METHOD REFERENCES AND DATA QUALIFIERS}

\section{DATA QUALIFIERS}

$\mathrm{U}=$ Indicates that the parameter was not detected at or above the-reported limit. The associated numerical value is the sample detection limit.

* = Indicates that the original sample result is greater than $4 \mathrm{x}$ the spike amount added.

\section{ABBREVIATIONS}

$\mathrm{MB}=$ Method or Preparation Blank.

MS = Matrix Spike.

MSD = Matrix Spike Duplicate.

REP = Sample Replicate

LC = Laboratory Control Sample.

$\mathrm{NC}=$ Not calculated.

A suffix of $-\mathrm{R},-\mathrm{S}$, or $-\mathrm{T}$ following these codes indicate a replicate, spike or sample duplicate analysis respectively.

\section{ANALYTICAL WET CHEMISTRY METHODS}

1. ASTM Standard Methods.

2. USEPA Methods for Chemical Analysis of Water and Wastes (USEPA 600/4-79020).

3. Test Methods for Evaluating Solid Waste (USEPA SW-846).

a. Standard Methods for the Examination of Water and Waste, 16 ed, (1983).

b. Standard Methods for the Examination of Water and Waste, 17 ed, (1989)/18ed (1992).

c. Method of Soil Analysis, Part 1, Physical and Mineralogical Methods, 2nd ed, (1986).

d. Method of Soil Analysis, Part 2, Chemical and Microbiological Properties, Am. Soc. Agron., Madison, WI (1965).

e. USEPA Contract Laboratory Program, Statement of Work for Inorganic Analysis.

f. Code of Federal Regulations. 
WCH-42

Rev. 1

Lionville Laboratory, Inc.

INORGANICS DATA SUMMARY REPORT 09/09/05

\begin{tabular}{|c|c|c|}
\hline SAMPLE & SITE ID & ANALYTE \\
\hline$m m=m m=n$ & 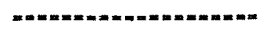 & 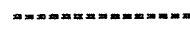 \\
\hline-001 & $503 \times 48$ & Chloride by IC \\
\hline-002 & $503 \times 49$ & Chloride by IC \\
\hline-003 & $303 \times 50$ & Chloride by IC \\
\hline-004 & J03X5I & Chloride by IC \\
\hline
\end{tabular}

LVL LOT \#: $0508 \mathrm{~L} 223$

\begin{tabular}{|c|c|c|c|}
\hline & & REPORTING & DILUTION \\
\hline RESULT & UNITS & LIMIT & FACTOR \\
\hline$m=n=x$ & $x \operatorname{sen} x=$ & $x=m m m=x=x=$ & $\Rightarrow=m=x=m=$ \\
\hline 62.8 & $M G / L$ & 2.5 & 10.0 \\
\hline 79.0 & MG/L & 2.5 & 20.0 \\
\hline 23.8 & $M G / L$ & 2.5 & 10.0 \\
\hline 30.6 & $M G / I_{L}$ & 2.5 & 20.0 \\
\hline
\end{tabular}


WCH-42

Rev. 1

Lionville Laboratory, Inc.

INORGANICS METHOD BLANK DATA SUMMARY PAGE 09/09/05

CLIENT: TNUHANFORD B05-039 H3340 WORK ORDER: 11343-605-001-9999-00

SAMPLE SITE ID

BLANK10 05IICA67-MBI
ANALYTE

Chloride by IC
LVL LOT \#: 0508L223

\begin{tabular}{|c|c|c|c|}
\hline & & REPORTING & DILUTION \\
\hline RESULT & UNITS & LIMIT & FACTOR \\
\hline$m=x$ & $m=m=m=$ & 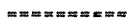 & 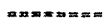 \\
\hline $0.25 \mathrm{u}$ & $M G / L$ & 0.25 & 1 \\
\hline
\end{tabular}


WCH-42

Rev. 1

Lionville Laboratory, Inc.

INORGANICS ACCURACY REPORT 09/09/05

CLIENT: TNUHANFORD B05-039 H3340 WORK ORDER: 11343-606-001-9999-00

$\begin{array}{lll}\text { SAMPLE } & \text { SITE ID } & \text { ANALYTE } \\ -001 & \text { J03X48 } & \text { Chloride by IC } \\ \text { BLANK10 } & \text { 05LICA67-MB1 } & \text { Chloride by IC }\end{array}$

LVL LOT \#: 0508L223

\begin{tabular}{|c|c|c|c|c|}
\hline SEIKED & INITIAL & SPIKED & & DILUTION \\
\hline SAMPLE & RESULT & AMOUNT & \&RECOV & FACTOR (SPK) \\
\hline$m=-=-\infty$ & 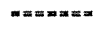 & $=\ln =\min$ & $x a=m=x=$ & $\Rightarrow w n=m=m=z$ \\
\hline 160 & 62.8 & 100 & 97.5 & 20.0 \\
\hline 4.7 & $0.25 u$ & 5.0 & 94.7 & 1.0 \\
\hline
\end{tabular}


WCH-42

Rev. 1

Lionville Laboratory, Inc.

INORGANICS PRECISION REPORT 09/09/05

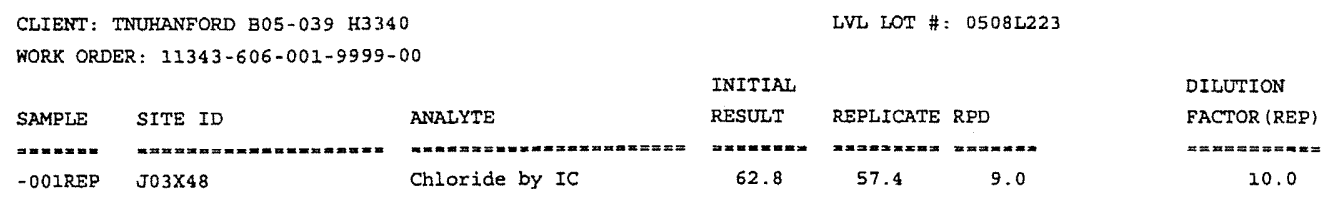




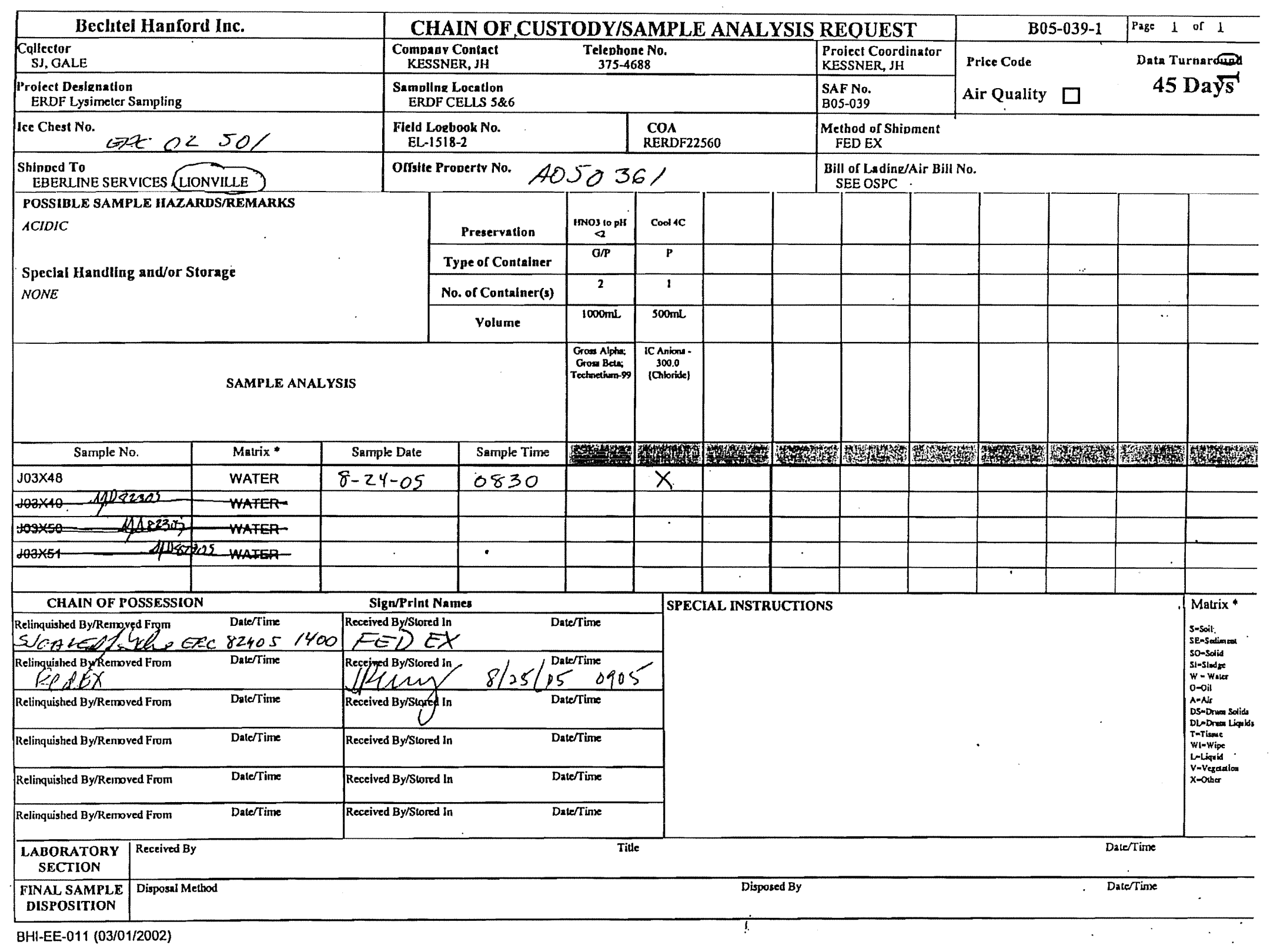




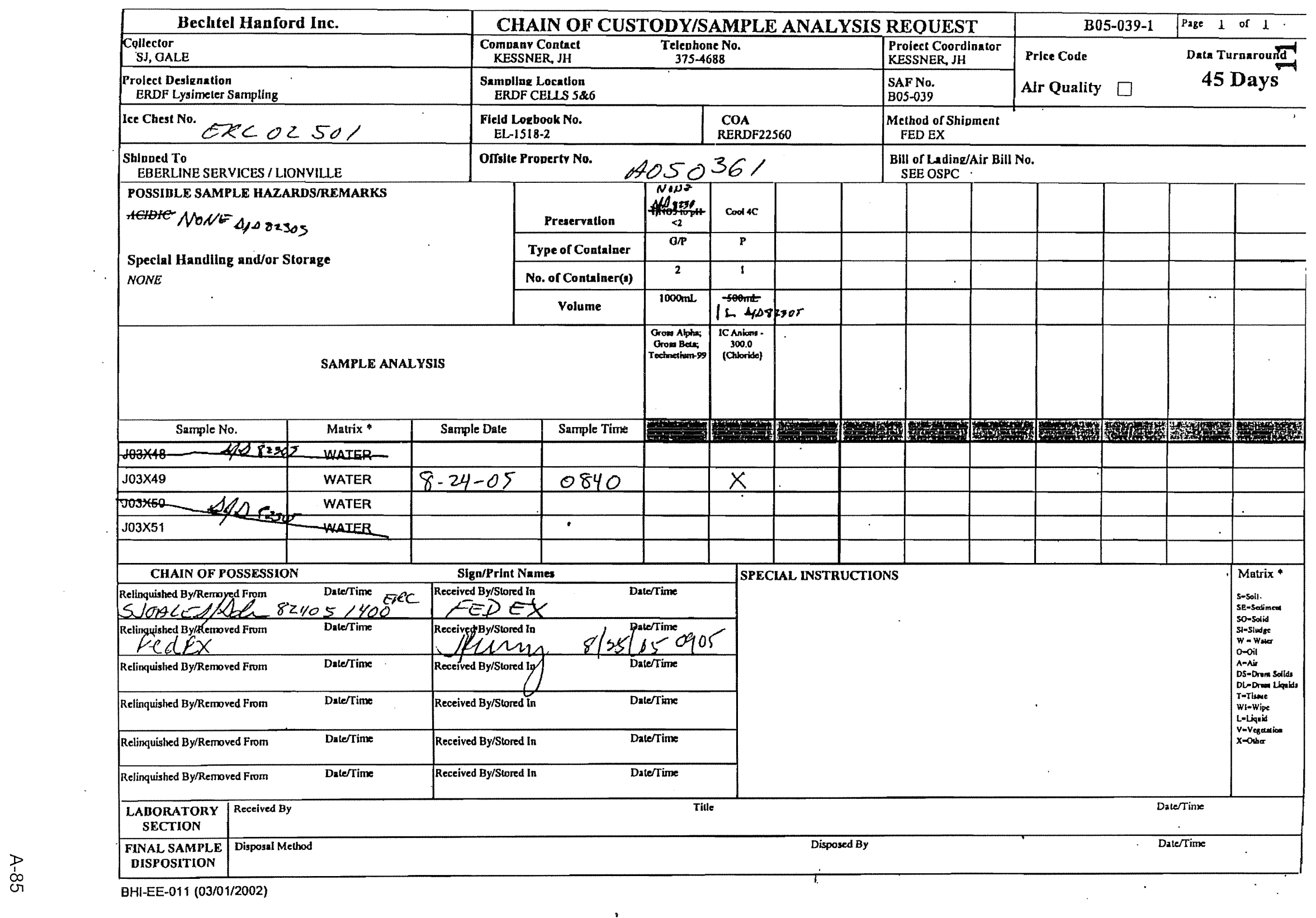




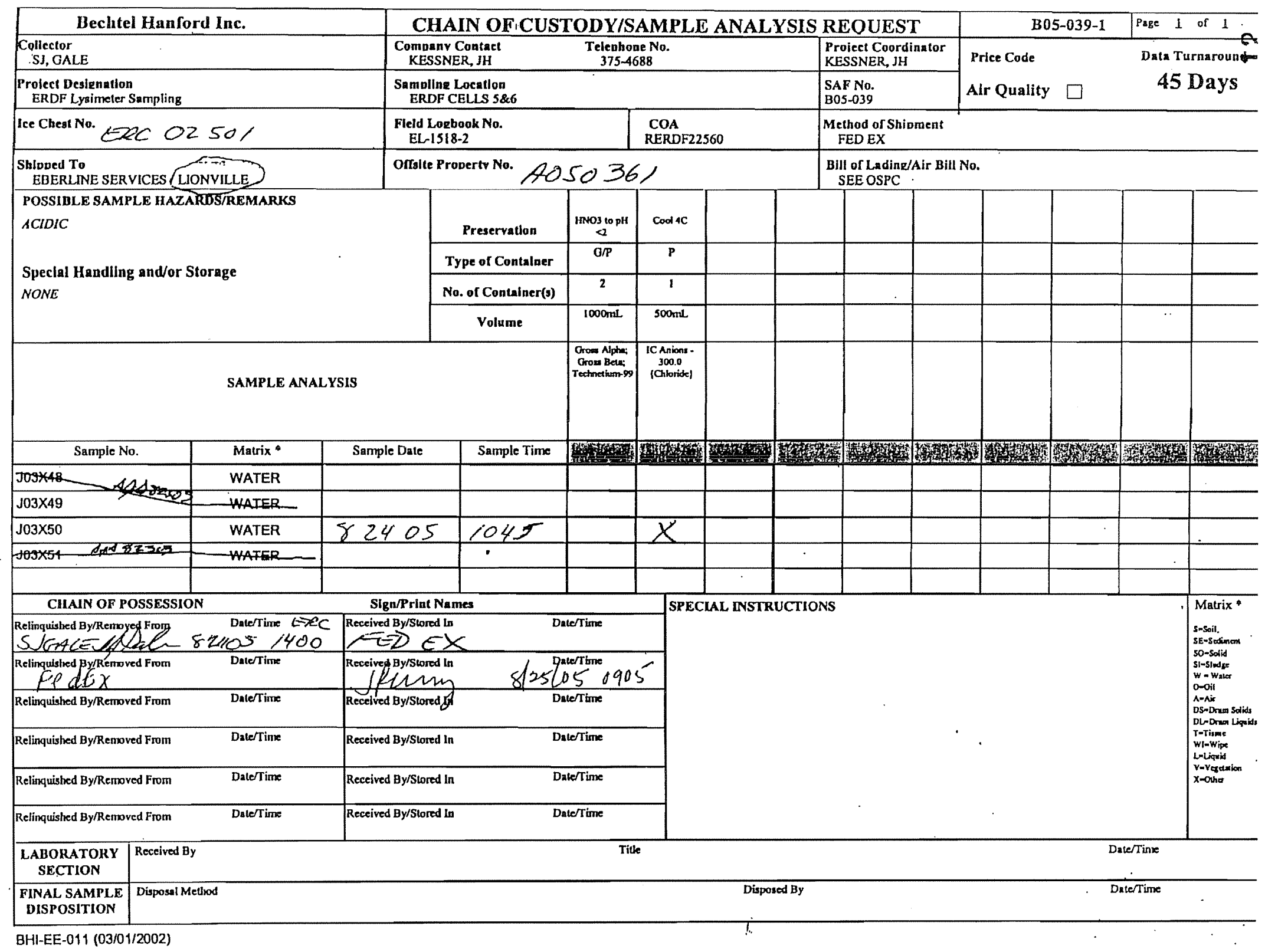




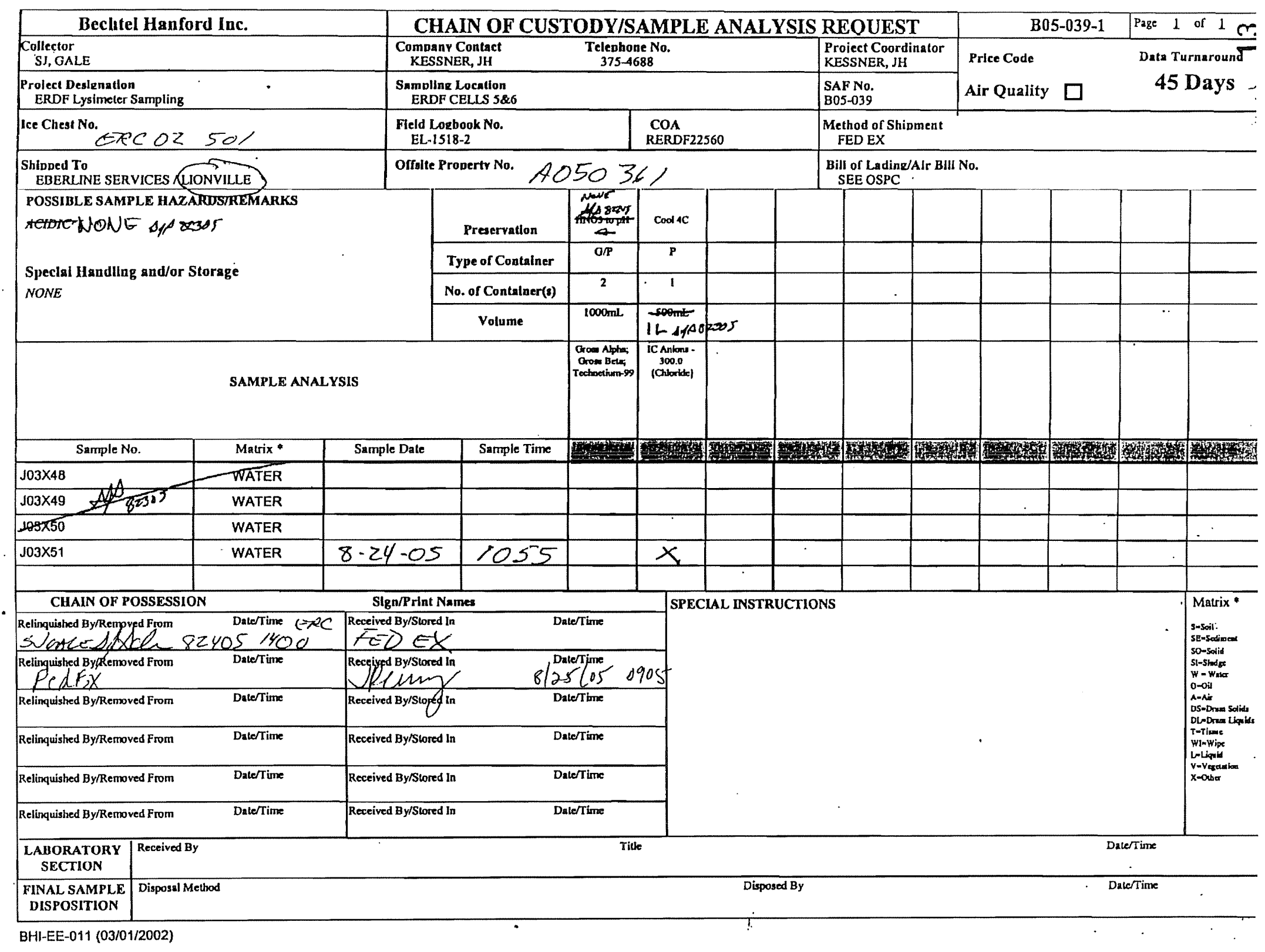




\section{SAMPLE RECEIPT CHECKLIST (SRC)}

CLIENT: TTU Hanford

Purchase Order / Project\# /

SAF\#/ SOW\# / Release \#: B, 5 -039

LvLI Batch \# : $0508 \angle 2>3$
Date: $8 / 25 / 05$

Sample Custodian:

Carrier fedEx

Airbill\# 792509835512

1. Samples Hand Delivered or Shipped

dYes $\quad$ ano

2. Custody seals on coolers or shipping container intact, signed and dated?

3. Outside of coolers or shipping containers are free from damage?

4. All expected paperwork received (coc and other client specific information) sealed in plastic bag and easily accessible?

5. Samples received cooledpr ambient?

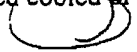

6. Custody seals on sample containers intact, signed and dated?

7. coc signed and dated?

8. Sample containers are intact?

9. All samples on coc received? All samples received on coc?

10. All sample label information matches coc?

11. Samples properly preserved?

12. Samples received within hold times? Short holds taken to wet lab?

13. VOA, TOC, TOX free of headspace?

14. QC stickers placed on bottles designated by client?

15. Shipment meets LvLI Sample Acceptance Policy? (Identify all bottles not within policy. See reverse side for policy)

16. Project Manager contacted concerning discrepancies? name/date (or samples outside criteria)
Q dYes ano

Temp $1.9^{\circ} \mathrm{C}$

$\alpha_{Y e S}$

$\square$ No

dyes

№

dYes

$\square$ No

GYes

aNo

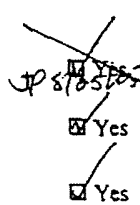

No

$\square$ No

$\square$ No

002,004-cocsoup matiz is waten, Sanples are Twater

$\square$ Yes

$\square$ No

$\square$ No

$\operatorname{sot} d s$

- absarbed in aN/A "foam"

pres

dYes

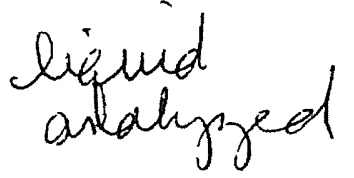

$\square$ No $\square$ No
QYes aNo

Discrepancies

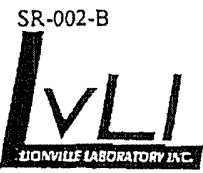




\section{DISTRIBUTION}

Washington Closure Hanford

K. R. Fecht

H4-21

S. J. Gale

$\mathrm{H} 4-22$

J. R. James

$\mathrm{T} 2-03$

A. R. Michael

T2-03

M. L. Proctor

H4-21

W. E. Remsen

T2-03

J. E. Rugg

T2-03

Records and Document Control

H4-11

DOE-RL Public Reading Room

$\mathrm{H} 2-53$

Hanford Technical Library

P8-55 
WCH-42

Rev. 1

Annual Report for Gravity Collection Lysimeter Monitoring Plan - ERDF Cells 5 and 6 